\title{
Measurement of Moisture Content in Sand, Slag, and Crucible Materials
}

by

J. H. Gray

Westinghouse Savannah River Company

Savannah River Site

Aiken, South Carolina 29808

P. S. Korinko

This paper was prepared in connection with work done under the above contract number with the U.S.

Department of Energy. By acceptance of this paper, the publisher and/or recipient acknowledges the U.S. Government's right to retain a nonexclusive, royalty-free license in and to any copyright covering this paper, along with the right to reproduce and to authorize others to reproduce all or part of the copyrighted paper. 


\section{DISCLAIMER}

This report was prepared as an account of work sponsored by an agency of the United States Government. Neither the United States Government nor any agency thereof, nor any of their employees, makes any warranty, express or implied, or assumes any legal liability or responsibility for the accuracy, completeness, or usefulness of any information, apparatus, product, or process disclosed, or represents that its use would not infringe privately owned rights. Reference herein to any specific commercial product, process, or service by trade name, trademark, manufacturer, or otherwise does not necessarily constitute or imply its endorsement, recommendation, or favoring by the United States Government or any agency thereof. The views and opinions of authors expressed herein do not necessarily state or reflect those of the United States Government or any agency thereof.

This report has been reproduced directly from the best available copy.

Available to DOE and DOE contractors from the Office of Scientific and Technical Information, P. O. Box 62, Oak Ridge, TN 37831; prices available from (423) 576-8401.

Available to the public from the National Technical Information Service, U. S. Department of Commerce, 5285 Port Royal Road, Springfield, VA 22161. 


\section{DISCLAIMER}

Portions of this document may be illegible in electronic image products. Images are produced from the best available original document. 
Measurement of Moisture Content In Sand, Slag, and Crucible Materials (U)

John H. Gray

Paul S. Korinko

Strategic MaterialsTechnology Department

Savannah River Technology Center

August 1999

hestinghouse Sa vannah River Company

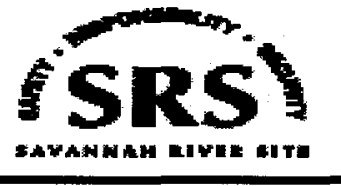


WSRC-TR-99-00275

Measurement of Moisture Content In Sand, Slag, and Crucible Materials

John H. Gray

Paul S. Korinko

Strategic Materials Technology Department

Savannah River Technology Center

August 1999

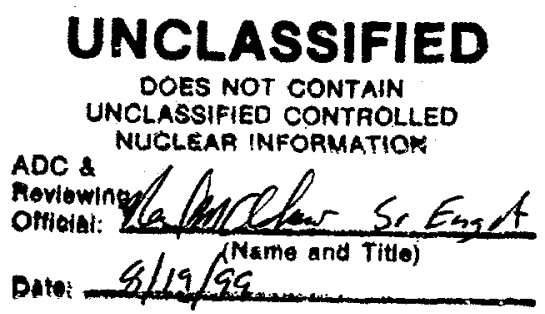

Technical Reviewers

David G. Karraker Dawelf fanatur 18 Ang 1999 Date

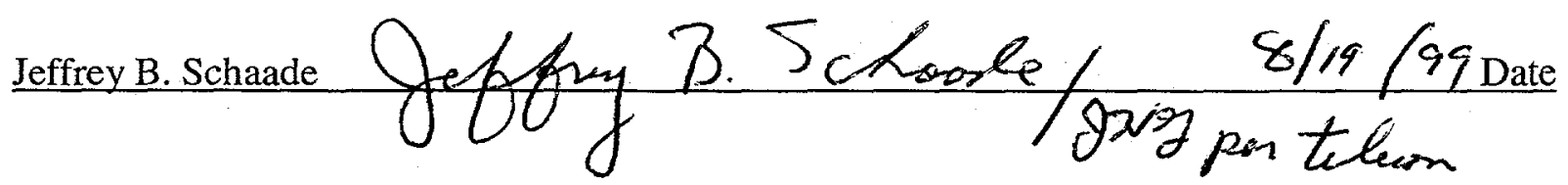


WSRC-TR-99-00275

Executive Summary

Purpose

The deinventory process at Rocky Flats (RFETS) has included moisture content measurements of sand, slag, and crucible (SSC) materials by performing weight loss measurements at $210^{\circ}$ $220^{\circ} \mathrm{C}$ on representative samples prior to packaging for shipment. Shipping requirements include knowledge of the moisture content. Work at the Savannah River Technology Center (SRTC) showed that the measurement at $210^{\circ}-220^{\circ} \mathrm{C}$ did not account for all of the moisture. The objective of the work in this report was to determine if the measurement at $210^{\circ}-220^{\circ} \mathrm{C}$ at RFETS could be used to set upper bounds on moisture content and therefore, eliminate the need for RFETS to unpack, reanalyze and repack the material.

\section{Rationale}

SRTC's gas generation work (Reference 1) showed that adsorbed moisture on $\mathrm{PuO}_{2}, \mathrm{Mg}(\mathrm{OH})_{2}$, and $\mathrm{Ca}(\mathrm{OH})_{2}$, and moisture available as free water all contributed to the generation of hydrogen gas in controlled tests. Chemically bound moisture as $\mathrm{Ca}(\mathrm{OH})_{2}$ did not contribute to hydrogen gas generation. All of these sources would contribute to a total moisture content determined by heating the materials to temperatures above $700^{\circ} \mathrm{C}$, but only free water and some of the adsorbed water would be measured by weight loss at $210^{\circ}-220^{\circ} \mathrm{C}$. $\mathrm{Mg}(\mathrm{OH})_{2}$ does not decompose to $\mathrm{MgO}$ and water until $350^{\circ} \mathrm{C}$ and $\mathrm{Ca}(\mathrm{OH})_{2}$ decomposes completely to $\mathrm{CaO}$ and water at $460^{\circ} \mathrm{C}$.

The rationale for this work was that the SSC materials had already seen temperatures in excess of $1000^{\circ} \mathrm{C}$. The $\mathrm{Mg}(\mathrm{OH})_{2}$ would have been converted to $\mathrm{MgO}$ which is not hygroscopic and will not readsorb significant moisture on cooling. Furthermore, $\mathrm{Ca}(\mathrm{OH})_{2}$ would be converted to $\mathrm{CaO}$ which is hygroscopic and, in conjunction with the carbon dioxide reaction in the air, produces the $\mathrm{Ca}(\mathrm{OH})_{2}$ plus some $\mathrm{CaCO}_{3}$ on cooling. The radiolysis of $\mathrm{Ca}(\mathrm{OH})_{2}$ does not contribute to hydrogen gas generation. So the only moisture which would contribute to hydrogen gas generation not represented by weight loss at $210^{\circ}-220^{\circ} \mathrm{C}$ is the balance of the adsorbed moisture. The work reported here sought to establish upper bounds on what the total adsorbed moisture could be given the weight loss at $210^{\circ}-220^{\circ} \mathrm{C}$ and the composition of the material.

\section{Discussion}

The weight change at $210^{\circ}-220^{\circ} \mathrm{C}$ for the SSC materials is comprised of the previously discussed water contributions and the potential for weight gain due to the oxidation of calcium metal and/or plutonium metal. This work utilized thermogravimetric analyses (TGA) and $\mathrm{x}$-ray diffraction (XRD) data to identify major and minor phases associated with weight changes as a function of temperature.

A model was developed which separates the weight loss at $210^{\circ}-220^{\circ} \mathrm{C}$ into its component parts. Application of this model to the composition of each of the SSC materials tested, and which is bounding relative to calcium and plutonium content, yields an upper bound estimate of the total adsorbed water which is capable of participating in the hydrogen gas generation reactions. 
Conclusions

- The maximum adsorbed moisture content for the highest $\mathrm{PuO}_{2}$ content (78 wt.\%) SSC is 2.3 wt.\%.

- Adjustments applied to moisture measurements for materials less than $78 \mathrm{wt} . \% \mathrm{PuO}_{2}$ result in total potential adsorbed moisture contents of less than $2.3 \mathrm{wt} . \%$.

- Any material exhibiting $>2.3 \mathrm{wt} . \%$ weight loss at $210^{\circ}-220^{\circ} \mathrm{C}$ should be considered to have free water and would not meet the "no net oxygen generation" requirement defined in Reference 1.

- Any material with a reported weight loss at $210^{\circ}-220^{\circ} \mathrm{C}$ as measured by the RFETS methodology to be $<2.3 \mathrm{wt}$.\% may be shipped within the bounds of the "no net oxygen generation" arguments presented in Reference 1.

\section{ACKNOWLEDGEMENTS}

The authors wish to express their appreciation to Clint Wolfe, Dan Wood, Marc Woodworth, and Joel Williams for their insight and contributions during the preparation of this report. The laboratory experimental work was conducted by Patrick Westover and Kevin Kalbaugh and $\mathrm{XRD}$ analyses of SSC materials were preformed by Art Jurgensen and David Missimer. Clerical assistance was provided by Gloria Turner. 
Table of Contents

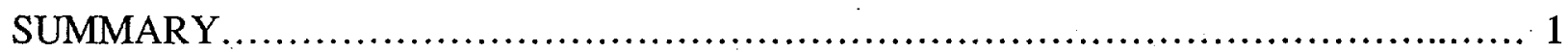

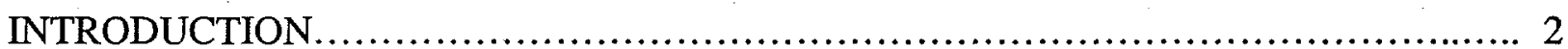

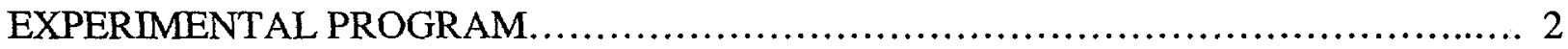

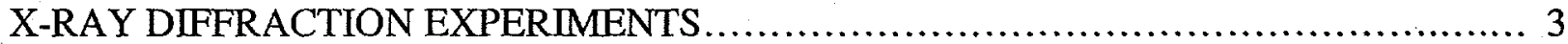

Characterization of SSC Materials................................................. 3

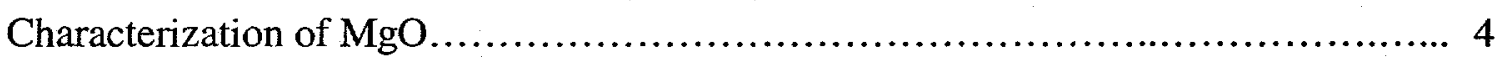

Characterization of Calcium Metal.................................................. 4

Thermal Treatment of SSC Materials............................................... 4

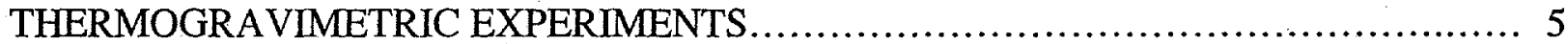

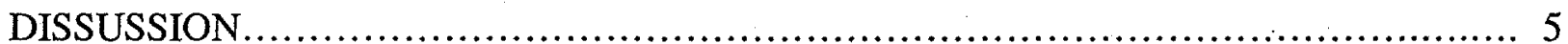

Adsorbed Moisture Content Measurement............................................. 5

Chemically Bound Moisture Content.............................................. 6

Calcium Metal Weight Gain...................................................... 6

LOI Weight Loss Adjustment .......................................................... 6

Calculation and Application of Adsorbed Moisture Content Measurements............. 7

Table I(a) Characterization of SSC Materials............................... 7

Table II(a) Calculated Total Physically Adsorbed Moisture Content Contributions in RFETS SSC Materials........................... 8

Table III(a) Comparison of LOI Measured at $210-220^{\circ} \mathrm{C}$ with Calculated Total Physically Adsorbed Moisture Weight Percent Contents..... 9

Adsorbed Moisture Content Ranges................................................. 9

Table IV(a) Experimental Weight Percent Adsorbed Moisture Content Ranges for the RF SSC Material Compositions................... 9

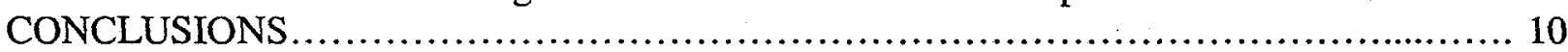

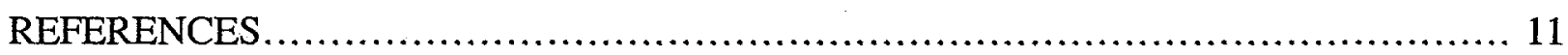

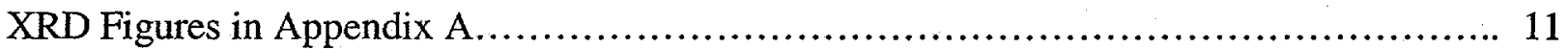

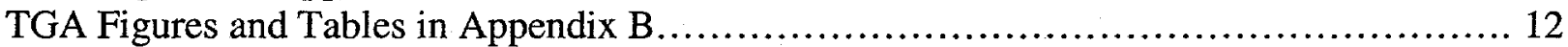




\section{MEASUREMENT OF MOISTURE CONTENT IN SAND, SLAG, AND CRUCIBLE MATERIALS}

\section{SUMMARY}

Concentration ranges have been determined for the adsorbed moisture in Rocky Flats Environmental Test Site (RFETS) sand, slag, and crucible (SSC) materials. The magnitude of each concentration range varied depending on $\mathrm{PuO}_{2}$ concentrations and on the use of either measured or bounding $\mathrm{Ca}(\mathrm{OH})_{2}$ concentrations. The highest adsorbed moisture content was 2.32 wt.\% found in SSC material containing $78 \mathrm{wt} . \% \mathrm{PuO}_{2}$. All other adsorbed moisture contents ranged from 0.12 wt. \% (both low $\mathrm{PuO}_{2}$ and $\mathrm{Ca}(\mathrm{OH})_{2}$ ) to 1.52 wt.\% (both high $\mathrm{PuO}_{2}$ and $\mathrm{Ca}(\mathrm{OH})_{2}$ ). Loss-on-ignition (LOI) testing of SSC materials at RFETS has reported wt.\% adsorbed moisture content losses below and within ranges established for similar SSC materials examined at the Savannah River Site (SRS).

A series of laboratory experiments was performed to determine total moisture contents in RFETS SSC materials. Initially, the testing process involved characterization of four different types of SSC materials with $x$-ray diffraction (XRD). Once chemical compositions were defined, samples from each SSC category were re-analyzed using thermogravimetric analysis (TGA) and XRD methods. The TGA testing provided thermal decomposition and oxidation behavior information needed to determine total moisture content in SSC materials. Similar analyses of pure samples of individual components found in SSC mixtures by XRD and TGA methods were done to understand individual component's moisture contribution to the SSC system.

Results from the XRD and TGA were used to support the use of RFETS LOI measurements at $210-220^{\circ} \mathrm{C}$ on SSC materials packaged for shipment to SRS. Based on assumptions that the SSC chemical compositions are known or at least are bounded, that the four SSC categories analyzed at SRS bound all SSC compositions, and that the results are representative of the behavior of all SSC materials, the total physically adsorbed moisture content in each SSC category can be related to LOI measurements made by RFETS.

The bases for application of adjustments made to LOI measurements are presented in this report. The only contributors to adsorbed moisture content in $\mathrm{SSC}$ materials come from $\mathrm{PuO}_{2}$ and $\mathrm{Ca}(\mathrm{OH})_{2}$. Adsorbed moisture on calcium metal has no significant contribution. The adjustments associated with weight gains from calcium metal oxidation during LOI measurements range from minor to insignificant. If adjustments are made based on TGA/XRD measurement of $\mathrm{PuO}_{2}$ and $\mathrm{Ca}(\mathrm{OH})_{2}$ content, they will differ depending on composition variations in samples selected for analysis. No adjustments to LOI measurements will be made when LOI results find adsorbed moisture contents greater than experimentally determined adsorbed moisture values. 
WSRC-TR-99-00275

\section{INTRODUCTION}

The initial effort of the sand, slag, and crucible (SSC) experimental program was focused on obtaining materials characterization data needed for flowsheet development work and on providing sufficient processing condition information for dissolution of RFETS SSC materials in canyon dissolvers at SRS. Four interim reports were issued (References 2, 3, 4 and 5) presenting results obtained from a series of laboratory experiments performed on SSC samples selected from four of the RFETS SSC categories. The selection of samples from the four categories was based on attempts to bound all chemical compositions for all SSC material categories which could be sent to SRS for processing.

Recent decisions affecting shipment of SSC materials from RFETS to SRS have resulted in expanding the original laboratory program. The additional experimental tests conducted were focused on: determining total moisture contents, measuring percents of adsorbed and chemically bound moisture associated with individual contributors, and measuring moisture fractions released as a function of heating conditions.

The results obtained will be used to provide moisture content data needed for shipment to and storage at SRS of RFETS SSC materials. The testing results support the adequacy of LOI measurements made at $210-220^{\circ} \mathrm{C}$ by RFETS for adsorbed moisture contents in SSC materials that are packaged and ready to ship to SRS. Additional weight loss measurements would need to be made at $400-450^{\circ} \mathrm{C}$ if it becomes necessary to measure the chemically bound moisture contributions from $\mathrm{Ca}(\mathrm{OH})_{2}$ to the total moisture content in SSC materials. Both types of moisture are related with individual contributions to radiolysis of water and hydrolysis/oxidation of calcium metal, two mechanisms identified with hydrogen gas production.

\section{EXPERIMENTAL PROGRAM}

The experimental approach involved performing a series of $\mathrm{x}$-ray diffraction (XRD) and thermogravimetric analysis (TGA) studies on samples from actual RFETS SSC materials. Samples of individual SSC components were supplied by RFETS and SRS and examined to complement the testing of RFETS SSC materials.

Both XRD and TGA studies were necessary to define the composition, to understand the chemistry, to establish the behavior of the SSC materials, and to resolve issues surrounding shipment to and storage at SRS. Initial XRD analyses were used to identify specific compounds and elements present in the SSC materials. Then TGA runs were made using the same SSC materials to measure weight changes occurring during time and temperature heating cycles. By measuring weight changes, the amount of specific compounds was calculated. Following the TGA studies, additional XRD analyses were made to identify what phase changes were occurring as the material was heated. Often repeat and additional TGA and XRD studies were made as initial results identified the need for more information to complete the experimental program. 
WSRC-TR-99-00275

\section{X-RAY DIFFRACTION EXPERIMENTS}

The first group of XRD experiments examined radioactive samples. These XRD tests were conducted on samples collected from four RFETS SSC categories after being pulverized, mixed, and repackaged for shipment. Both low (the L-series) and high (the $\mathrm{H}$-series) plutonium content samples were collected from the same category. The intent of this sampling approach was to bound all SSC IDC categories located at RFETS for shipment, storage, and processing at SR.

The final group of XRD experiments was performed to support and to clarify results obtained from TGA studies. These XRD scans identified phase changes that occurred during the TGA heating cycles used to quantify the behavior of SSC materials. Two different XRD test units were used. One XRD setup was used to analyze plutonium samples. This unit had a muffle furnace to subject materials to a specific time and temperature heating cycle. The heated materials were then transferred to an XRD unit and changes identified which occurred during the heating cycle. The second XRD unit was used on all non radioactive samples. It simultaneously recorded phase changes occurring at specific temperatures. The figures used to study SSC materials are presented in Appendix A.

Characterization of SSC Materials

The RFETS SSC categories are identified by Item Description Codes (IDC). The first SSC category examined by XRD was IDC 390 . That material was unpulverized slag that had been crushed and mixed before repackaging and shipping to SRS. Samples were taken for analysis from low (L-series) and high (H-series) plutonium content mixtures. The XRD scans are shown in Figures A-1 and A-2. The bulk of the material consisted of calcium compounds: $\mathrm{CaF}_{2}, \mathrm{CaO}$, $\mathrm{Ca}(\mathrm{OH})_{2}, \mathrm{CaCO}_{3}$, and $\mathrm{MgO}$ and $\mathrm{PuO}_{2}$. No plutonium or calcium metal, $\mathrm{PuF}_{4}$, or $\mathrm{Mg}(\mathrm{OH})_{2}$ were detected in this IDC or any of the IDCs tested. The minimum detection limit for these compounds is low enough, usually less than one weight present, so that the two compounds would have been identified if they were present in significant quantities. However, small amounts of both metals could be present if sufficient oxide layers were on the surface to shield the metal underneath from detection.

The second SSC category re-examined by XRD was IDC 392 which contained unpulverized sand, slag, and crucible material. The compounds identified in Figures B-1 and B-2 were the same as for IDC 390 except that no $\mathrm{CaCO}_{3}$ was detected. However, in high plutonium sample $\mathrm{H}$ 8 , graphite was detected. The presence of graphite was unexpected, was not present in the IDC 392 low plutonium material (L-3), and was not found in any of the other IDC categories.

The XRD scans for two remaining SSC categories, IDC 395 and IDC 398, are presented in Figures C-1, C-2, and D-1, D-2, respectively. IDC 395 contains unpulverized slag and crucible and IDC 398 contains pulverized sand, slag, and crucible. The basic compounds common to all IDC categories were again identified in these two materials: $\mathrm{CaF}_{2}, \mathrm{Ca}(\mathrm{OH})_{2}, \mathrm{CaO}, \mathrm{CaCO}_{3}, \mathrm{MgO}$, and $\mathrm{PuO}_{2}$. The fundamental difference between IDCs is the variation in amounts of calcium, magnesium, and plutonium compounds. 
WSRC-TR-99-00275

\section{Characterization of $\mathrm{MgO}$}

The behavior of $\mathrm{MgO}$ sand and crucible material used by RFETS to insulate and contain plutonium during the bomb reduction process is illustrated in Figures XRD-1, XRD-2, XRD-4, and $\mathrm{XRD}-5$. During the bomb reduction process, calcium metal reduces $\mathrm{PuF}_{4}$ to plutonium metal and temperatures approaching $2000^{\circ} \mathrm{C}$ are generated. Any $\mathrm{Mg}(\mathrm{OH})_{2}$ that was originally present in $\mathrm{MgO}$ materials was completely converted to $\mathrm{MgO}$ after a few minutes at temperatures greater than $380^{\circ} \mathrm{C}$. Following additional heating to $1000^{\circ} \mathrm{C}$, reformation of $\mathrm{Mg}(\mathrm{OH})_{2}$ did not occur after exposure of the calcined $\mathrm{MgO}$ to moist air for short periods below $300^{\circ} \mathrm{C}$. These results show that following exposure to elevated temperatures experienced during the bomb reduction process, $\mathrm{MgO}$ will not hydrate to form $\mathrm{Mg}(\mathrm{OH})_{2}$. Results from TGA runs confirmed there are insignificant weight gains or losses below $380^{\circ} \mathrm{C}$ from $\mathrm{Mg}(\mathrm{OH})_{2}$ or adsorbed moisture in the SSC magnesium materials that have been stored for 10-15 years at RFETS. The trace amount of $\mathrm{Mg}(\mathrm{OH})_{2}$ identified by TGA in one of the SSC samples was assumed to be from crosscontamination with glovebox floor sweepings. Therefore, $\mathrm{MgO}$ is not expected to contribute any moisture to the SSC system.

\section{Characterization of Calcium Metal}

The behavior of calcium metal used in the bomb reduction process is illustrated in Figures XRD3, XRD-6, XRD-14, XRD-15, XRD-16, XRD-17, XRD-18, and XRD-23. Calcium metal will form a $\mathrm{Ca}(\mathrm{OH})_{2}$ protective layer when exposed to moist air at ambient temperatures. Depending on the thickness of the $\mathrm{Ca}(\mathrm{OH})_{2}$ layer, XRD scans will or will not be able to detect calcium metal below the surface. Polishing the surface of calcium metal removed the surface layer of $\mathrm{Ca}(\mathrm{OH})_{2}$. This clean calcium metal surface reformed new $\mathrm{Ca}(\mathrm{OH})_{2}$ layers after exposure to moist air at $90^{\circ} \mathrm{C}$ for 14 hours. The calcium metal layer underneath was still detectable by XRD. As the exposure time at $90^{\circ} \mathrm{C}$ increased, the thickness of $\mathrm{Ca}(\mathrm{OH})_{2}$ increased until calcium metal underneath could no longer be detected. At no time could any $\mathrm{CaO}$ be identified during the oxidation of calcium metal. The same results were obtained when clean calcium metal was heat treated at $150^{\circ} \mathrm{C}$ in moist air. A protective $\mathrm{Ca}(\mathrm{OH})_{2}$ layer continued to build up until the calcium metal beneath the surface could no longer be detected.

\section{Thermal Treatment of SSC Materials}

The XRD scans of four types of RFETS SSC materials generated as a function of heat treatment are illustrated in Figures XRD-7 through XRD-12 and XRD-17. Essentially the observations made for the four IDC categories were identical. All IDC categories contain initially the same basic compounds, $\mathrm{CaO}, \mathrm{Ca}(\mathrm{OH})_{2}, \mathrm{CaF}_{2}, \mathrm{CaCO}_{3}, \mathrm{MgO}$, and $\mathrm{PuO}_{2}$. Any $\mathrm{CaO}$ identified in XRD scans of SSC materials is the fraction left after conversion of calcium metal to either $\mathrm{CaO}$ or $\mathrm{CaF}_{2}$ during the bomb reduction process. Plutonium metal and calcium metal were never directly seen, but may be present in small amounts. Because all $\mathrm{MgO}$ had been sintered by high temperatures generated during the bomb reduction process, no $\mathrm{Mg}(\mathrm{OH})_{2}$ was expected.

Heating the SSC samples in air at $210^{\circ} \mathrm{C}$ did not result in any changes to the XRD peaks. Whenever $\mathrm{Mg}(\mathrm{OH})_{2}$ is present, heating at $380^{\circ} \mathrm{C}$ for minutes would caused the XRD peak(s) of $\mathrm{Mg}(\mathrm{OH})_{2}$ to disappear. Heating at $450^{\circ} \mathrm{C}$ caused the $\mathrm{Ca}(\mathrm{OH})_{2} \mathrm{XRD}$ peaks to disappear as 
$\mathrm{Ca}(\mathrm{OH})_{2}$ converted to $\mathrm{CaO}$. Also after one hour at $450^{\circ} \mathrm{C}$, the $\mathrm{CaCO}_{3}$ peaks began to appear as some $\mathrm{CaO}$ reacted with $\mathrm{CO}_{2}$ to form $\mathrm{CaCO}_{3}$. After heating at $600^{\circ} \mathrm{C}$ for one hour, no additional peaks formed or were lost. The final heating step between $620-670^{\circ} \mathrm{C}$ converted all $\mathrm{CaCO}_{3}$ to $\mathrm{CaO}$. Now the only XRD peaks remaining were those of $\mathrm{CaO}, \mathrm{CaF}_{2}, \mathrm{PuO}_{2}$, and $\mathrm{MgO}$. These four compounds, along with any unreacted calcium or plutonium metal, are the major constituents in SSC materials remaining from the bomb reduction process. $\mathrm{No} \mathrm{Ca}(\mathrm{OH})_{2}, \mathrm{CaCO}_{3}$, or $\mathrm{Mg}(\mathrm{OH})_{2}$ compounds are initially present after the bomb reduction process and at most, only small amounts of plutonium and calcium metal remain. All experimental evidence obtained during the SSC dissolution studies (References 2, 3, 4 and 5) and results from the XRD scans suggest only small amounts of plutonium and calcium metals remain in these SSC materials.

\section{THERMOGRAVIMETRIC EXPERIMENTS}

The experimental program and data obtained from the TGA investigation of SSC materials are presented in Appendix B and in Reference 6. All tables and figures generated from the TGA study are included in this section of the report.

\section{DISCUSSION}

The results from TGA and XRD runs have defined the chemical compositions of SSC materials and established the expected behavior under different thermal conditions. During heating in air of SSC mixtures from ambient temperatures to the LOI $210-220^{\circ} \mathrm{C}$ set point, an initial weight loss is observed. This weight loss is due to the loss of physically adsorbed moisture from calcium metal, $\mathrm{Ca}(\mathrm{OH})_{2}$, and $\mathrm{PuO}_{2}$. This weight loss will be measured until weight gains associated with the oxidation of calcium metal result in a zero net weight change. This zero change can be reached before or during heating at the LOI $210-220^{\circ} \mathrm{C}$ set point.

Continued heating up to $400^{\circ} \mathrm{C}$ will result in additional weight gains due to further oxidation of calcium metal and reaction of the $\mathrm{CO}_{2}$ in air with $\mathrm{Ca}(\mathrm{OH})_{2}$ to from $\mathrm{CaCO}_{3}$. At $400^{\circ} \mathrm{C}$ the decomposition of $\mathrm{Ca}(\mathrm{OH})_{2}$ to $\mathrm{CaO}$ begins which is complete by $460-480^{\circ} \mathrm{C}$. Then additional weight gains due to oxidation of remaining calcium metal and reaction of the $\mathrm{CaO}$ with $\mathrm{CO}_{2}$ in air to form $\mathrm{CaCO}_{3}$ will occur. Decomposition of $\mathrm{CaCO}_{3}$ to $\mathrm{CaO}$ begins around $600^{\circ} \mathrm{C}$ and is complete by $650-670^{\circ} \mathrm{C}$. Above this temperature only $\mathrm{CaO}, \mathrm{MgO}, \mathrm{CaF}_{2}$, and $\mathrm{PuO}_{2}$ remain in the SSC materials.

\section{Adsorbed Moisture Content Measurement}

The TGA runs showing an initial moisture weight loss during oxidation of calcium metal are presented in Figures 3a through 3f. The largest measured weight loss due to adsorbed moisture was from calcium metal fines. The 0.43 adsorbed moisture wt. $\%$ loss for this calcium metal is reported in Table VIII. However, calculations of adsorbed moisture contributions to total adsorbed moisture contents are insignificant.

All calcium compounds, except the $\mathrm{Ca}(\mathrm{OH})_{2}$ and $\mathrm{CaCO}_{3}$ present in $\mathrm{SSC}$ materials, are thermally formed during the bomb reduction process. Therefore, the adsorbed moisture content associated with the $\mathrm{Ca}(\mathrm{OH})_{2}$ found in SSC materials was measured from calcium metal which had been 
oxidized to $\mathrm{CaO}$ and then hydrolyzed to $\mathrm{Ca}(\mathrm{OH})_{2}$. This $\mathrm{Ca}(\mathrm{OH})_{2}$ is the second source of adsorbed moisture. The $2.0 \mathrm{wt} . \%$ maximum available absorbed moisture content from thermally formed $\mathrm{Ca}(\mathrm{OH})_{2}$ was determined from the TGA run in Figure 10 . The value of $2.0 \mathrm{wt} . \%$ accounts for the adsorbed moisture content contribution from $\mathrm{CaCO}_{3}$ seen in thermally formed and reagent grade $\mathrm{Ca}(\mathrm{OH})_{2}$.

The third source of adsorbed moisture is from $\mathrm{PuO}_{2}$. The TGA runs used to measure the total adsorbed moisture content in $\mathrm{PuO}_{2}$ are presented in Figures 1la, 11b, and 12a through 12c. The results reported in Table VI suggest that up to $50 \%$ of the $2.9 \mathrm{wt} . \%$ total available adsorbed moisture in $\mathrm{PuO}_{2}$ may be lost during the LOI weight measurement heating cycle. The result that all available adsorbed moisture in $\mathrm{PuO}_{2}$ may not be lost during LOI measurements at $210-220^{\circ} \mathrm{C}$ is used to partially explain why LOI results fall below and within the wt.\% loss range and not near maximum values.

\section{Chemically Bound Moisture Content}

Chemically bound moisture is the $\mathrm{H}_{2} \mathrm{O}$ lost when the $\mathrm{Ca}(\mathrm{OH})_{2}$ is heated and decomposes to the oxide. The main source of chemically bound moisture in SSC materials is from $\mathrm{Ca}(\mathrm{OH})_{2}$. The chemically bound moisture contribution to total moisture contents is directly calculated from $\mathrm{Ca}(\mathrm{OH})_{2}$ wt. \% values reported in Table I(a). The upper wt.\% numbers for $\mathrm{Ca}(\mathrm{OH})_{2}$ are concentrations determined from wt.\% losses measured from TGA runs at $400-450^{\circ} \mathrm{C}$. The lower wt.\% numbers for $\mathrm{Ca}(\mathrm{OH})_{2}$ are maximum concentrations available assuming all available elemental calcium not tied with $\mathrm{CaF}_{2}$ has been hydrolyzed to $\mathrm{Ca}(\mathrm{OH})_{2}$. For every one gram of $\mathrm{Ca}(\mathrm{OH})_{2}$ in SSC materials, there are 0.24 grams of chemically bound water.

\section{Calcium Metal Weight Gain}

During heating cycles from ambient temperatures to the LOI $210-220^{\circ} \mathrm{C}$ set point, weight gains are occurring in the SSC materials due to oxidation of calcium metal. The TGA runs showing weight gains as a function of time and temperature are shown in Figures $3 \mathrm{a}$ through $3 \mathrm{c}, 4 \mathrm{a}$, and 4b. These weight gains are due to reactions with $\mathrm{O}_{2}, \mathrm{H}_{2} \mathrm{O}$, and $\mathrm{CO}_{2}$ to form $\mathrm{Ca}(\mathrm{OH})_{2}$ and $\mathrm{CaCO}_{3}$. The reactions occurring with fine calcium metal particles at $210-220^{\circ} \mathrm{C}$ (Figure $4 \mathrm{~b}$ ) show a weight gain of $0.30 \mathrm{wt} . \%$ can be expected after 30 minutes and a $0.50 \mathrm{wt} . \%$ can be expected after 60 minutes.

\section{LOI Weight Loss Adjustment}

Two weight loss adjustments apply to the RFETS LOI measurements on SSC materials. One is from the simultaneous weight gains of calcium metal. Another adjustment is because not all of the available adsorbed moisture on the $\mathrm{PuO}_{2}$ is removed during the LOI measurement heating cycle to $210-220^{\circ} \mathrm{C}$.

Calculations have shown calcium metal weight gains occurring during the LOI heating cycle to $210-220^{\circ} \mathrm{C}$ are insignificant. For every one wt.\% calcium metal in the SSC material heated at $210-220^{\circ} \mathrm{C}$, the adsorbed moisture content adjustment after 60 minutes is equivalent to an adsorbed moisture content increase of only $0.005 \mathrm{wt} . \%$. 
Any adjustments for the $\mathrm{PuO}_{2}$ adsorbed moisture contributions may be determined to be unrealistic. It could be decided to use adsorbed moisture contents established from laboratory results. An adjustment increase of 50 wt.\% or more for the $\mathrm{PuO}_{2}$ contribution during LOI measurements will just bring LOI results at $221-220^{\circ} \mathrm{C}$ closer to total available adsorbed moisture contents measured during the laboratory studies.

Calculation and Application of Adsorbed Moisture Content Measurements

The bases for determining total moisture contents in SSC materials are presented in TABLE I(a). Information provided in this table identifies adsorbed moisture content contributors and was obtained from XRD and TGA studies and from chemical composition data provided from previous materials characterization studies reported in References 2, 3,4 and 5.

There are two types of moisture in SSC materials. The first type is adsorbed (physi-sorbed) moisture associated with individual contributors in SSC materials. The adsorbed moisture represents the weight loss observed during LOI measurements at $210-220^{\circ} \mathrm{C}$. The second type is the chemically bound (chemi-sorbed) moisture of $\mathrm{Ca}(\mathrm{OH})_{2}$ and $\mathrm{Mg}(\mathrm{OH})_{2}$. The contribution to total moisture from $\mathrm{Mg}(\mathrm{OH})_{2}$ is insignificant because so little adsorbed moisture is present in the trace concentrations of $\mathrm{Mg}(\mathrm{OH})_{2}$. The chemically bound moisture from $\mathrm{Ca}(\mathrm{OH})_{2}$ is released only over the $400-450^{\circ} \mathrm{C}$ temperature range and is a major contributor to total moisture contents in SSC materials. The weight percent of chemically bound moisture can be stoichiometrically calculated from the wt.\% $\mathrm{Ca}(\mathrm{OH})_{2}$ numbers reported in Table $\mathrm{I}(\mathrm{a})$.

TABLE 1(a). Characterization of SSC Materials

\begin{tabular}{|l|l|l|l|l|l|l|}
\hline $\begin{array}{l}\text { Sample } \\
\#\end{array}$ & $\begin{array}{l}\text { IDC } \\
\#\end{array}$ & $\begin{array}{l}\text { Comp. } \\
\text { Source }\end{array}$ & $\begin{array}{l}\text { PuO2 } \\
\text { wt. \% }\end{array}$ & $\begin{array}{l}\text { Ca } \\
\text { wt. \% }\end{array}$ & $\begin{array}{l}\text { Ca (OH)2 } \\
\text { wt. \% }\end{array}$ & $\begin{array}{l}\text { Available Ca } \\
\text { wt. \% }\end{array}$ \\
\hline & & & & & & \\
\hline L-1 & 390 & slag & 2.86 & 2.5 & $18.1 / 45.3$ & $13.3 / 24.5$ \\
\hline H-2 & 390 & slag & 24.4 & $(1.2)^{*}$ & $(16.3) / 24.4$ & $(12.4) / 13.2$ \\
\hline L-3 & 392 & SSC & 1.27 & 0.75 & $11.7 / 20 / 4$ & $8.2 / 11.0$ \\
\hline H-8 & 392 & SSC & 78.0 & $(0.36)$ & $(1.8) / 2.8$ & $(1.4) / 1.5$ \\
\hline L-4 & 395 & slag+C & 0.83 & 4.34 & $4.1 / 30.5$ & $9.0 / 16.5$ \\
\hline H-7 & 395 & slag+C & 7.9 & 2.07 & $24.3 / 34.0$ & $17.3 / 18.4$ \\
\hline L-5 & 398 & SSC & 2.0 & 2.07 & $7.5 / 18.7$ & $7.3 / 10.1$ \\
\hline H-6 & 398 & SSC & 48.1 & $(1.0)$ & $(4.2) / 6.3$ & $(3.2) / 3.4$ \\
\hline
\end{tabular}

$0^{*}$ All (xyz) numbers were calculated based on $\mathrm{H}-7$ results.

Both low (L-1) and high (H-2) wt.\% plutonium samples were taken from IDC 390 . This SSC category contains essentially only slag. The wt. $\% \mathrm{PuO}_{2}$ values for the $\mathrm{L}-1$ and $\mathrm{H}-2$ samples are measured numbers based on experimental material balance determinations. The measured plutonium wt.\% contents in the L-1 and H-2 samples agreed well with RFETS NDA

measurements. Similar agreements were observed for the other three IDC categories reported in Table I(a).

The calcium metal, upper $\mathrm{Ca}(\mathrm{OH})_{2}$, and upper available elemental calcium wt.\% numbers in Table I(a) columns for metal, hydroxide, and carbonate formation were determined from the TGA studies. The lower $\mathrm{Ca}(\mathrm{OH})_{2}$ and lower available elemental calcium wt.\% numbers in 
columns are based on the laboratory experimental material balance determinations. The difference between the upper and lower available elemental calcium wt.\% numbers is the amount of available calcium which could be present as $\mathrm{CaO}$. The $\mathrm{CaF}_{2}$ wt.\% fraction has been removed from these available calcium wt.\% numbers.

The $\mathrm{PuO}_{2}$, calcium metal, and $\mathrm{Ca}(\mathrm{OH})_{2}$ concentrations reported in Table I(a) were used to calculate the adsorbed moisture contents from these three contributors. The wt.\% adsorbed moisture in $\mathrm{PuO}_{2}$ has been determined to be $2.9 \mathrm{wt}$.\%. This value was the maximum number observed during the TGA studies of $\mathrm{PuO}_{2}$. The total available adsorbed moisture from $\mathrm{PuO}_{2}$ was calculated by multiplying the $2.9 \mathrm{wt}$. $\%$ content by the measured $\mathrm{PuO}_{2}$ wt. $\%$ concentrations (Table I(a)) in each IDC material. It has been determined that only $50 \%$ of the available adsorbed moisture in $\mathrm{PuO}_{2}$ will normally be available as a weight loss during the LOI measurements up to $210-220^{\circ} \mathrm{C}$.

Similar calculations were made for the calcium metal and $\mathrm{Ca}(\mathrm{OH})_{2}$ contributions to adsorbed moisture. The lower values in columns for the total adsorbed moisture available from $\mathrm{Ca}(\mathrm{OH})_{2}$ assumed that all calcium not tied up with $\mathrm{CaF}_{2}$ has been converted to $\mathrm{Ca}(\mathrm{OH})_{2}$ by oxidizing all calcium metal, hydrolyzing all $\mathrm{CaO}$ to $\mathrm{Ca}(\mathrm{OH})_{2}$, and converting any carbonate to $\mathrm{Ca}(\mathrm{OH})_{2}$. Total calcium contents for SSC materials are presented in References 2, 3, 4 and 5. The adsorbed moisture content used for calcium metal is $0.43 \mathrm{wt} . \%$. The adsorbed moisture content used for $\mathrm{Ca}(\mathrm{OH})_{2}$ is $2.0 \mathrm{wt}$.\%.

TABLE 11(a). Calculated Total Physically Adsorbed Moisture Content Contributions in RFETS SSC Materials

\begin{tabular}{|l|l|l|l|l|}
\hline $\begin{array}{l}\text { Sample } \\
\#\end{array}$ & $\begin{array}{l}\text { Moisture in } \\
\mathrm{PuO2} \text { (wt. \%) }\end{array}$ & $\begin{array}{l}\text { Moisture in } \\
\mathrm{Ca} \text { (wt. \%) }\end{array}$ & $\begin{array}{l}\text { Moisture in } \\
\mathrm{Ca}(\mathrm{OH}) 2 \text { (wt. \%) }\end{array}$ & $\begin{array}{l}\text { Total } \\
\text { Moisture (wt. \%) }\end{array}$ \\
\hline & & & & \\
\hline L-1 (slag) & 0.082 & 0.0095 & $0.36 / 0.91$ & $0.45 / 1.00$ \\
\hline H-2 (slag) & 0.71 & 0.005 & $0.326 / 0.49$ & $1.04 / 1.21$ \\
\hline L-3 (SSC) & 0.037 & 0.003 & $0.23 / 0.41$ & $0.27 / 0.45$ \\
\hline H-8 (SSC) & 2.25 & 0.015 & $0.036 / 0.06$ & $2.30 / 2.32$ \\
\hline L-4 (slag+C) & 0.024 & 0.019 & $0.08 / 0.61$ & $0.12 / 0.65$ \\
\hline H-7 (slag+C) & 0.23 & 0.009 & $0.49 / 0.68$ & $0.73 / 0.92$ \\
\hline L-5 (SSC) & 0.058 & 0.009 & $0.15 / 0.37$ & $0.22 / 0.45$ \\
\hline H-6 (SSC) & 1.40 & 0.004 & $0.08 / 0.13$ & $1.46 / 1.53$ \\
\hline
\end{tabular}

By examining information provided in Table II(a), the major contributors to LOI wt.\% losses at $210-220^{\circ} \mathrm{C}$ are identified for all the SSC compositions. When high plutonium contents are present, the $\mathrm{PuO}_{2}$ contributions to the LOI measurement dominate. For the low plutonium concentrations, the $\mathrm{Ca}(\mathrm{OH})_{2}$ contribution dominates. In no situation will the calcium metal content be a significant contributor to weight loss. 
WSRC-TR-99-00275

TABLE 111 (a). Comparison of LOI Measured at $210-220^{\circ} \mathrm{C}$ with Calculated Total Physically Adsorbed Moisture Weight Percent Contents

\begin{tabular}{|l|l|l|l|l|}
\hline $\begin{array}{l}\text { Sample } \\
\#\end{array}$ & $\begin{array}{l}\text { RFETS LOI } \\
\text { wt. \% Loss }\end{array}$ & $\begin{array}{l}\text { SRS LOI } \\
\text { wt. \% Loss }\end{array}$ & $\begin{array}{l}\text { SRS Calculated } \\
\text { wt. \% Loss }\end{array}$ & $\begin{array}{l}\text { Max. Available } \\
\text { wt. \% Loss }\end{array}$ \\
\hline & & & & \\
\hline L-1 (slag) & & $1.7,0.62,0.43$ & 0.45 & 1.00 \\
\hline H-2 (slag) & $0.16,0.29$ & & 1.04 & 1.21 \\
\hline L-3 (SSC) & & 0.24 & 0.27 & 0.45 \\
\hline H-8 (SSC) & 1.87 & & 2.30 & 2.32 \\
\hline L-4 (slag+C) & & 0.12 & 0.12 & 0.65 \\
\hline H-7 (slag+C) & 0.86 & $0.40,0.20$ & 0.73 & 0.92 \\
\hline L-5 (slag+C) & & 0.10 & 0.22 & 0.44 \\
\hline H-6(SSC) & $1.08,0.44$ & & 1.48 & 1.53 \\
\hline
\end{tabular}

The comparison of calculated versus measured wt.\% losses from LOI measurements at 210$220^{\circ} \mathrm{C}$ is presented in Table III(a). In most cases differences between measured and calculated can be explained. The high $1.70 \mathrm{wt} . \%$ loss value measured at SRS indicates that TGA sample was not representative. Even assuming all available elemental calcium has been converted to $\mathrm{Ca}(\mathrm{OH})_{2}$, a higher wt.\% $\mathrm{PuO}_{2}$ is needed to reach a $1.70 \mathrm{wt} . \%$ loss value. However, since the TGA sample sizes are only 20 milligrams or so, it should not be surprising that this particular sample had a high $\mathrm{PuO}_{2}$ content. Most LOI measured versus calculated wt.\% losses appear to fit well within expected ranges.

\section{Adsorbed Moisture Content Ranges}

TABLE IV(a). Experimental Weight Percent Adsorbed Moisture Content Ranges for the Different RFETS SSC Material Compositions

\begin{tabular}{|c|c|c|c|c|c|}
\hline $\begin{array}{l}\text { Material } \\
\text { Comp. }\end{array}$ & $\begin{array}{l}\mathrm{PuO} 2 / \mathrm{Ca}(\mathrm{OH}) 2 \\
\text { Range, wt. \% }\end{array}$ & $\begin{array}{l}\text { Ads. Moist. } \\
\text { Range, wt. \% }\end{array}$ & $\begin{array}{l}\mathrm{PuO} 2 / \mathrm{Ca}(\mathrm{OH}) 2 \\
\text { Range, wt. \% }\end{array}$ & $\begin{array}{l}\text { Ads. Moist. } \\
\text { Range, wt. \% }\end{array}$ & $\begin{array}{l}\text { Min.-Max. } \\
\text { Range, wt. \% }\end{array}$ \\
\hline $\begin{array}{l}\text { Slag } \\
(390)\end{array}$ & $\begin{array}{l}2.8 / 19 \text { to } \\
2.8 / 46\end{array}$ & $\begin{array}{l}0.44 \text { to } \\
1.00\end{array}$ & $\begin{array}{l}25 / 17 \text { to } \\
25 / 25\end{array}$ & $\begin{array}{l}1.07 \text { to } \\
1.23\end{array}$ & $\begin{array}{l}0.44 \text { to } 1.23(1) \\
0.84 \text { to } 1.92(2)\end{array}$ \\
\hline $\begin{array}{l}\text { Slag+C } \\
(395)\end{array}$ & $\begin{array}{l}1.0 / 4.1 \text { to } \\
1.0 / 31\end{array}$ & $\begin{array}{l}0.12 \text { to } \\
0.65\end{array}$ & $\begin{array}{l}8.0 / 24 \text { to } \\
8.0 / 34\end{array}$ & $\begin{array}{l}0.73 \text { to } \\
0.92\end{array}$ & $\begin{array}{l}0.12 \text { to } 0.92(1) \\
0.19 \text { to } 1.59(2)\end{array}$ \\
\hline $\begin{array}{l}\text { SSC(1) } \\
(392)\end{array}$ & $\begin{array}{l}1.2 / 11.7 \text { to } \\
1.2 / 20.4\end{array}$ & $\begin{array}{l}0.27 \text { to } \\
0.45\end{array}$ & $\begin{array}{l}78 / 1.8 \text { to } \\
78 / 2.8\end{array}$ & $\begin{array}{l}2.30 \text { to } \\
2.32 \\
\end{array}$ & $\begin{array}{l}0.27 \text { to } 2.32(1) \\
0.50 \text { to } 2.37(2) \\
\end{array}$ \\
\hline $\begin{array}{l}\mathrm{SSC}(2) \\
(398)\end{array}$ & $\begin{array}{l}2.0 / 7.5 \text { to } \\
2.0 / 18.7\end{array}$ & $\begin{array}{l}0.21 \text { to } \\
0.43\end{array}$ & $\begin{array}{l}48 / 4.2 \text { to } \\
48 / 6.3\end{array}$ & $\begin{array}{l}1.48 \text { to } \\
1.52\end{array}$ & $\begin{array}{l}0.21 \text { to } 1.52(1) \\
0.36 \text { to } 1.64(2)\end{array}$ \\
\hline $\begin{array}{l}\text { Sand }+C \\
(391)\end{array}$ & $\begin{array}{l}1.0 / 12 \text { to } \\
1.0 / 21\end{array}$ & $\begin{array}{l}0.27 \text { to } \\
0.45\end{array}$ & $\begin{array}{l}32 / 4.2 \text { to } \\
32 / 6.3\end{array}$ & $\begin{array}{l}1.01 \text { to } \\
1.05\end{array}$ & $\begin{array}{l}0.27 \text { to } 1.05(1) \\
0.50 \text { to } 1.18(2)\end{array}$ \\
\hline
\end{tabular}

(1) Range based on 2.9 wt. \% adsorbed moisture in $\mathrm{PuO}_{2}, 2.0$ wt. \% adsorbed moisture in $\mathrm{Ca}(\mathrm{OH})_{2}$

(2) Range based on 2.9 wt. \% adsorbed moisture in $\mathrm{PuO}_{2}, 4.0$ wt. \% adsorbed moisture in $\mathrm{Ca}(\mathrm{OH})_{2}$

Two sets of wt.\% ranges for adsorbed moisture contents in four of the RF SSC material categories are presented in Table IV(a). The range for the first set (1) assumed the $2.0 \mathrm{wt} . \%$ adsorbed moisture content in $\mathrm{Ca}(\mathrm{OH})_{2}$ is the correct value to use to bound adsorbed moisture 
concentrations. The second set (2) doubled the adsorbed moisture content from 2 wt. $\%$ to 4 wt.\% to reflect $\mathrm{Ca}(\mathrm{OH})_{2}$ that has been exposed to high $(100 \%)$ relative humidities. Laboratory results obtained from testing the SSC materials in IDC 392 and IDC 398 were used to bound the concentration.wt.\% ranges for the sand and crucible material present in IDC 391. The minimum range value for each material composition is based on low plutonium contents and on the actual measured wt. $\%$ concentrations of $\mathrm{Ca}(\mathrm{OH})_{2}$. The maximum range value for each material composition is based on high plutonium concentrations and on a maximum $\mathrm{Ca}(\mathrm{OH})_{2}$ content that assumes all elemental calcium not tied up as $\mathrm{CaF}_{2}$ has been hydrolyzed to $\mathrm{Ca}(\mathrm{OH})_{2}$.

Results from LOI measurements at $210-220^{\circ} \mathrm{C}$ have identified physically adsorbed moisture concentrations below minimum range values reported in Table IV(a). For example, the low RFETS LOI results reported in Table III(a) for $\mathrm{H}-2$ slag and $\mathrm{H}-6$ SSC reflect the incomplete removal of adsorbed moisture from both $\mathrm{PuO}_{2}$ and $\mathrm{Ca}(\mathrm{OH})_{2}$ and the possibility that lower $\mathrm{Ca}(\mathrm{OH})_{2}$ concentrations may be present. When the LOI results fall within bounding concentration ranges, all adjustments to these LOI results will still keep adsorbed moisture contents below the maximum value reported for each SSC material in Table IV(a).

The model used to bound the adsorbed moisture content in a given SSC sample multiplies the NDA $\mathrm{PuO}_{2}$ wt. \% result by the 2.9 wt. \% factor for adsorbed moisture in $\mathrm{PuO}_{2}$. Then it adds to that wt.\% number the product of the available $\mathrm{Ca}(\mathrm{OH})_{2}$ wt.\% content times the 2.0 wt. $\%$ factor for adsorbed moisture in $\mathrm{Ca}(\mathrm{OH})_{2}$.

Using as an example from Table IV(a), a sample of the slag from IDC 390 containing a $\mathrm{PuO}_{2}$ wt.\% range from 2.8 to 25 would have a wt.\% adsorbed moisture contribution range from 0.08 to 0.725 . In a similar manner, the $\mathrm{Ca}(\mathrm{OH})_{2}$ wt. $\%$ range would decrease from 46 to 25 . Therefore, the wt.\% adsorbed moisture contribution would decrease from 0.92 to 0.5 .

\section{CONCLUSIONS}

The following conclusions and associated assumptions were identified during generation and comparison of moisture content data for RFETS SSC materials.

The bounding concentrations for physically absorbed moisture in RFETS SSC materials have been established. The LOI measurements at $210-220^{\circ} \mathrm{C}$ may report adsorbed moisture contents below, in between, and above the bounding concentration ranges established from the laboratory studies. All of these results are to be expected and are understood based of the knowledge of the chemistry of the SSC system.

The two major contributors to total moisture content in SSC materials are $\mathrm{PuO}_{2}$ and $\mathrm{Ca}(\mathrm{OH})_{2}$. The $\mathrm{Ca}(\mathrm{OH})_{2}$ contributes chemically bound moisture and both $\mathrm{PuO}_{2}$ and $\mathrm{Ca}(\mathrm{OH})_{2}$ contribute to the physically adsorbed moisture content. Only the physically adsorbed moisture is released during LOI measurements at $210-220^{\circ} \mathrm{C}$.

Neither calcium metal or $\mathrm{Mg}(\mathrm{OH})_{2}$ are significant contributors to total moisture content in SSC materials. 
WSRC-TR-99-00275

Calcium metal is the contributor to weight gains during LOI measurements at $210-220^{\circ} \mathrm{C}$. These weight gains result in insignificant adjustments to LOI measurements.

There is only a small amount of plutonium metal in RFETS SSC materials. The XRD scans never were able to detect plutonium metal. Laboratory results obtained during SSC dissolution studies, References 2, 3, 4 and 5, established most of the plutonium in SSC materials is high fired, small $\mathrm{PuO}_{2}$ particles formed during the high temperature bomb reduction process.

Laboratory measurement of wt.\% $\mathrm{PuO}_{2}$ and $\mathrm{Ca}(\mathrm{OH})_{2}$ was necessary to obtain total physically adsorbed moisture contents available for release during LOI measurements.

LOI measurements performed at $210-220^{\circ} \mathrm{C}$ indicate only a fraction of the total available physically adsorbed moisture may be released during weight loss measurements.

\section{REFERENCES}

(1) WSRC-TR-99-00223, Gas Generation Test Support for Transportation and Storage of Plutonium Residue Materials, R. R. Livingston, August 1999

(2) SRT-CHT-98-1076 (Rev. 1), Processing RF IDC\# 398 SSC Material, Interim Report, J. H. Gray, January 22, 1999

(3) SRT-CHT-98-1081, Processing RF IDC\# 390 SSC Material, Interim Report, J. H. Gray, January 22, 1999

(4) SRT-CHT-99-1007, Processing RF IDC\# 395 SSC Material, Interim Report, J. H. Gray, March 16, 1999

(5) SRT-CHT-99-1011, Processing RF IDC\# 392 SSC Material, Interim Report, J. H. Gray, March 16, 1999

(6) SRT-MTS-99-3021, Thermal Analysis of Constituents Comprising SS\&C and Low Pu Containing SS\&C Samples, P. S. Korinko, July 14, 1999

Appendix A

XRD figures A-1 through D-2 and XRD-1 through XRD-23 generated during SSC materials characterization studies are included in this section. 


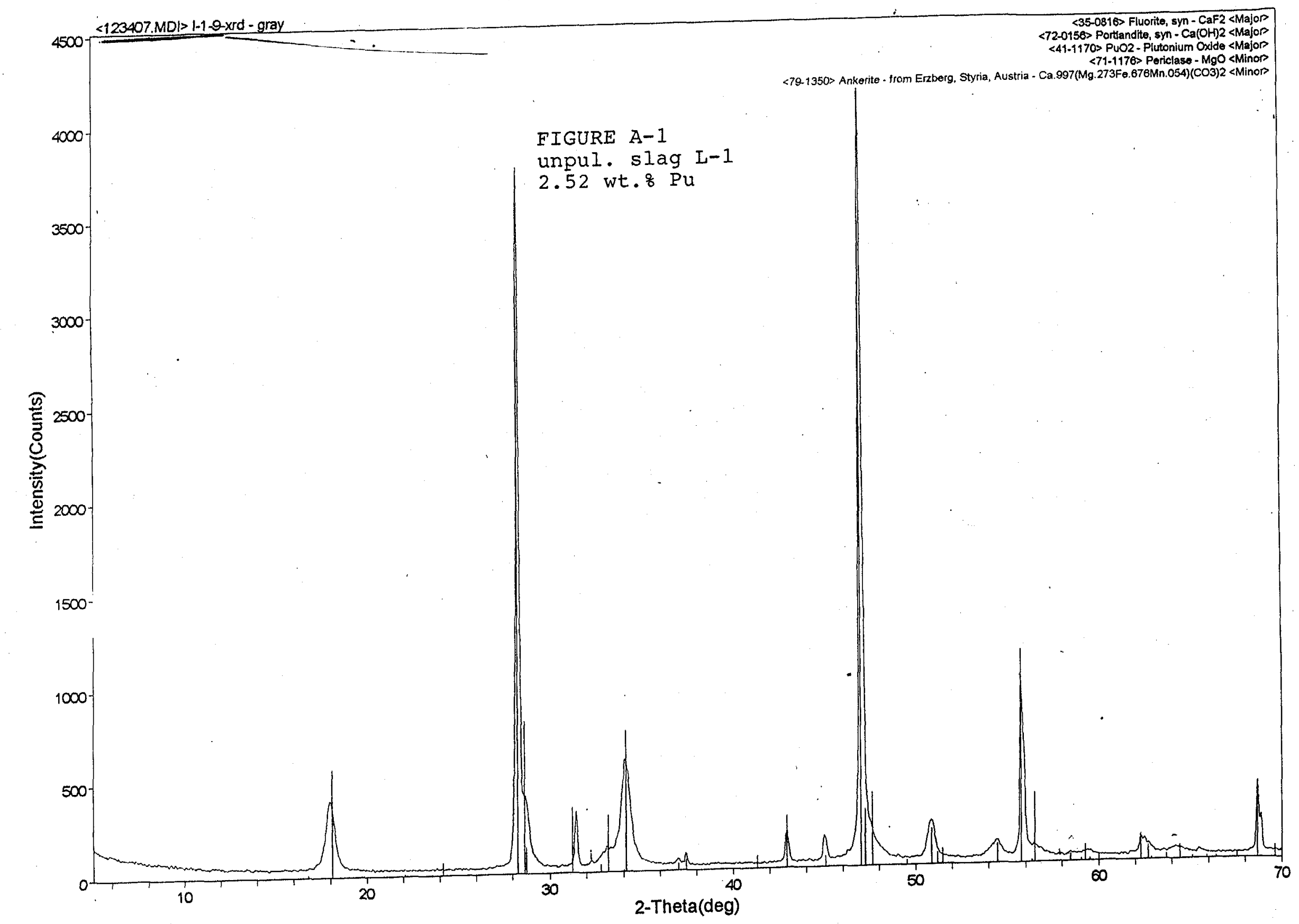

ef:Urd-1899> Thursday, Mar 11, 1989 10:17a 


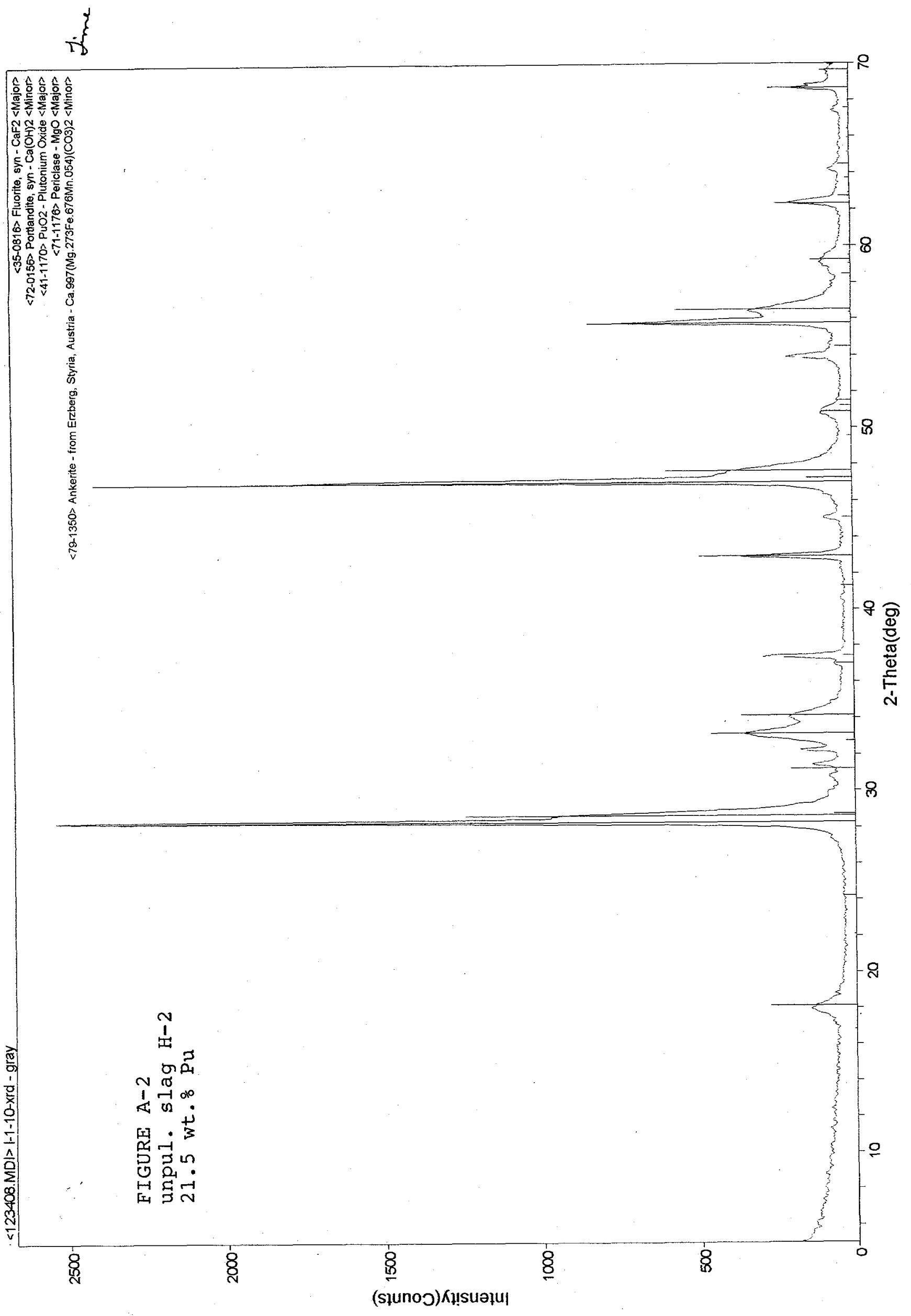




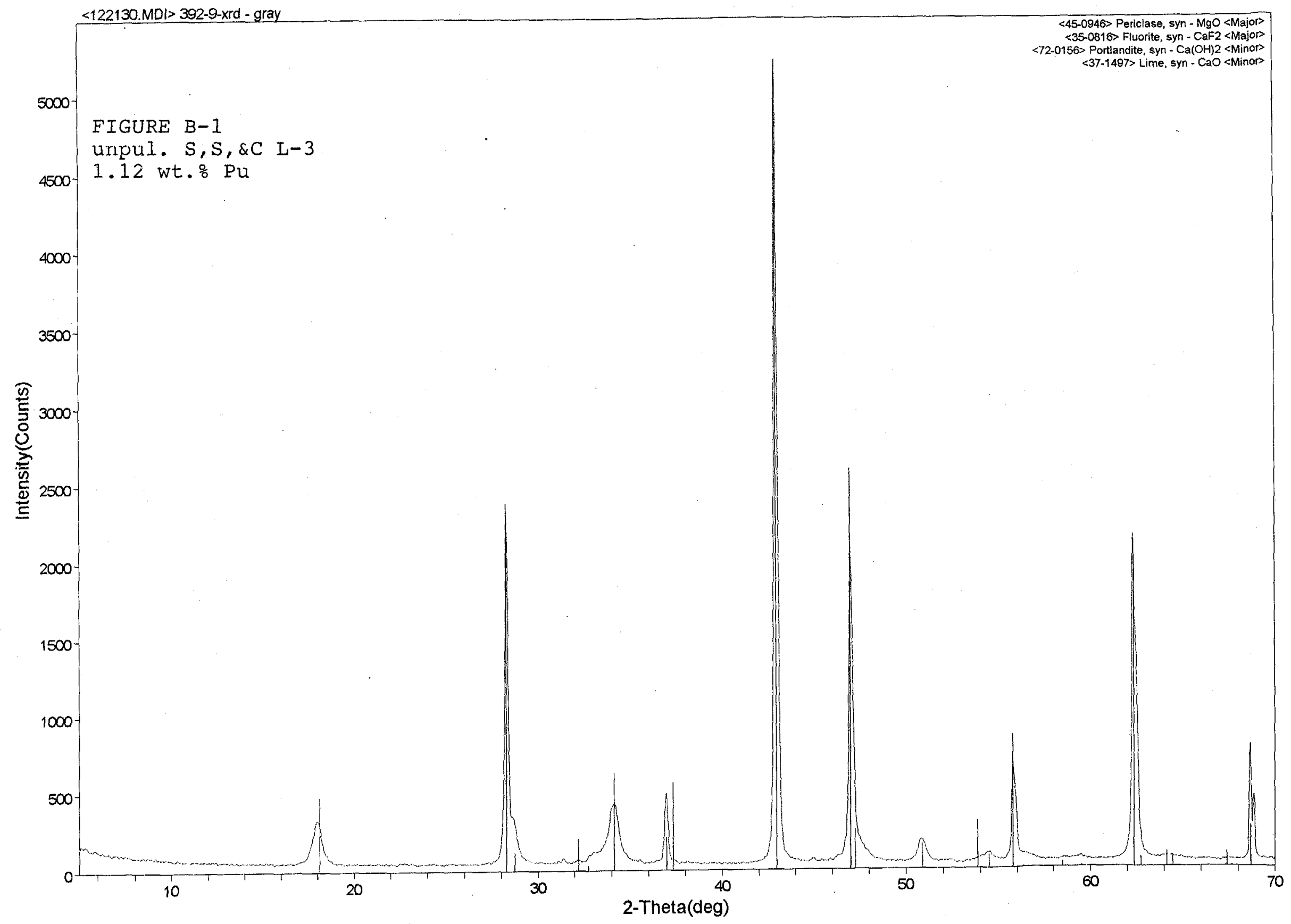


FIGURE B-2

unpul. $\mathrm{S}, \mathrm{S}, \& \mathrm{C} \mathrm{H}-8$

2000

68.6 wt. 8 Pu

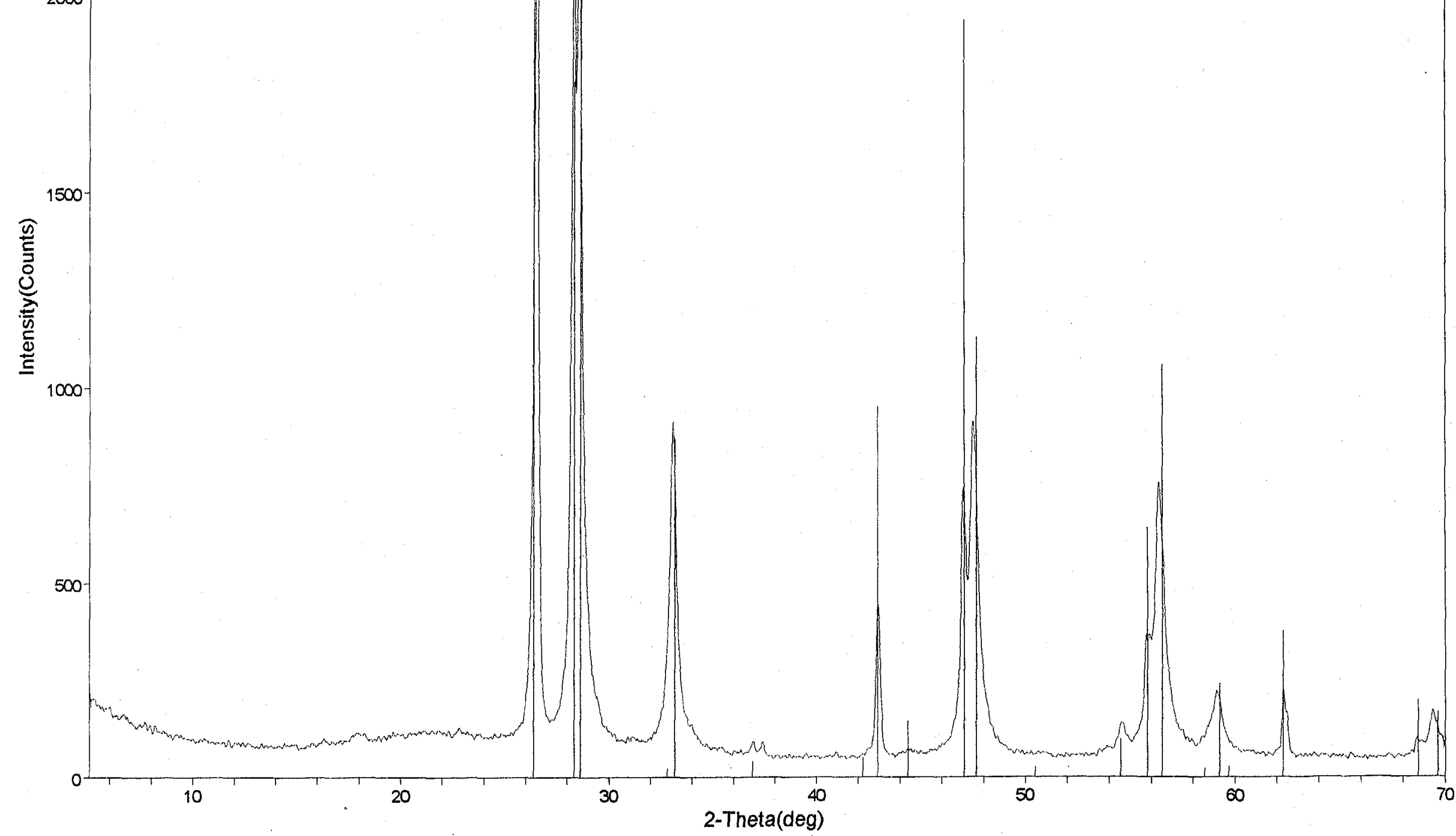




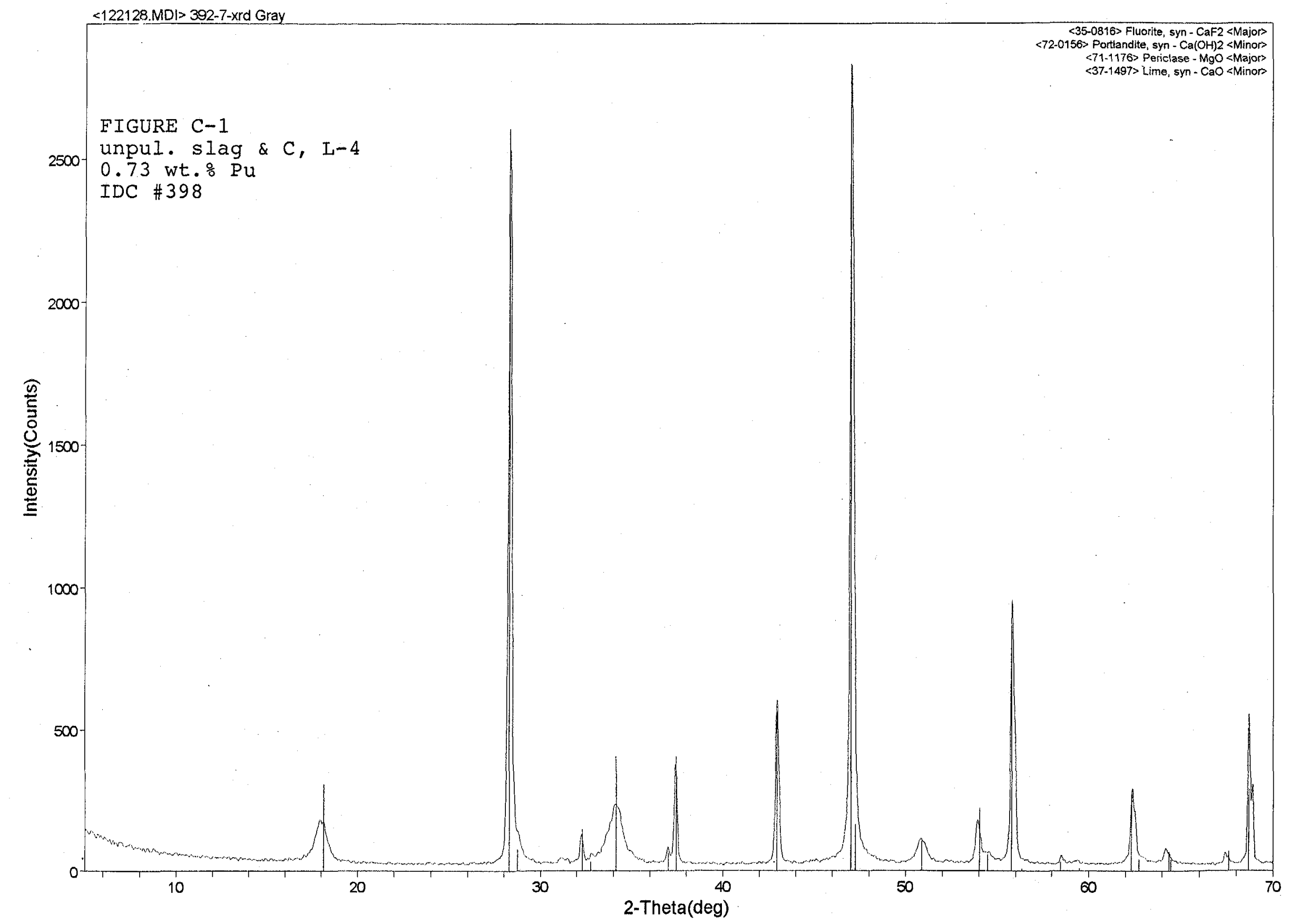




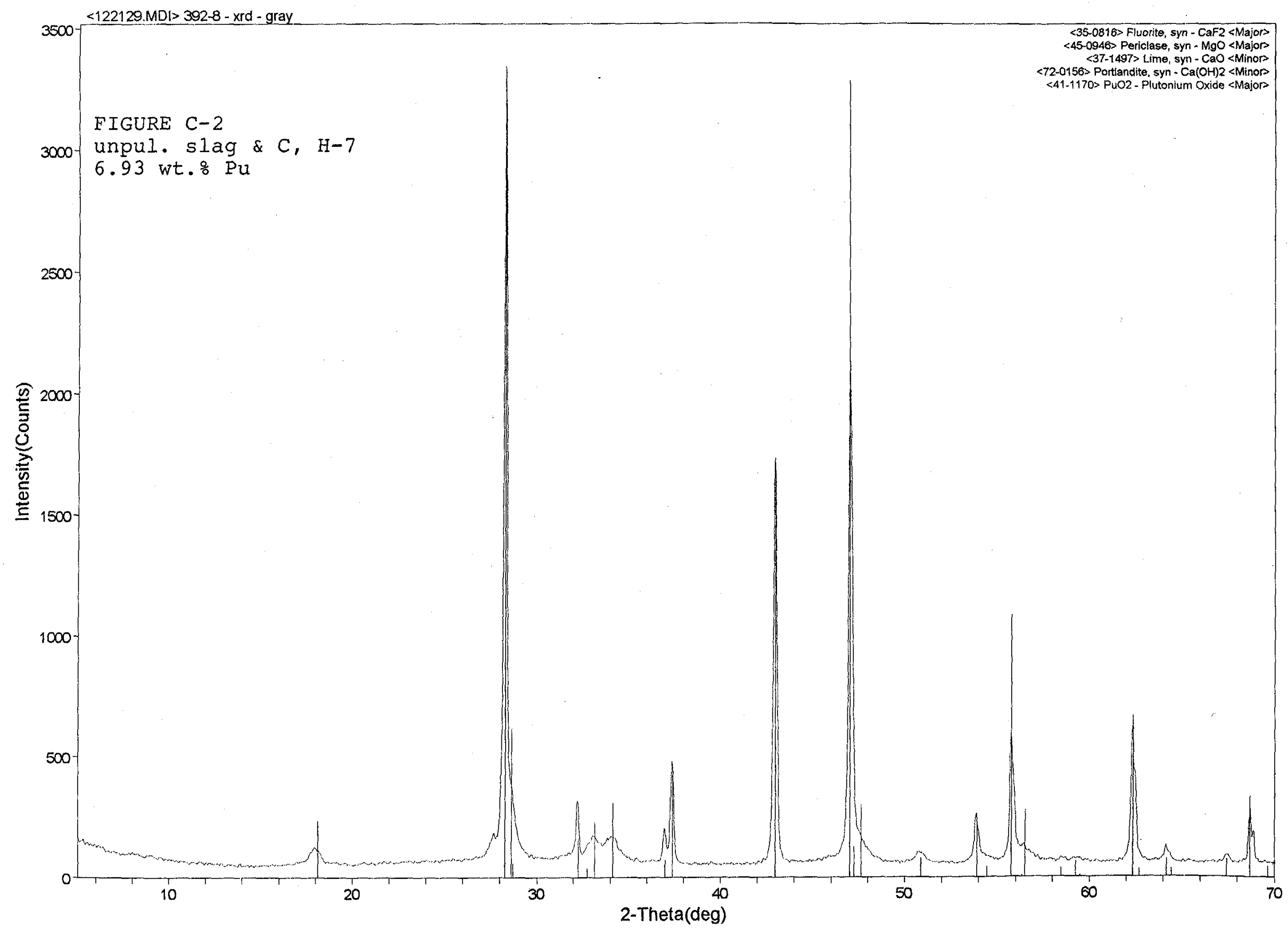




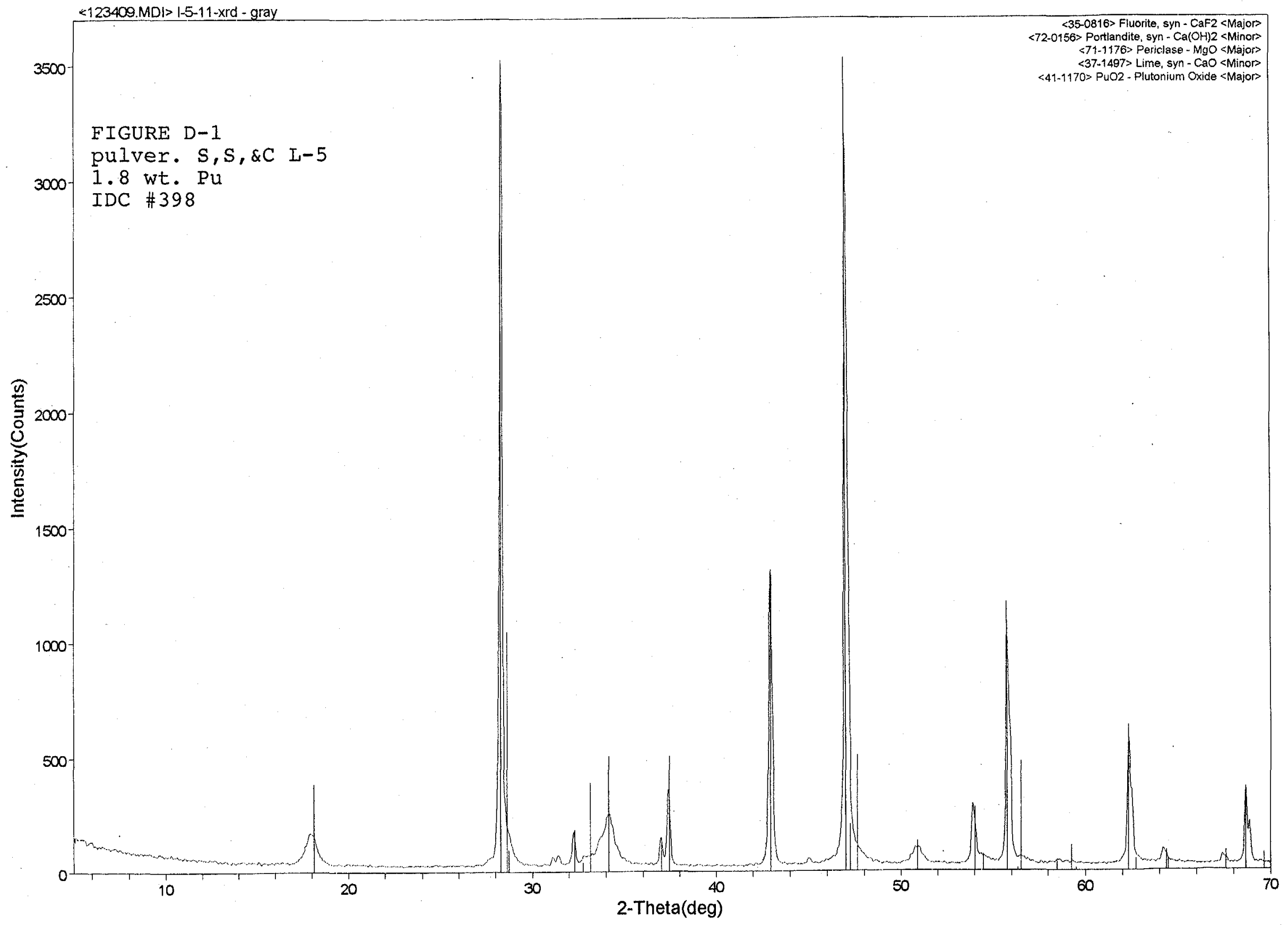




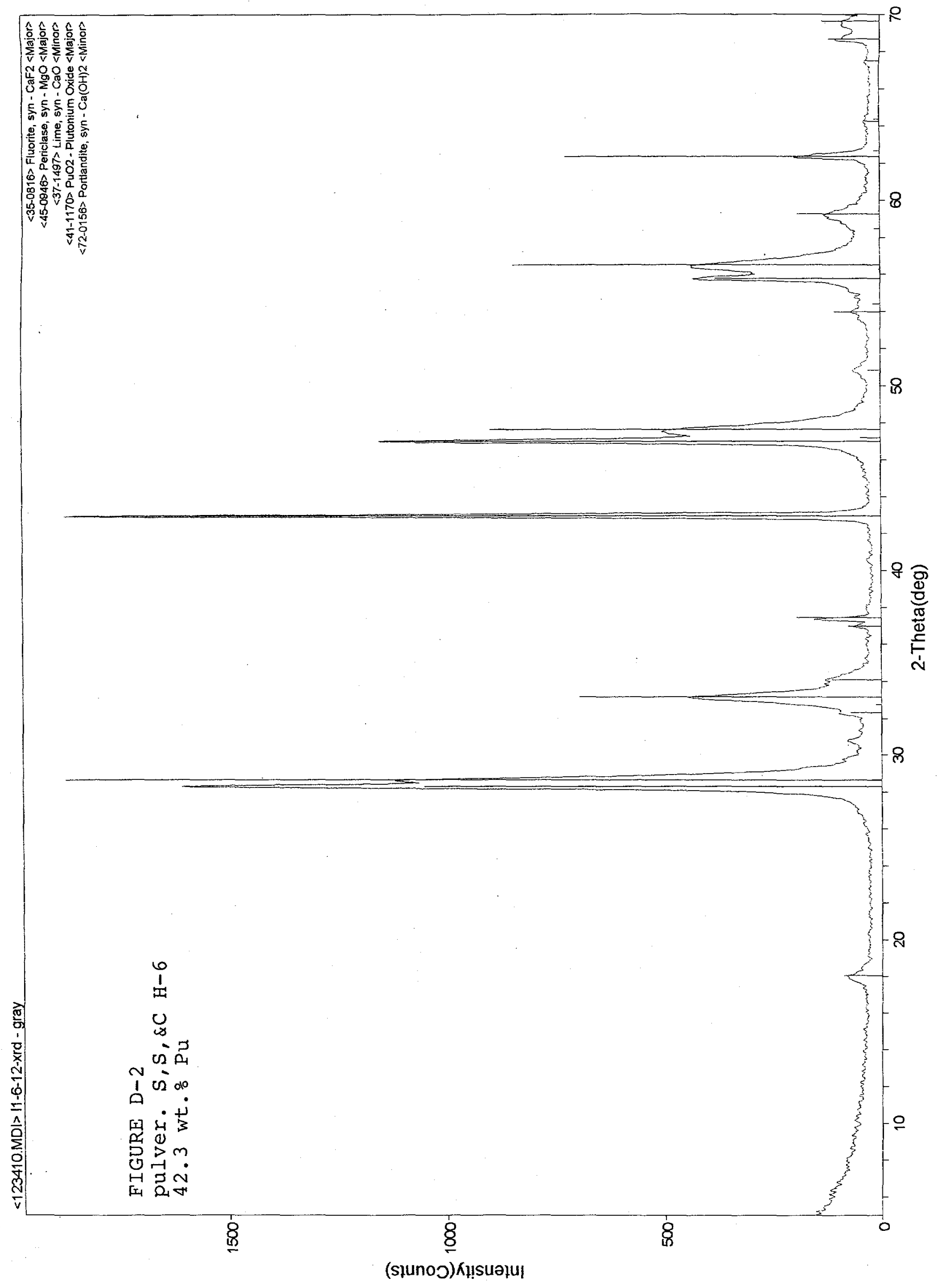


$\angle M G 01000$ MDI> MgO HEATED TO $1000 \mathrm{C}$ FOR 1 HOUR GRAY $2 B$

$\triangle M G O 600 \mathrm{MDI}>\mathrm{MgO}$ HEATED TO $600 \mathrm{C}$ GRAY $2 \mathrm{~B}$

$\angle M G O 380 \mathrm{MD}>>$ MgO HEATED TO $380 \mathrm{C}$ FOR 1 HOUR GRAY -28

$\angle M G O 220 A A M D I>M g O A$ HEATED TO 2200 FOR 1 HOUR MATERIAL - GRAY -2B

$\angle M G O A . M D \mid>$ MgOA AS RECEIVED UNHEATED MATERIAL - GRAY -2B

$<07.0239>$ Brucite, syn - Mg(OH) $2<$ Minor $>2$

FIGURE XRD-1

$1250^{-}$

TRD 1

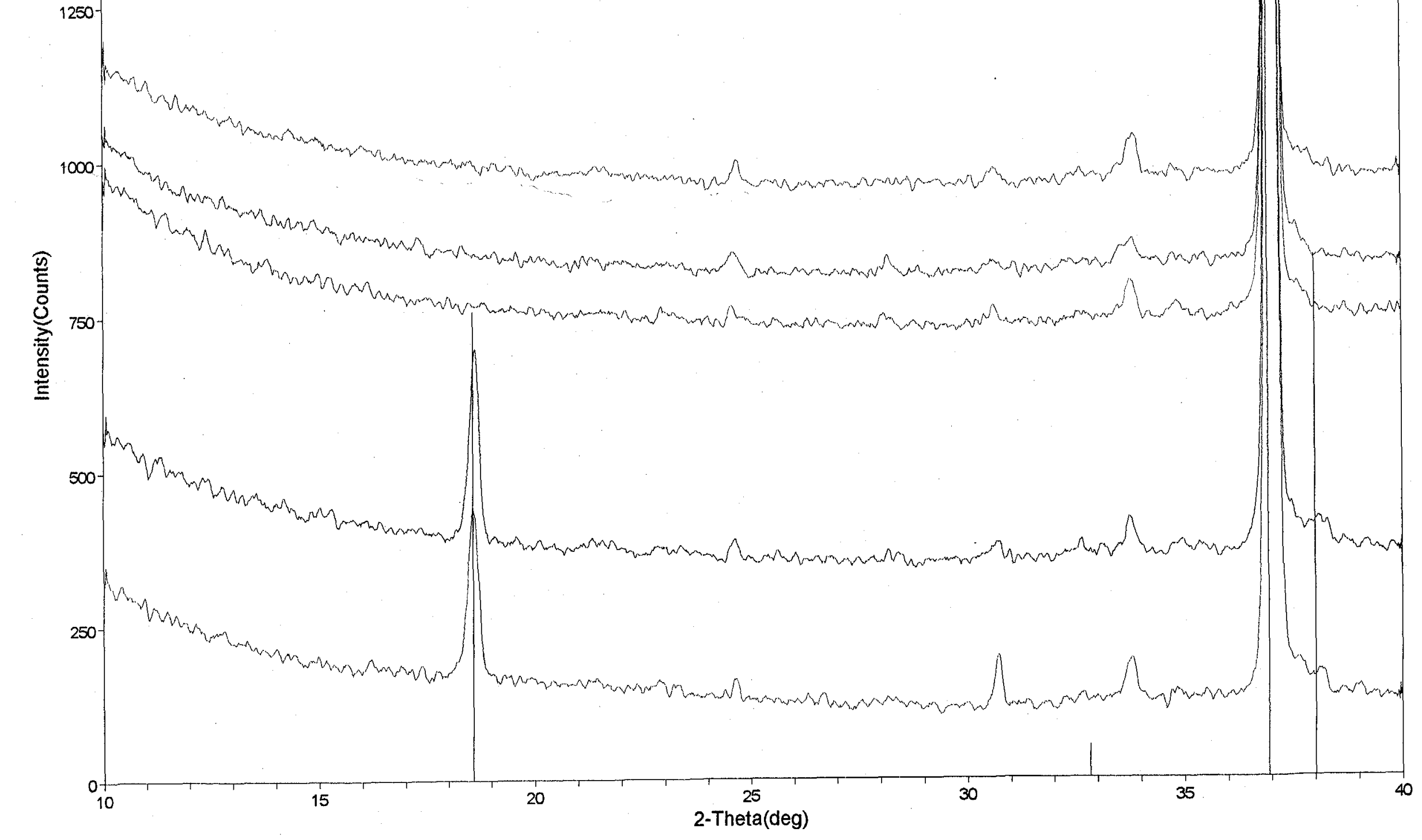




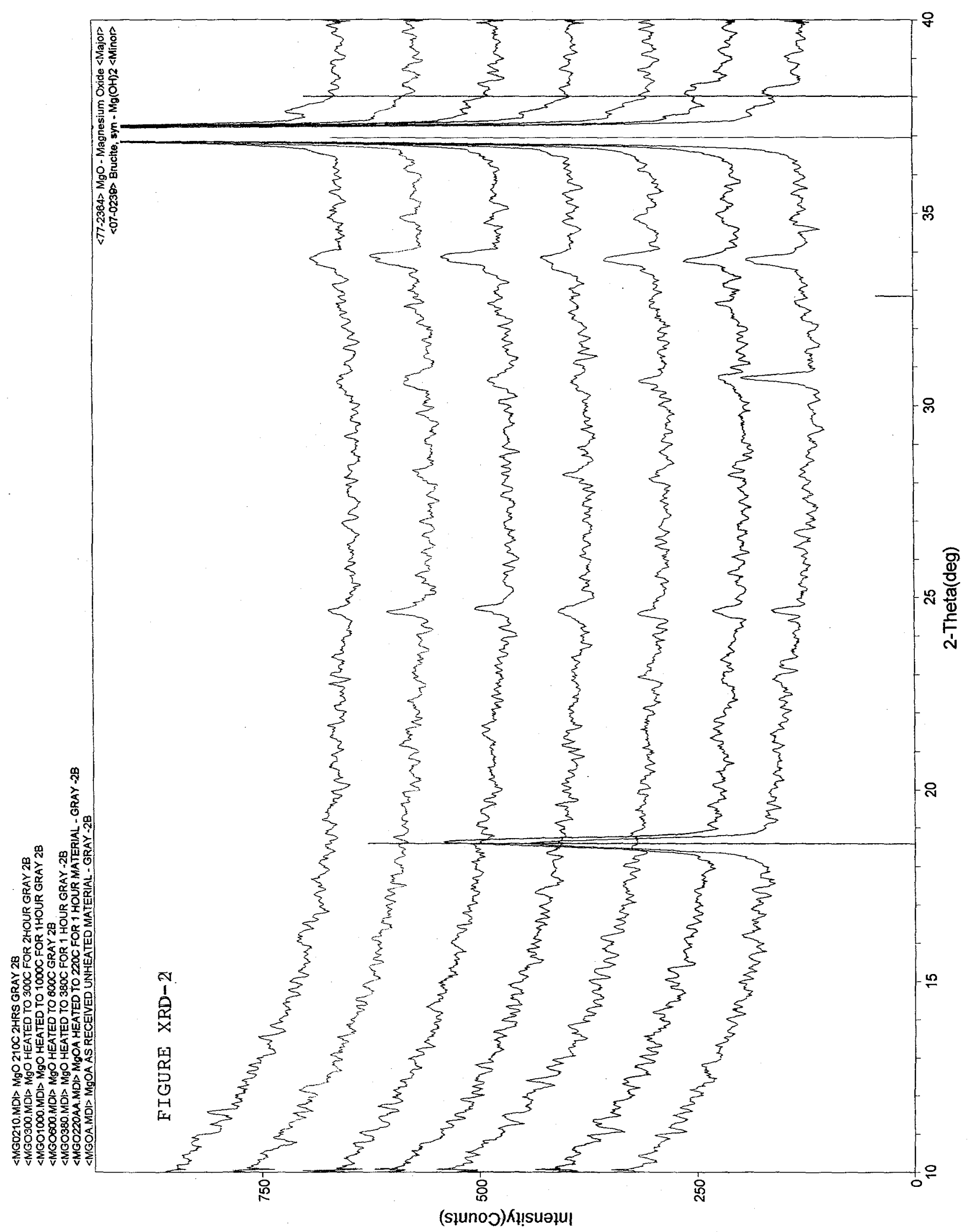




\CAMETAL.MDI> Ca METAL NOT GROUND VASELINE DUSTED SIEVED GRAY 1 B

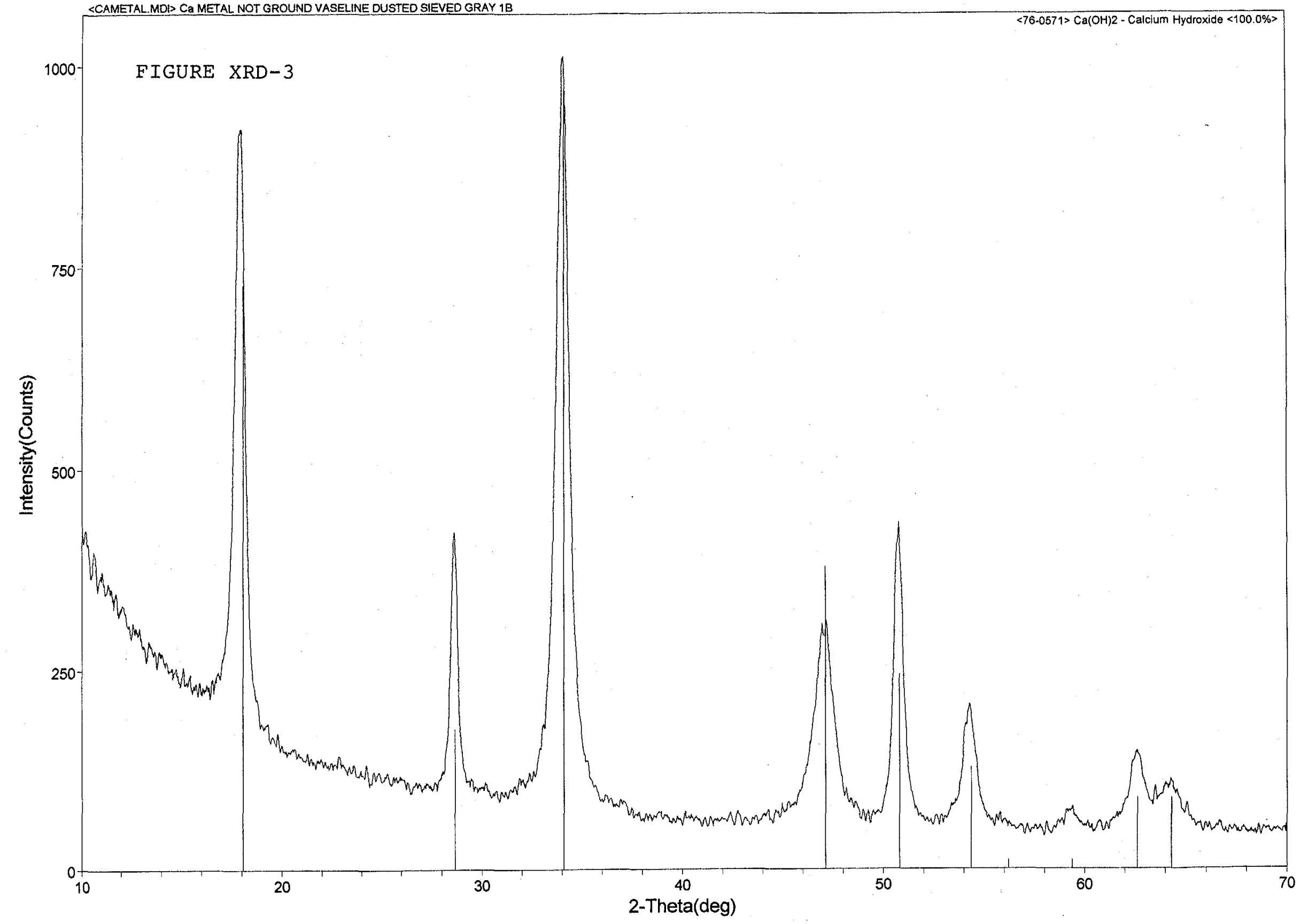




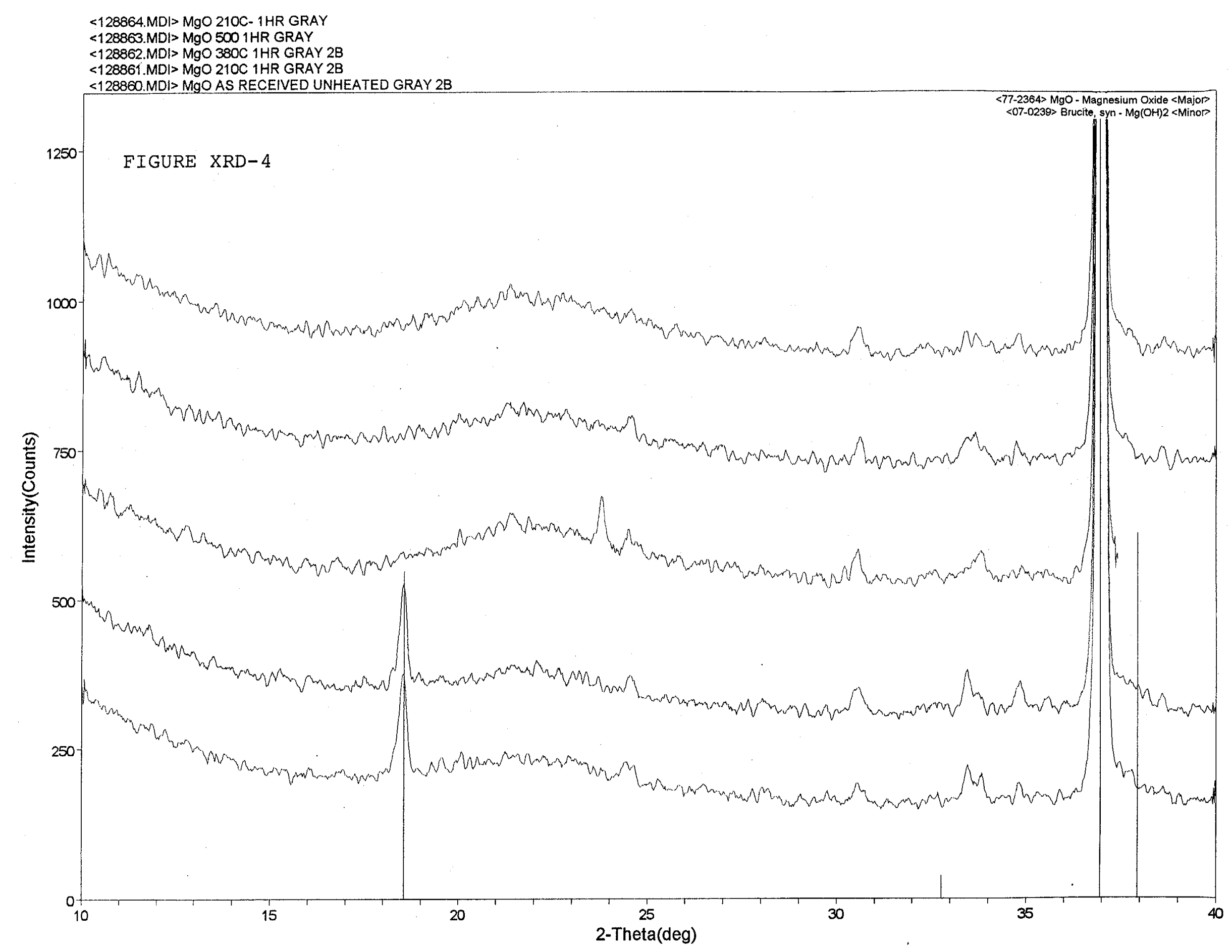




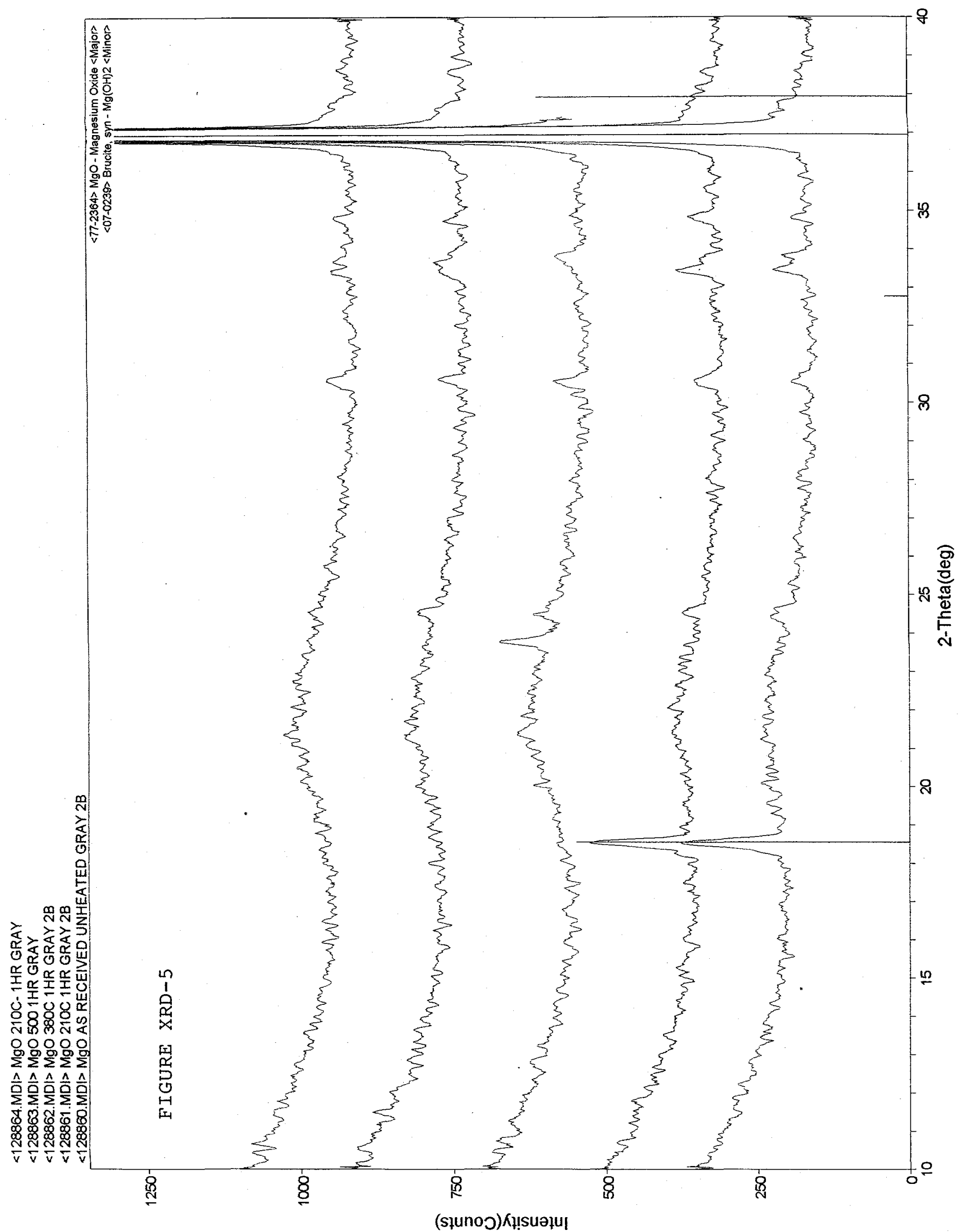

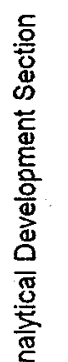




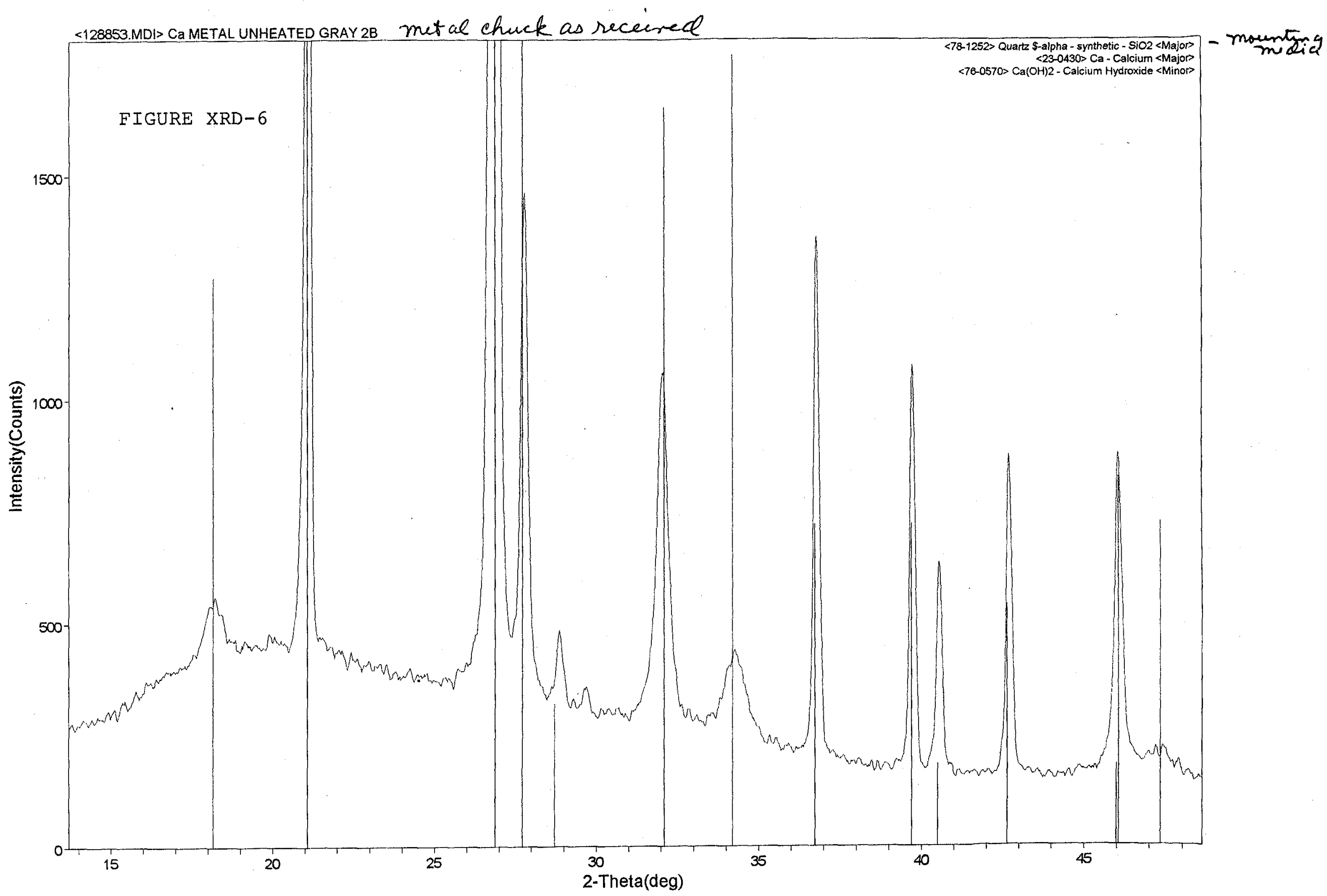

nalytical Development Section

<c:ldatasc 3ldata-99> Wednesday, Jun 16, $1999 @ 11: 53 a$ 
128723.MDI> SSC-L1.700C-1HR GRAY $2 A$

$<128722$ MDI $>$ SSC-L1-600C 1HR GRAY

$<128721$ MDI> SSC-L1-45OC 1HR GRAY

$<128720$.MDI> SSC-L1 380C 1HR gray $2 \mathrm{a}$

$<128719$.MDI> SSC-L1 210C 2HRS gray $2 a$

$\left(\varepsilon_{0} \varepsilon_{0}\left(\sigma_{0}\right)\left(M_{30}\right) P_{4 O_{2}} \quad P_{4} O_{2}\right.$

$<128718 \mathrm{MDI}>\mathrm{SSC}-\mathrm{L} 1$ unheated gray $2 \mathrm{a}$
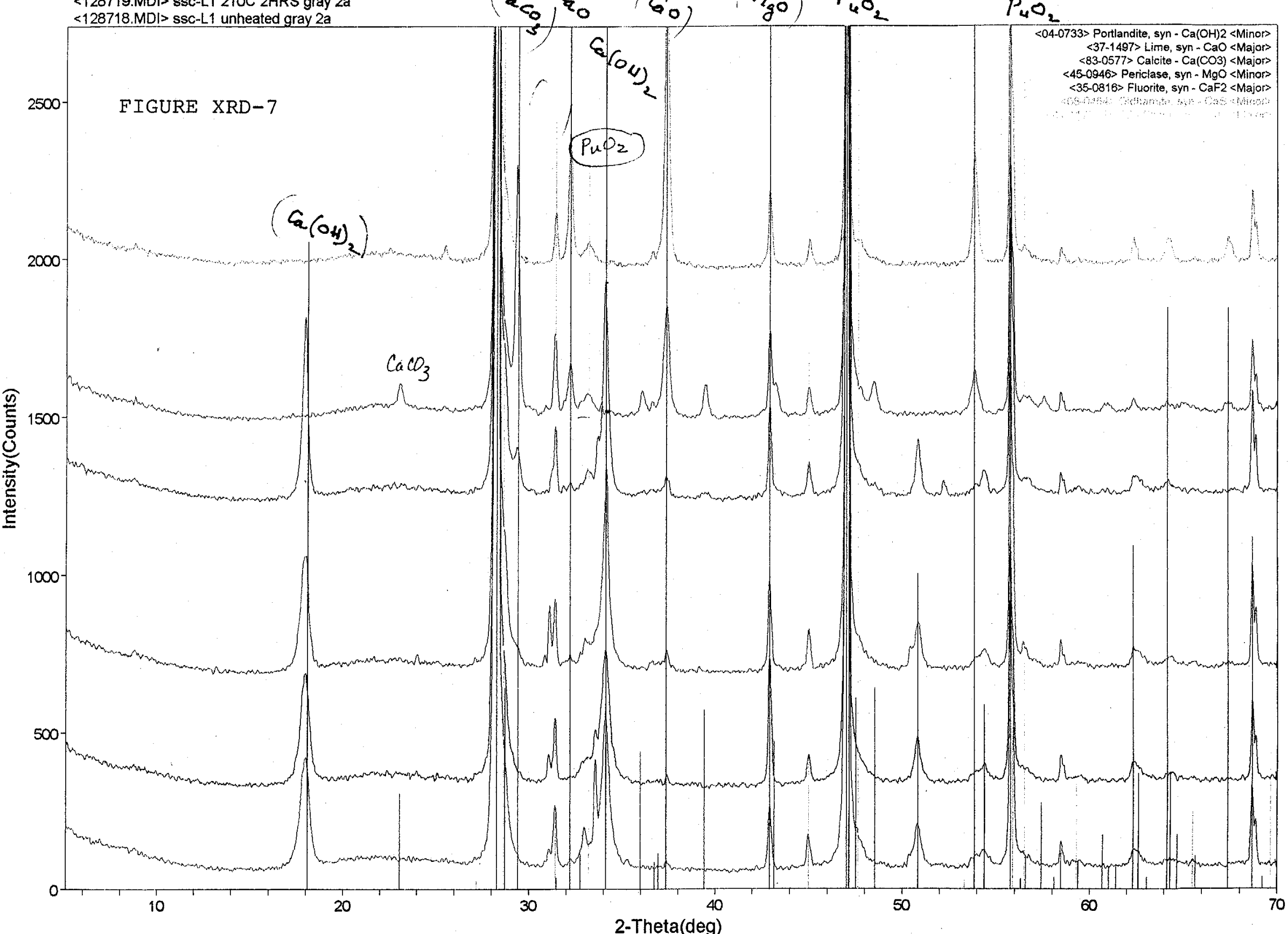
(L1)

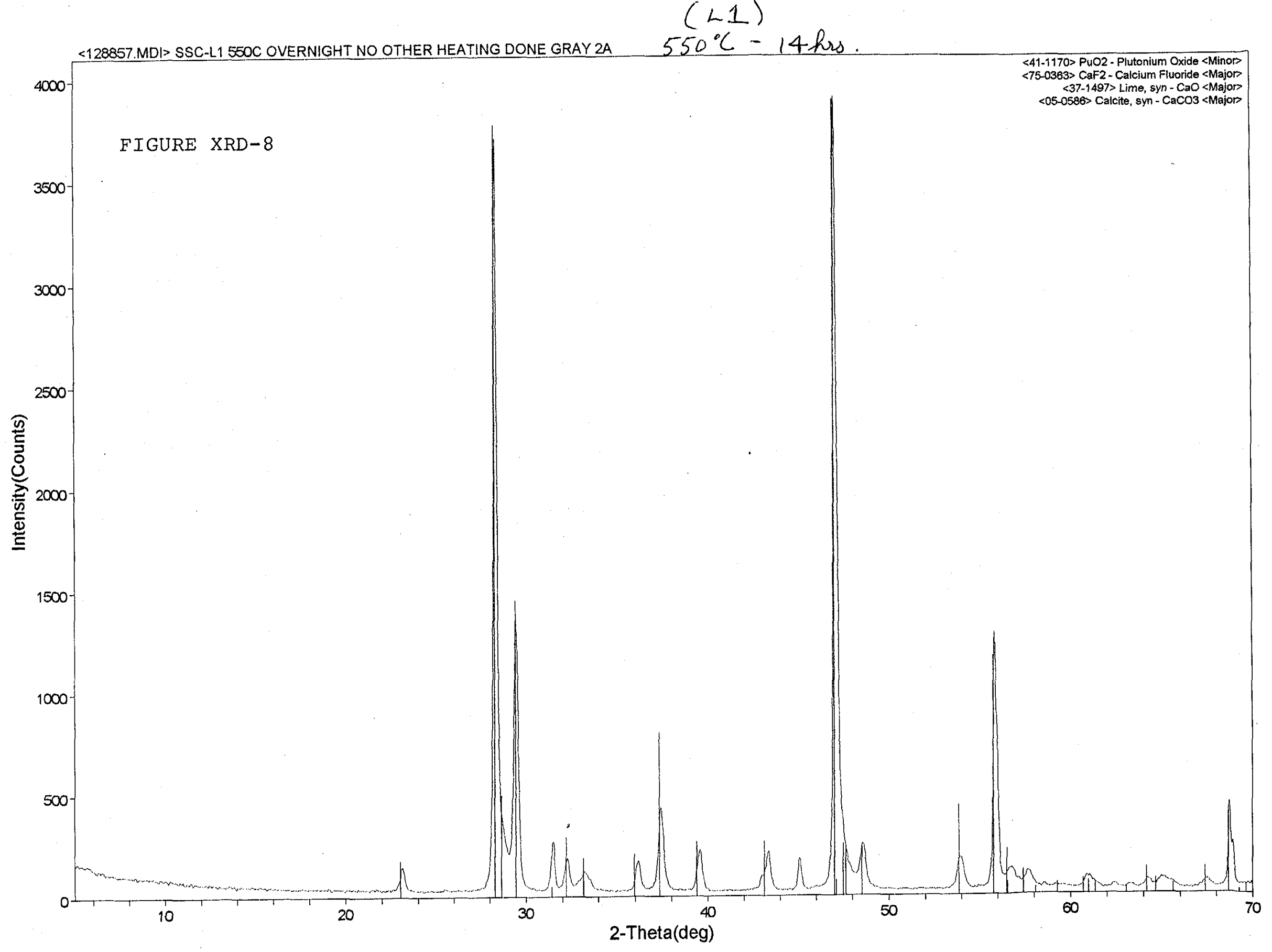






ralytical Development Section

<f:Lrd-1999> Monday, Jun 21, $1999 @ 08: 34 a$ 


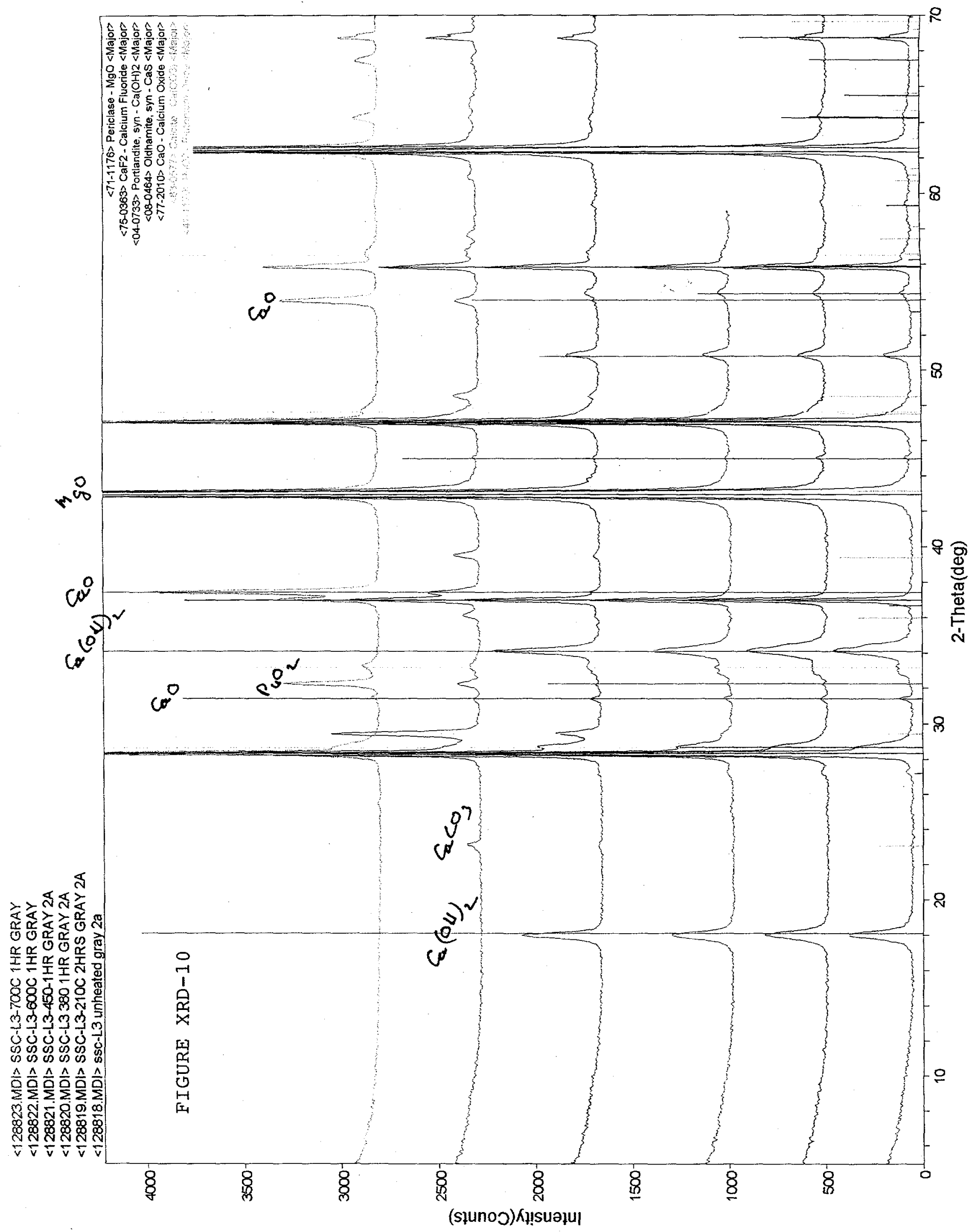


128829.MDI> SSC-L44700C 1HR GRAY

$<128828$.MDI> SSC-L4600C 1HR GRAY

$<128827 . M D \mid>$ SSC-L4450-1HR GRAY $2 A$

$<128826$.MDI> SSC-L4380-1HR GRAY 2A

$<128825$ MDl> SSC-L4-210C 2HRS GRAY 2A

$<128824 . \mathrm{MDI}>\mathrm{sSC}-$ L4 UNHEATED gray $2 \mathrm{a}$

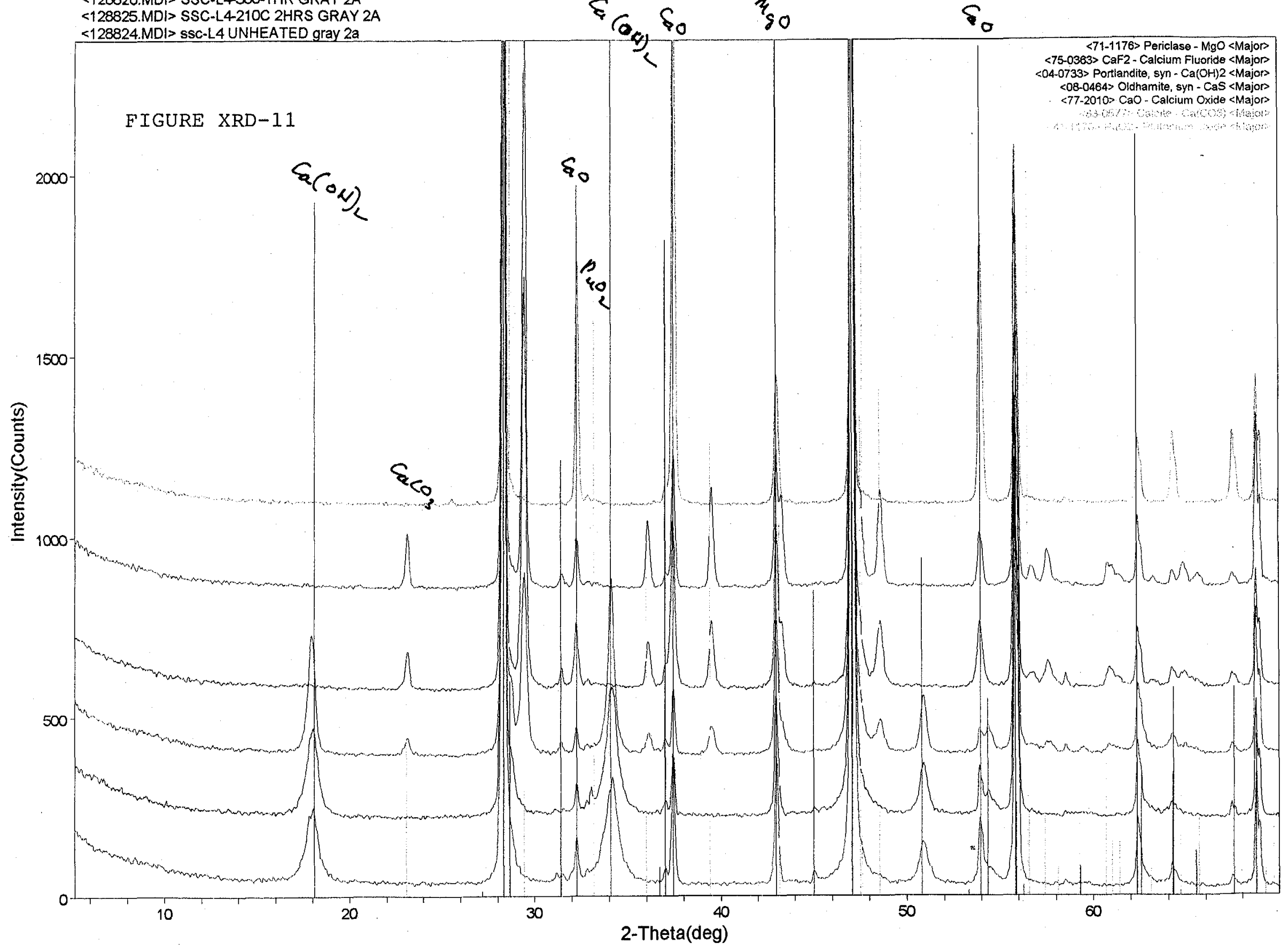




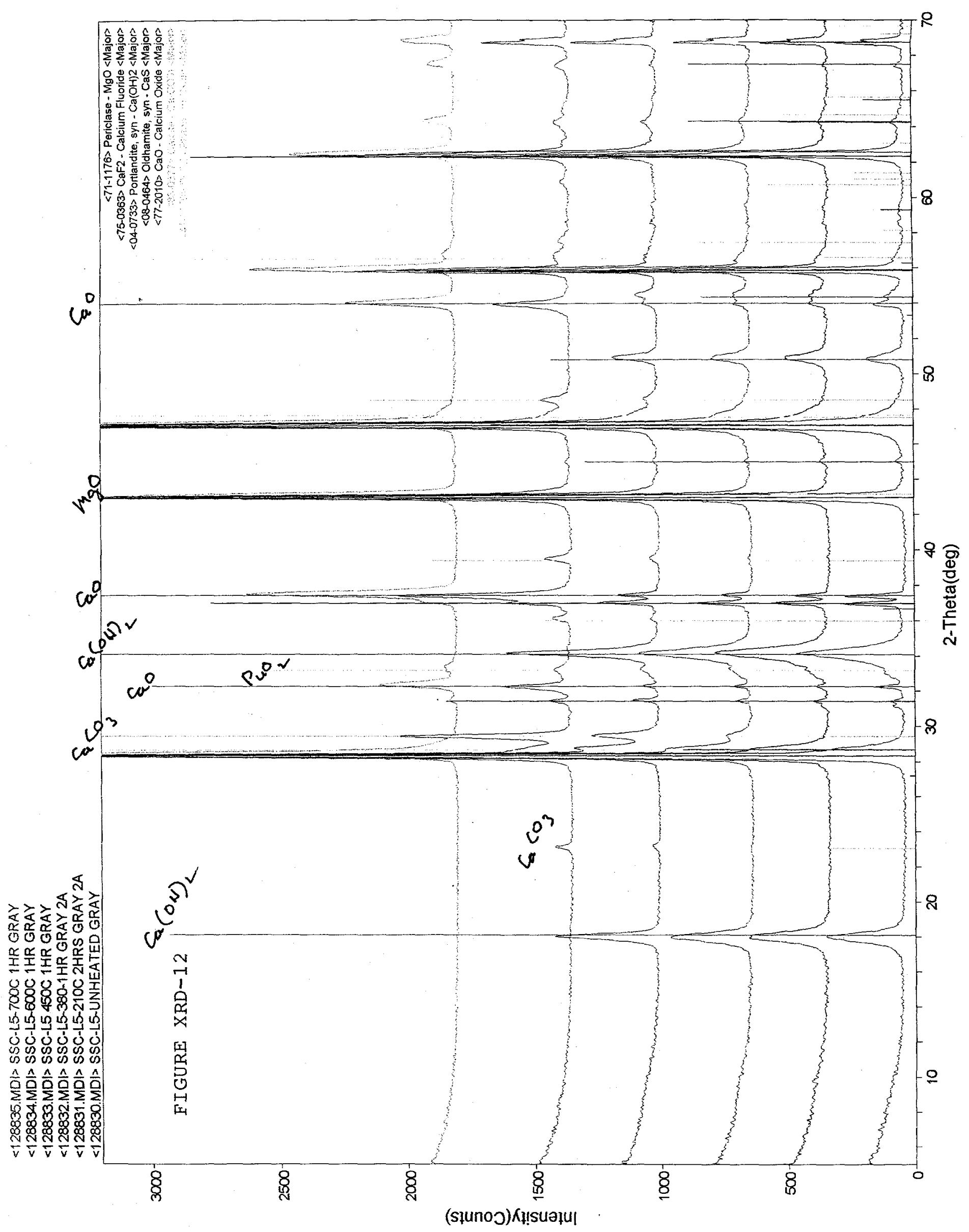




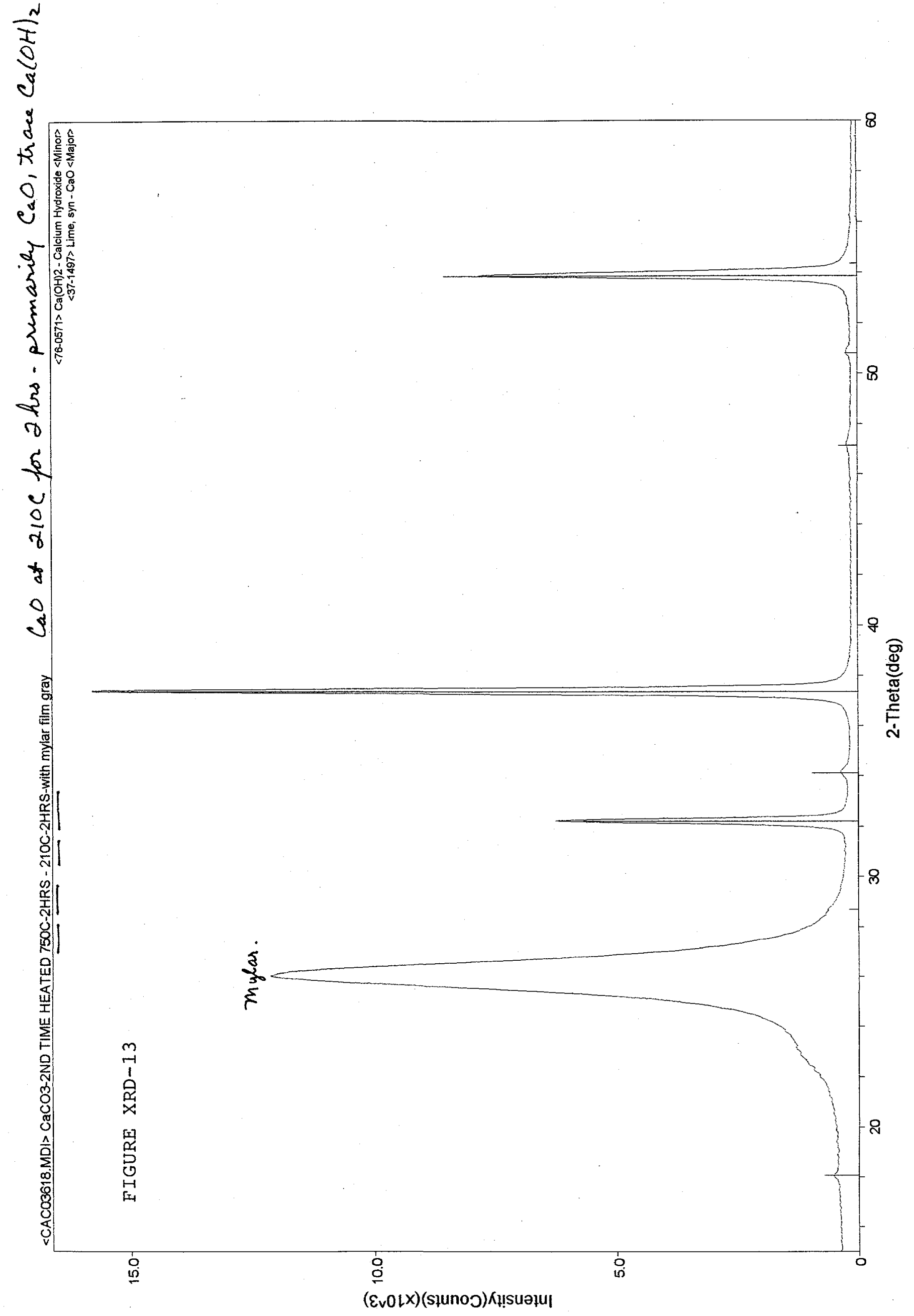




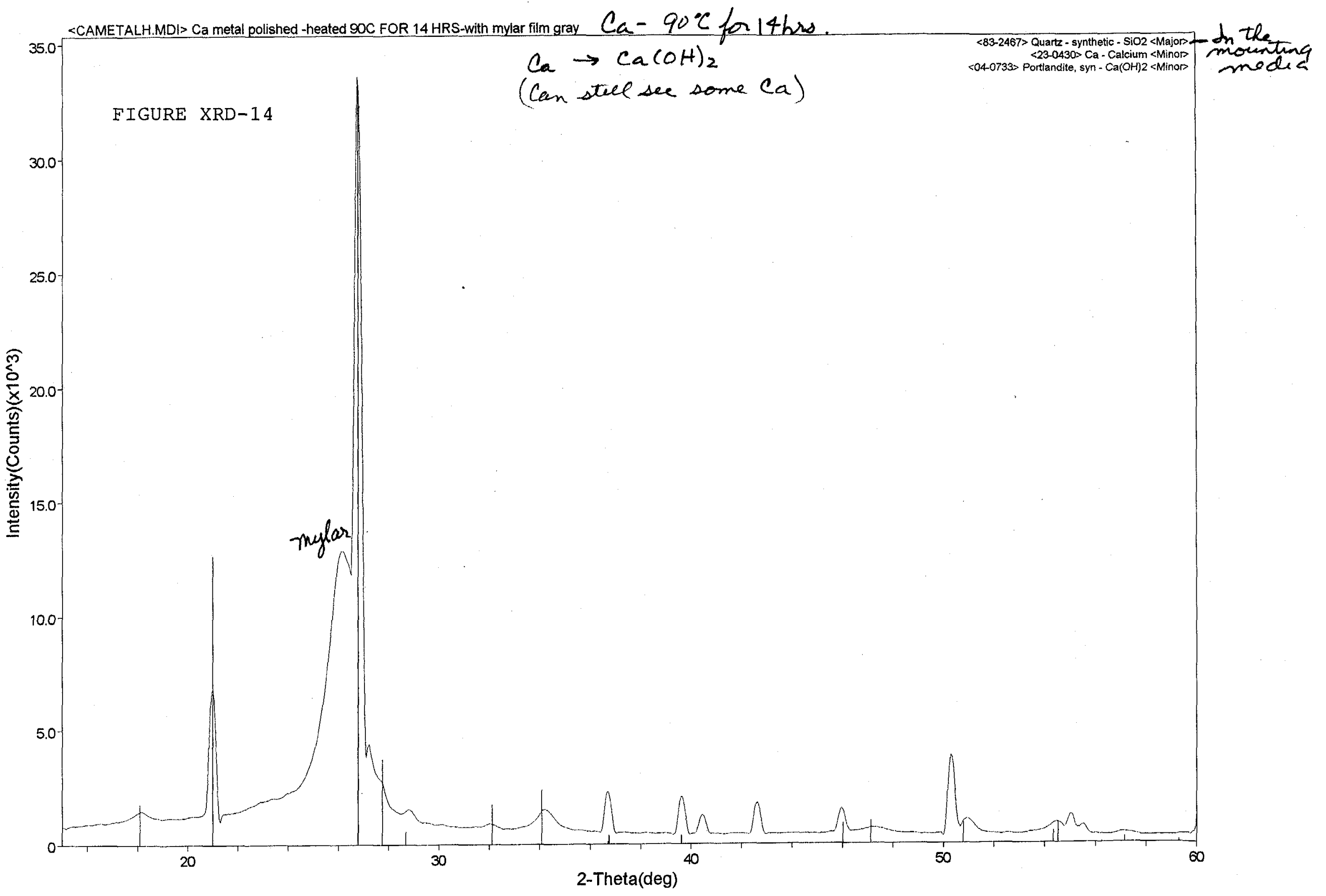

alytical Development Section

<f:Wrd-1999> Monday, Jun 21, $1999 @ 10: 33 a$ 


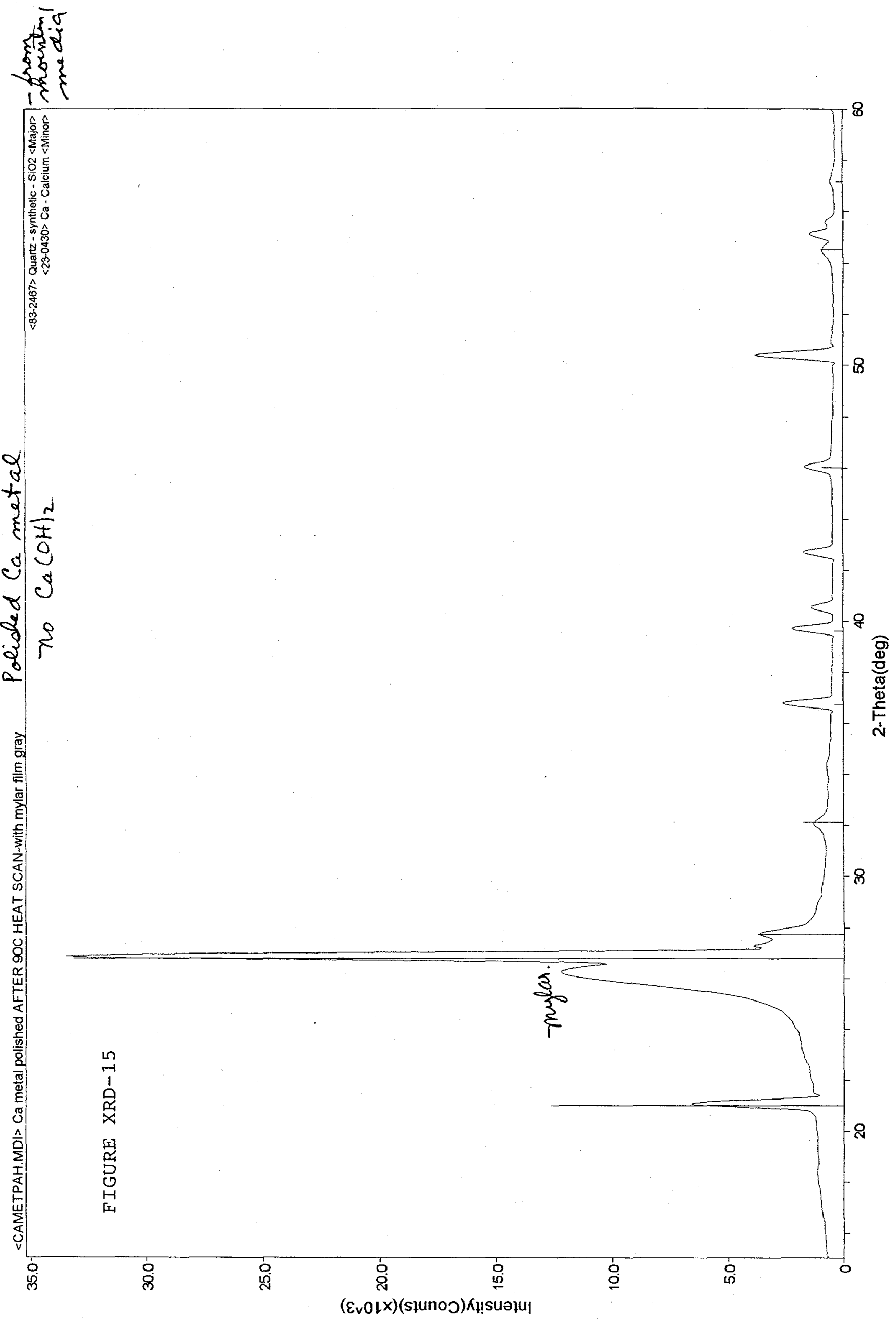




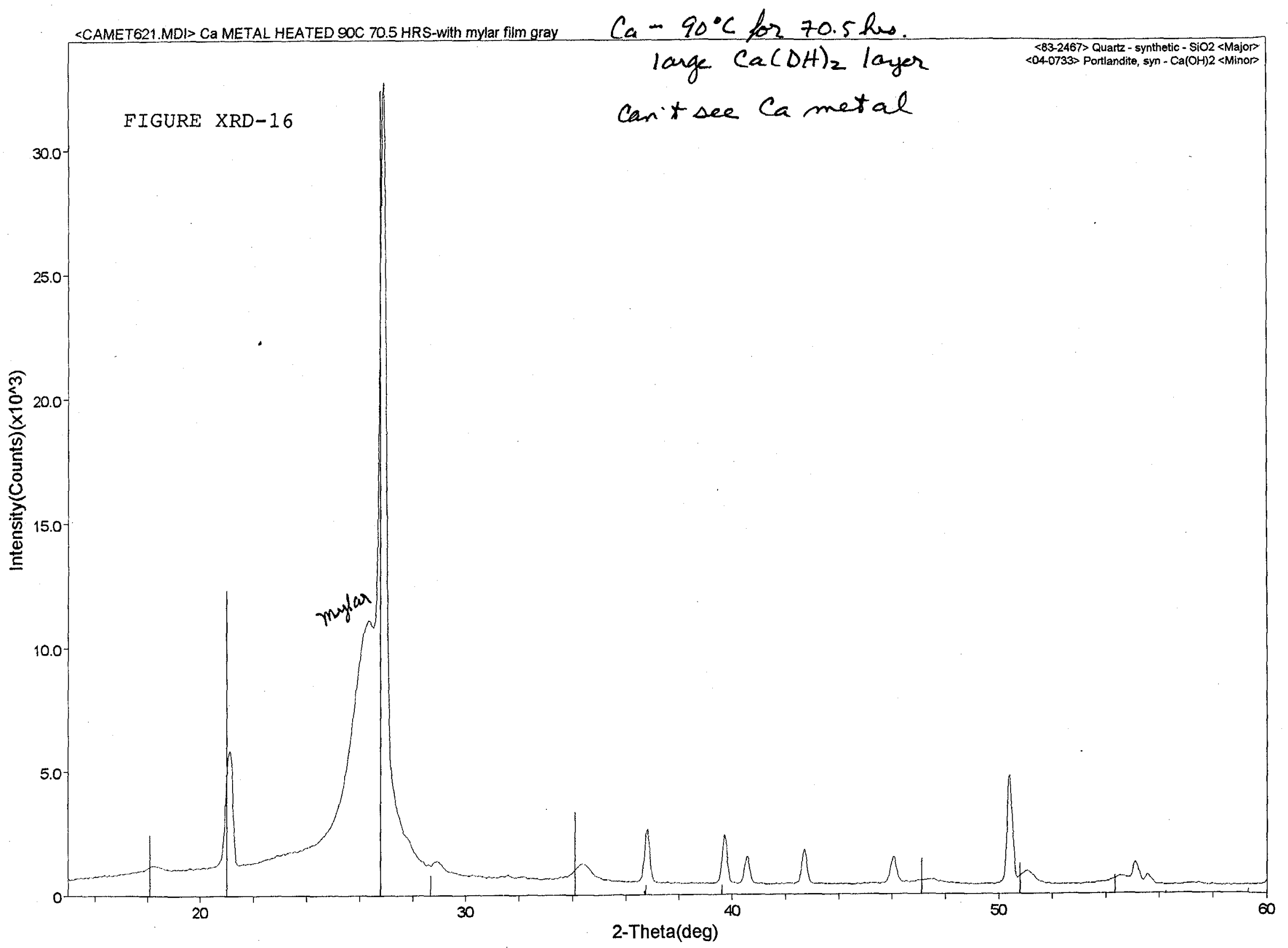

nalytical Development Section

$<f:$ Xrd-1999> Monday, Jun 21, $1999 @ 10: 36$ a 
12501

L1600C17MDI>SSC-L1-600C FOR 17HRS GRAY at $600^{\circ} \mathrm{C}$, only CaO efrists : too high for $\mathrm{Ca} \mathrm{CO}_{3}$

FIGURE XRD-17

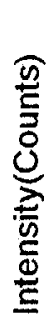

1000

$750-$

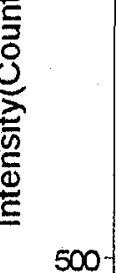

500

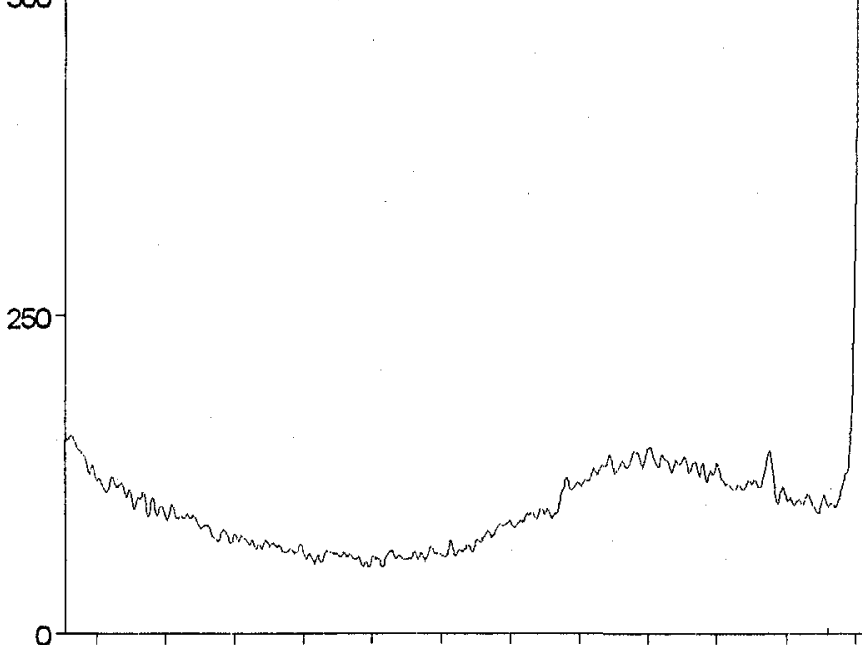

10
20

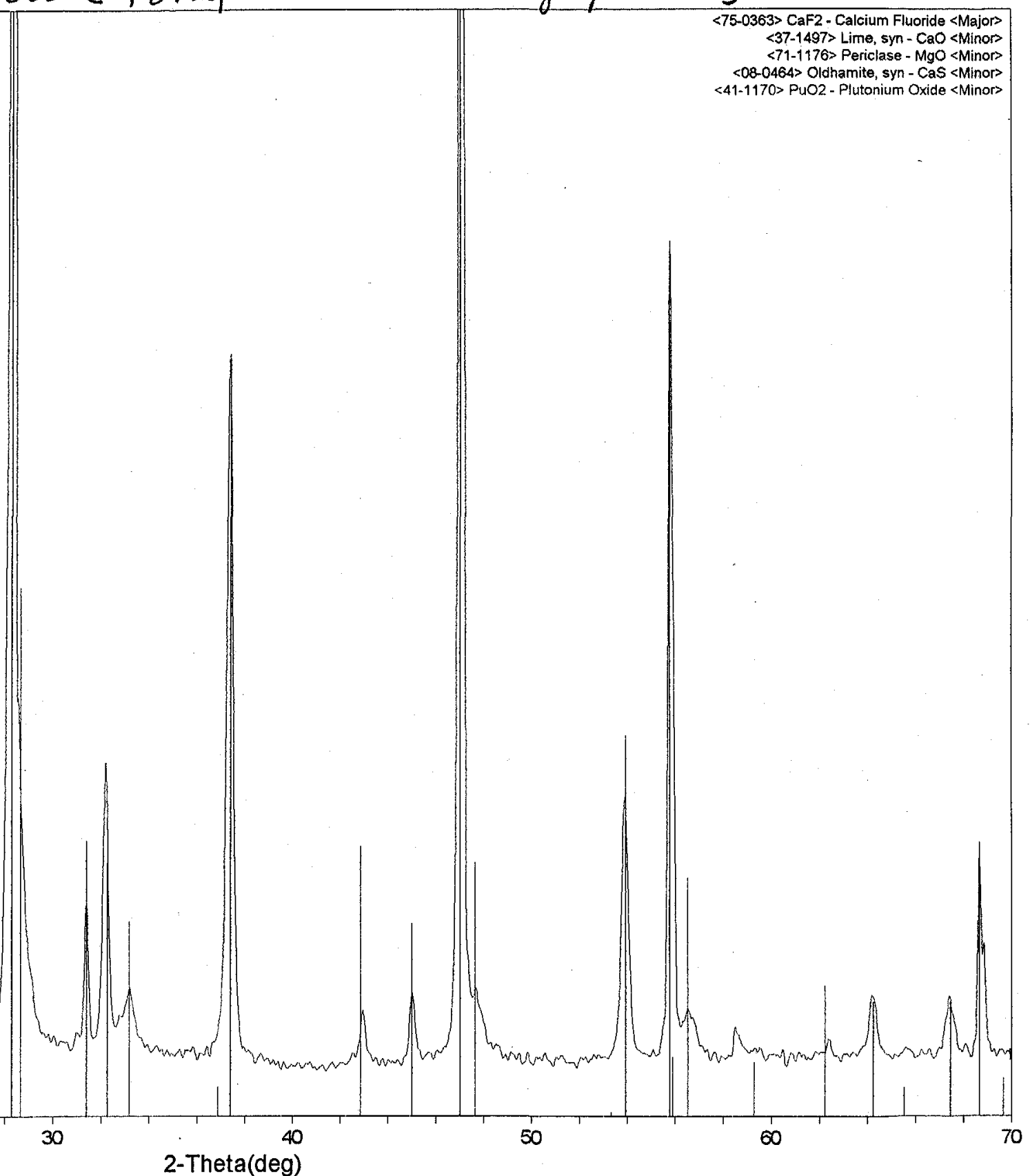




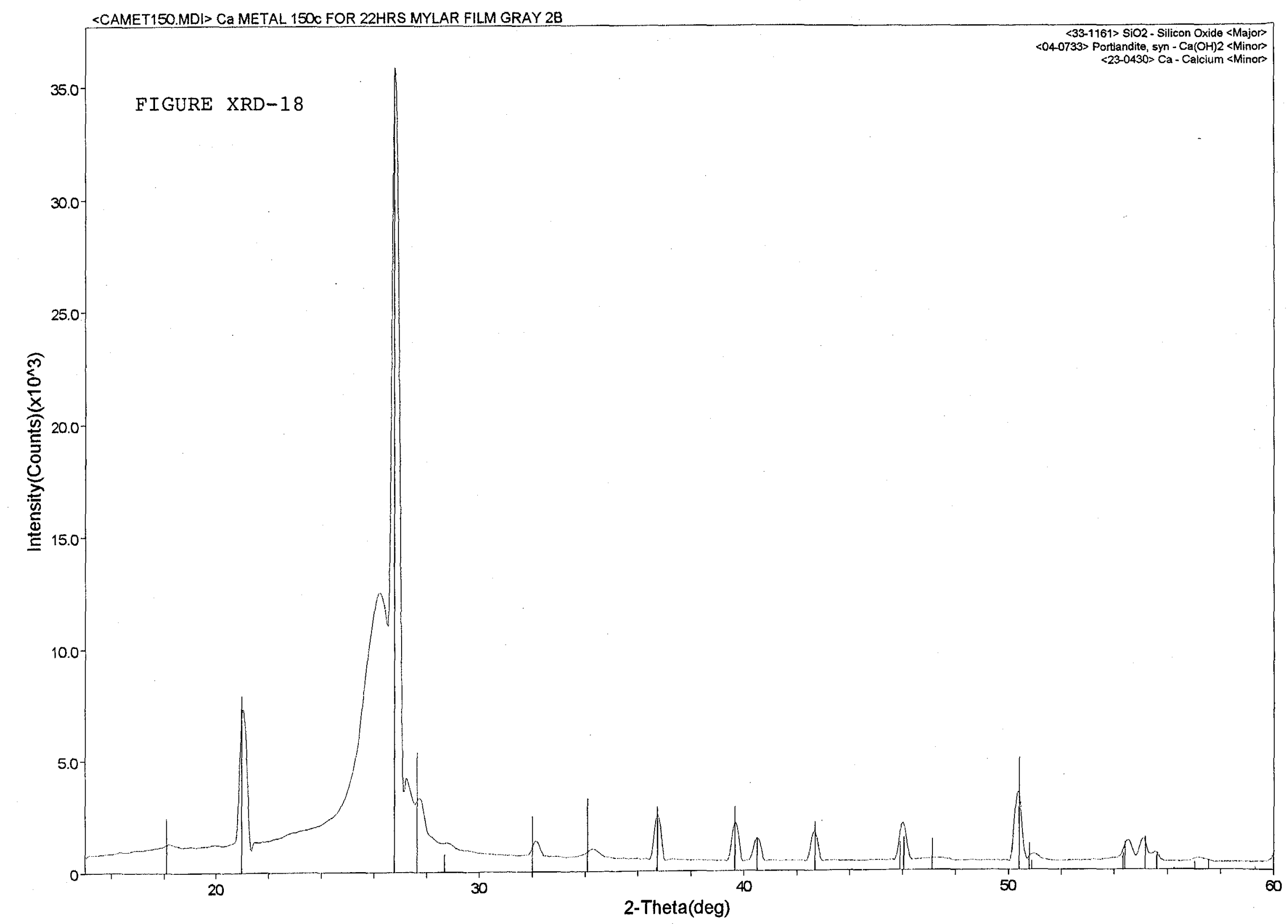




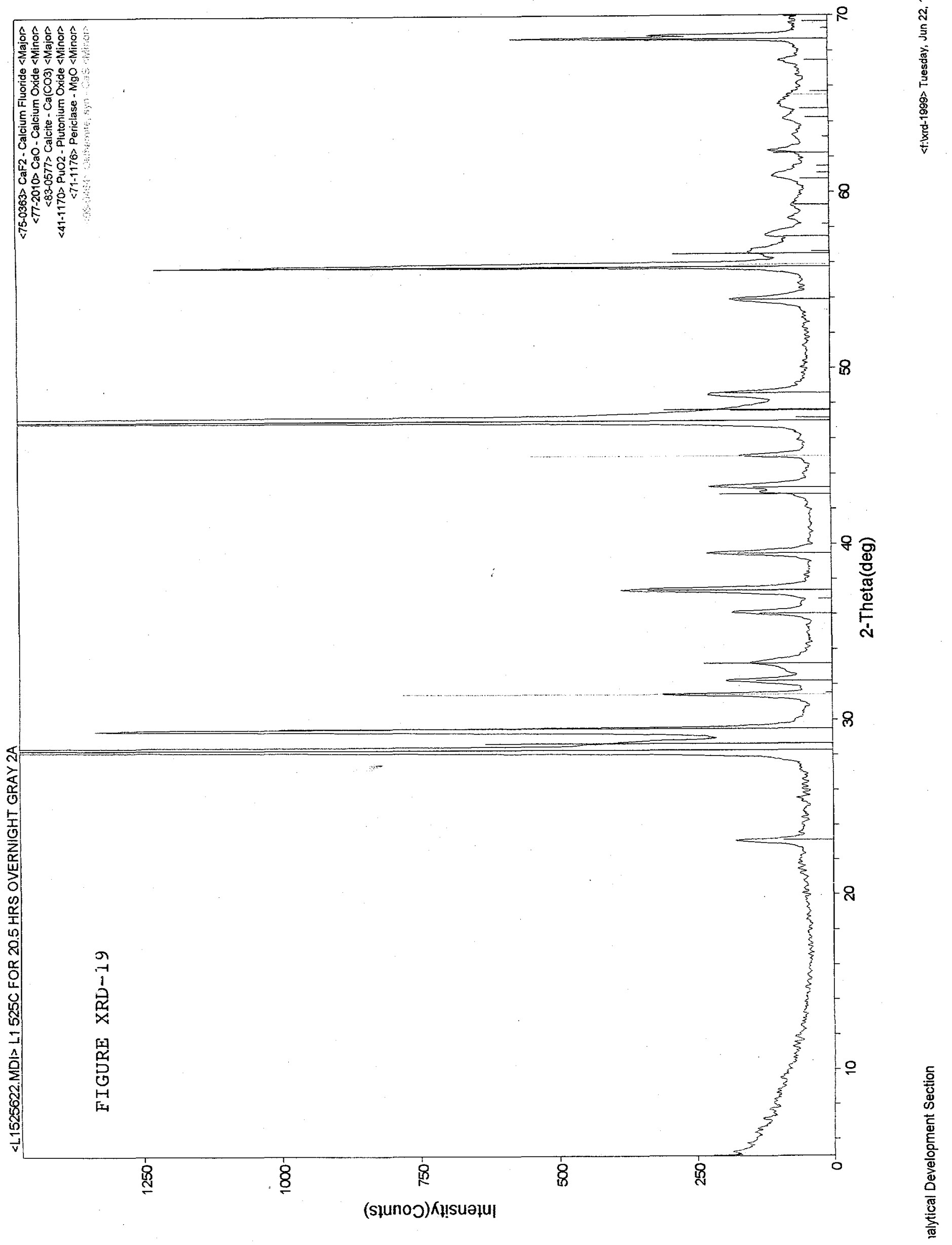


<L1600C17.MDI> SSC-L1-600C FOR 17HRS GRAY

$<128857 . \mathrm{MDI}>$ SSC-L1 550C OVERNIGHT NO OTHER HEATING DONE GRAY 2A

$<$ 1525622.MDI> L1 525C FOR 20.5 HRS OVERNIGHT GRAY 2A









$<128857 . M D \mid>$ SSC-L1 550C OVERNIGHT NO OTHER HEATING DONE GRAY 2A

$<$ L1550625.MDI> L1 550C FOR 74 HOURS GRAY 2A

FIGURE XRD-22

$2000-$

1500

号

1000

500

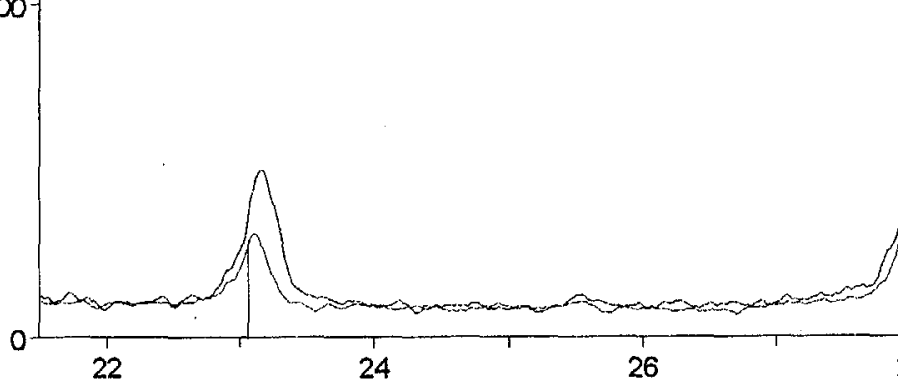

22

24

28

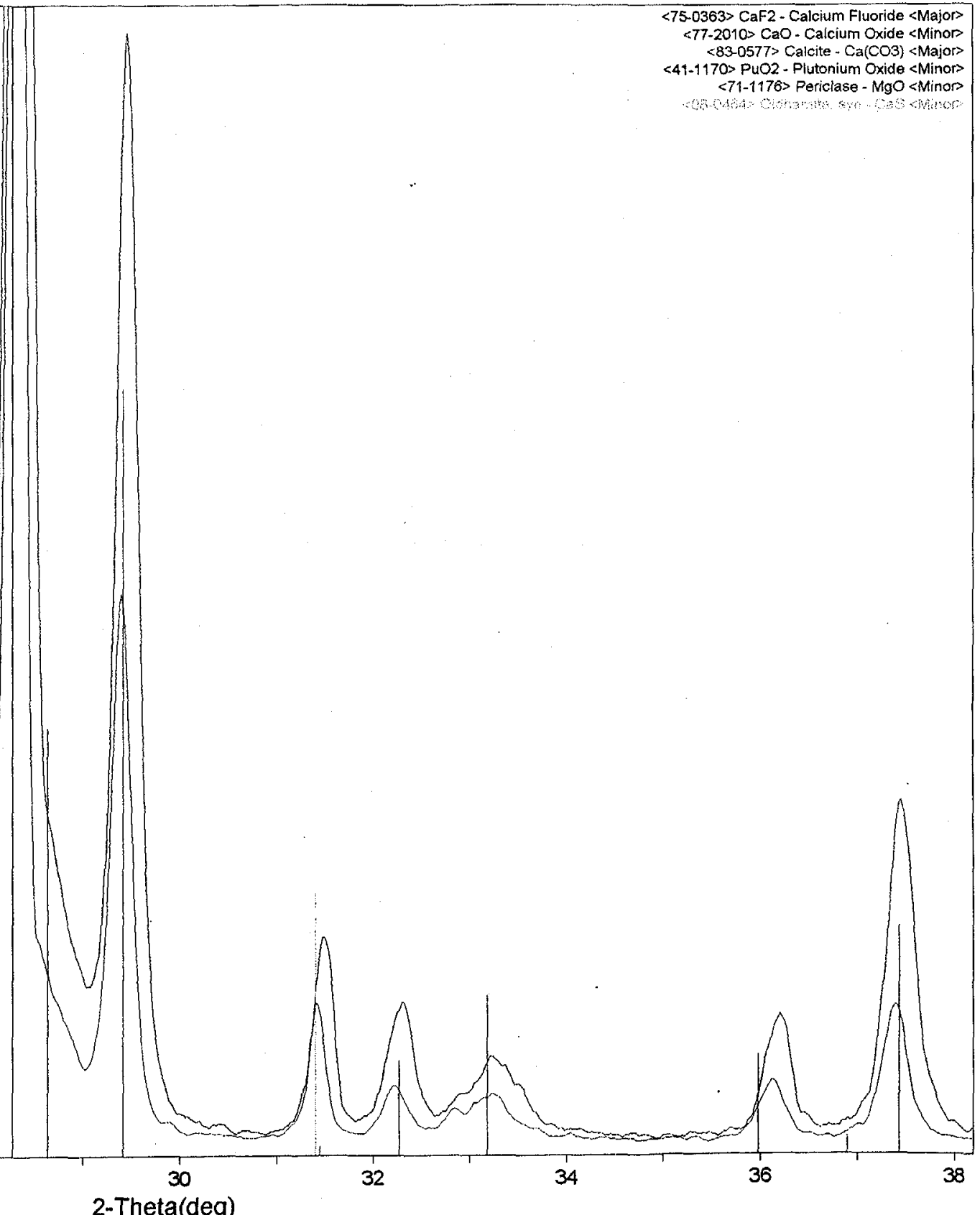




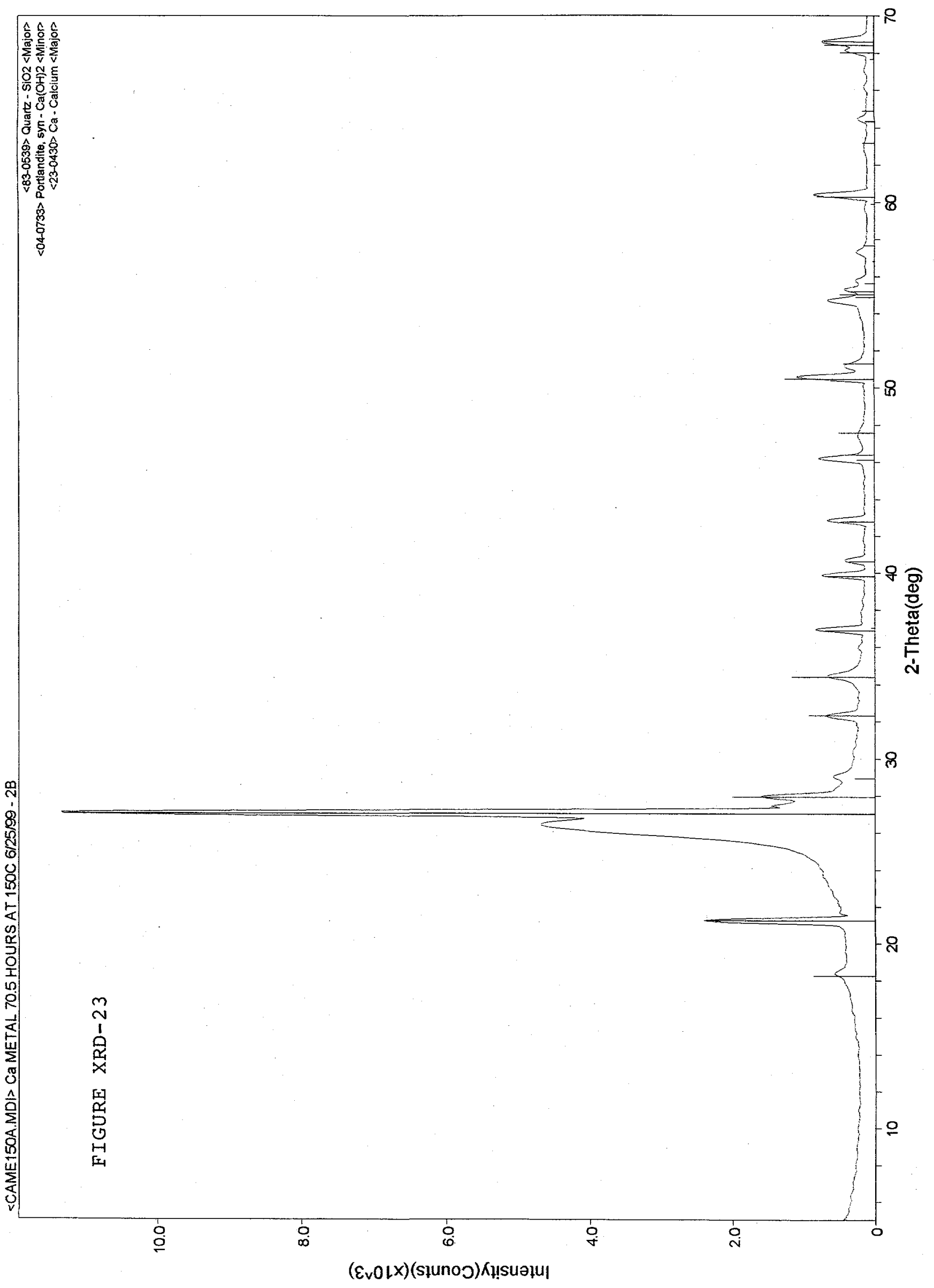

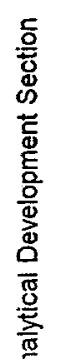


WSRC-TR-99-00275

\section{Appendix B}

\section{THERMOGRAVIMETRIC EXPERIMENTS}

A series of thermogravimetric analysis (TGA) experiments was conducted to better understand the decomposition characteristics of the pure materials found in the RFETS SSC materials. In addition, actual SSC samples were tested

The following pure materials were investigated to determine their thermal decomposition, oxidation behavior, and moisture content: calcium metal, $\mathrm{Ca}(\mathrm{OH})_{2}, \mathrm{CaCO}_{3}$, RFETS $\mathrm{MgO}$ sand and crucible, and $\mathrm{Mg}(\mathrm{OH})_{2}$. The RFETS SSC samples that had low and high plutonium assays were also studied.

Test practice

A TA Instruments Model 951 TGA was used for this test program. For the oxides, hydroxides, and carbonate, a sample between 10 and $25 \mathrm{mg}$ was placed on a platinum pan after it had been tared. A heating rate of $10^{\circ} \mathrm{C} / \mathrm{min}$ was commonly used. An isothermal soak at a set point of $210^{\circ} \mathrm{C}$ was used to determine the weight change characteristics at this temperature. The control and data acquisition systems were such that the actual temperature in the cell was monitored and reported while the furnace temperature was controlled by a thermocouple embedded in the furnace. In addition, the position of the reference (sample) thermocouple was not fixed, i.e. it could be displaced away from the sample which could have adversely affected the temperature precision. It was found that the sample temperature had from a zero offset at $210^{\circ} \mathrm{C}$ to as high as a $30^{\circ} \mathrm{C}$ offset. In addition, the final temperature was as much as $70^{\circ} \mathrm{C}$ lower to as much as $50^{\circ} \mathrm{C}$ higher than the set point depending on heating rate, thermocouple placement, gas flow, etc.

Empty sample pans were run under identical conditions to help deconvolute the gravimetric data from buoyancy and instrument heating influences.

Characterization of $\mathrm{MgO}$ and $\mathrm{Mg}(\mathrm{OH})_{2}$

Samples of as-received RFETS MgO sand and crucible material were heated to final temperatures of $500,750,1000$, and $1200^{\circ} \mathrm{C}$. The heating rate was $10^{\circ} \mathrm{C} / \mathrm{min}$ from room temperature to $210^{\circ} \mathrm{C}$ with a 30 minute hold and subsequent heating to the final temperature at $10^{\circ} \mathrm{C} / \mathrm{min}$ with a 5 minute hold. The samples were then cooled at a rate of $20^{\circ} \mathrm{C} / \mathrm{min}$ to approximately $30^{\circ} \mathrm{C}$ or to $210^{\circ} \mathrm{C}$ and held for 600 minutes prior to cooling to room temperature. The tests were conducted to determine the amount of $\mathrm{Mg}(\mathrm{OH})_{2}$ and adsorbed moisture, and the stability of the $\mathrm{MgO}$ once it had been calcined. The RFETS MgO tested is not completely representative of the actual SSC material since it had not undergone any type of high temperature processing like what occurs during bomb reduction, nor had it been exposed to a radiation field. It is an appropriate surrogate though to determine total content of adsorbed moisture and worst case conditions for $\mathrm{Mg}(\mathrm{OH})_{2}$ content.

The sample size, amount of adsorbed moisture, and $\mathrm{Mg}(\mathrm{OH})_{2}$ to $\mathrm{MgO}$ transitions, are listed in Table I. The RFMGO and GAS-GEN.001 identifications refer to "as received" RFETS MgO. 
The sample size, amount of adsorbed moisture, and $\mathrm{Mg}(\mathrm{OH})_{2}$ to $\mathrm{MgO}$ transitions, are listed in Table I. The RFMGO and GAS-GEN.001 identifications refer to "as received" RFETS MgO. The GAS. 003 was run on SRS-MgO while GAS-GEN.044 was run on reagent grade $\mathrm{Mg}(\mathrm{OH})_{2}$. As can be seen from the data, most samples exhibited small apparent weight gains on heating to $210^{\circ} \mathrm{C}$. However, these weight gains were likely due to buoyancy and heating effects of the balance. The transition at approximately $365^{\circ} \mathrm{C}$ was due to the evolution of water from the decomposition of $\mathrm{Mg}(\mathrm{OH})_{2}$. A sample of reagent grade $\mathrm{Mg}(\mathrm{OH})_{2}$ was used to confirm this decomposition reaction and temperature. The variations in the transition temperature reported can be attributed to differences in the sample size, heating rate, purity, thermocouple placement, etc. The reported temperature is the inflection point for the transition rather than onset or endpoint, as shown in Figure 1 plots for the two samples that were-heated and cooled continuously.

Table I. Weight changes for RFETS MgO at $210^{\circ} \mathrm{C}$ and at the transition temperature.

\begin{tabular}{|l|l|l|l|l|l|l|}
\hline Sample & $\begin{array}{l}\text { Size } \\
(\mathrm{mg})\end{array}$ & $\begin{array}{l}\text { Temp. } \\
\left({ }^{\circ} \mathrm{C}\right)\end{array}$ & $\begin{array}{l}\text { Change } \\
(\%)\end{array}$ & $\begin{array}{l}\text { Trans } \\
\left({ }^{\circ} \mathrm{C}\right)\end{array}$ & Trans** $(\%)$ & $\begin{array}{l}\text { Final Temp } \\
\left({ }^{\circ} \mathrm{C}\right)\end{array}$ \\
\hline RFMGO.001 & 16.005 & 179 & 0.0958 & 370 & 0.0270 & $1000^{+}$ \\
\hline RFMGO.003 & 23.990 & 200 & -0.0685 & 369 & 0.0294 & $1200^{+}$ \\
\hline RFMGO.006 & 23.016 & 200 & -0.0121 & 359 & 0.0875 & $1000^{\#}$ \\
\hline RFMGO.014 & 19.332 & 204 & -0.0185 & 360 & 0.0309 & $750^{\#}$ \\
\hline RFMGO.017 & 26.507 & 158 & 0.0259 & 357 & 0.0547 & $500^{\#}$ \\
\hline GAS-GEN.001 & & 191 & -0.0376 & 360 & 0.0370 & $900^{+}$ \\
\hline GAS-GEN.003 & 19.517 & 199 & -0.0275 & 378 & 0.307 & $900^{+}$ \\
\hline GAS-GEN.044 & 15.805 & 202 & 0.384 & 404 & 25.9 & $900^{+}$ \\
\hline
\end{tabular}

Note: (1) (-) values indicate weight gains using the TA instrument convention .

(2) ${ }^{* *}$ This transition is a weight loss that occurred over a small temperature range (approximately $20^{\circ} \mathrm{C}$ ).

The reported transition temperature is the inflection point that is calculated by the TA instruments program. This temperature will be dependent on the sample size, heating rate, etc. The heating rate was held constant at $10^{\circ} \mathrm{C} / \mathrm{min}$., but the sample size varied between 15 and 25

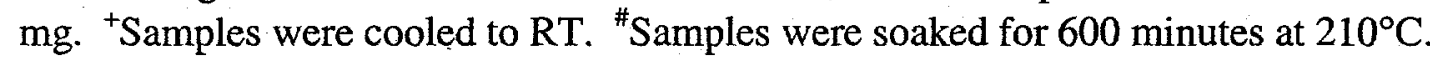

Samples RFMGO $.006, .014$, and .017 were held at $210^{\circ} \mathrm{C}$ after being taken to the "final" temperatures indicated in the last column of the table. The intent was to determine the propensity of the calcined $\mathrm{MgO}$ to form $\mathrm{Mg}(\mathrm{OH})_{2}$ (Brucite) on cooling. It is clear from the weight change plots (Figures 2a-2c) that no Brucite formed in the time allotted for formation. The weight change curves for the entire run are presented in the Figure 2 plots. The apparent weight changes during the cooling portions of the curves were likely due to heating and cooling of the furnace electronics.

Characterization of calcium metal

Calcium is a Group IIa metal with a large negative free energy of formation for calcium oxide. This large free energy of formation for the oxide indicates that the oxide is more stable than the 
WSRC-TR-99-00275

metal. However, the free energy data does not provide any insight into the kinetics of the reaction. Experimentally, it was demonstrated that the oxidation rate is measurable at temperatures as low as $90^{\circ} \mathrm{C}$.

Samples of calcium metal powders were obtained from a fellow researcher. It was observed that the powder had a bimodal distribution of sizes that could be easily segregated into "coarse" and "fine". The coarse particles were spherical with a diameter between 1 and $2 \mathrm{~mm}$ while the fine particles were flake like with dimensions of less than $1 \mathrm{~mm}$. The particle surfaces had a gray to white coloration with an existing hydroxide film on them.

Powdered coarse calcium metal samples were exposed to still laboratory air and humidity at 90 , 105,210 , and $373^{\circ} \mathrm{C}$. The heating rate from room temperature to the oxidation temperature was typically $10^{\circ} \mathrm{C} / \mathrm{min}$ which caused some concurrent oxidation as well as an initial evolution of moisture. In several cases, the samples were heated to $900^{\circ} \mathrm{C}$ after oxidation to determine the reaction products based on the peak heights of the decomposition products. The TGA data for samples of both coarse and fine calcium metal samples that were isothermally held at the respective temperature are presented in the Figure 3 plots. The amount of moisture on the particles varied depending on particle size. In some cases, no measured moisture was detected and in others as much as $0.43 \%$ was detected. The moisture contents and amount of water and $\mathrm{CO}_{2}$ evolved are presented in Table II. The relative amounts of $\mathrm{Ca}(\mathrm{OH})_{2}$ and $\mathrm{CaCO}_{3}$ were calculated and compared to the amount determined in the starting material by rapid TGA means (see below). In general, the weight gain was continuous but the rate decreased with time. Figure 4a shows a summary of the samples with the data plotted on one graph, while Figure $4 \mathrm{~b}$ shows an expanded $\mathrm{Y}$-axis of the same data. The second sample run at $105^{\circ} \mathrm{C}$ exhibited an increase in the amount of $\mathrm{Ca}(\mathrm{OH})_{2}$ over the starting material for coarse calcium metal. This is likely due to the formation of $\mathrm{Ca}(\mathrm{OH})_{2}$ concurrent with oxidation of the calcium metal. The results from other runs are mixed. The results are likely due to variability in the starting powder. The test method employed used only 2-3 coarse particles of calcium which could have different amounts of $\mathrm{Ca}(\mathrm{OH})_{2}$ and $\mathrm{CaCO}_{3}$ present depending on surface condition and surface area.

Table II. Adsorbed moisture, $\mathrm{Ca}(\mathrm{OH})_{2}$ and $\mathrm{CaCO}_{3}$ after oxidation of calcium metal.

\begin{tabular}{|c|c|c|c|c|c|c|c|c|c|}
\hline Sample & Run & Temp $_{i}$ & Temp $_{f}$ & $\begin{array}{l}\text { Moisture } \\
(\%)\end{array}$ & $\begin{array}{l}\mathrm{H}_{2} \mathrm{O} \\
\text { (\%) }\end{array}$ & $\begin{array}{l}\mathrm{CO}_{2} \\
(\%)\end{array}$ & $\begin{array}{l}\mathrm{Ca}(\mathrm{OH})_{2} \\
(\%)\end{array}$ & $\begin{array}{l}\mathrm{CaCO}_{3} \\
(\%)\end{array}$ & $\begin{array}{l}\text { Final } \\
\text { Weight } \\
(\%)\end{array}$ \\
\hline $\begin{array}{l}\text { Ca Ramp } \\
\text { coarse (c) }\end{array}$ & 030 & 58 & 179 & 0.12 & 1.20 & 0.558 & 2.18 & 1.26 & 111 \\
\hline $\begin{array}{l}\text { Ca 10C/min } \\
\text { fines (f) }\end{array}$ & $\overline{022}$ & 28 & 150 & 0.43 & 3.11 & 1.24 & 12.8 & 2.8 & 114.5 \\
\hline $\mathrm{Ca} 90 \mathrm{c}$ & 026 & 35 & 90 & 0.13 & \multicolumn{4}{|c|}{ Not ramped above decomposition temp } & $103.2^{*}$ \\
\hline $\mathrm{Ca} 105-2 \mathrm{c}$ & 040 & & 106 & 0.35 & 2.751 & 0.5191 & 11.31 & 1.18 & 110.7 \\
\hline $\mathrm{Ca} 105-1 \mathrm{c}$ & 016 & \multicolumn{3}{|c|}{ No Drop } & \multicolumn{4}{|c|}{ Not ramped above decomposition temp } & $102 * *$ \\
\hline $\mathrm{Ca} 210 \mathrm{c}$ & 032 & 27 & 162 & 0.22 & 0.11 & 0.24 & 0.44 & 0.55 & 124 \\
\hline $\mathrm{Ca} 220 \mathrm{f}$ & GG113 & 28 & 172 & 0.37 & 1.11 & 1.010 & 4.55 & 2.3 & 113 \\
\hline Ca $373 \mathrm{c}$ & & & & & & & & & \\
\hline $10 \mathrm{Cramp}$ & 024 & 23 & 182 & 0.044 & 0.058 & 0.38 & 0.2 & 5.75 & \\
\hline
\end{tabular}

Notes: Run refers to the data file. Temp $\mathrm{i}_{\mathrm{i}}$ and $\mathrm{Temp}_{\mathrm{f}}$ refer to the initial and final temperatures, respectively, for the moisture weight loss determination. $\mathrm{H}_{2} \mathrm{O}$ and $\mathrm{CO}_{2}$ contents are based on the 
decomposition at approximately 450 and $600^{\circ} \mathrm{C}$. The relative contribution of $\mathrm{Ca}(\mathrm{OH})_{2}$ and $\mathrm{CaCO}_{3}$ are determined by stoichiometry. Bold values are considered starting constituent compositions for the coarse and fine particles. * Final temperature was $500^{\circ} \mathrm{C}$. ** Final temperature was $105^{\circ} \mathrm{C}$.

Oxidation rates were calculated from the TGA data. The data plots from the TA instruments control and data analysis software were scanned and digitized so that the data could be manipulated in Excel. Both linear and parabolic curve fits were used. The data were fit parabolically using both square root time and weight squared algorithms; it is generally recognized that diffusion related reactions are modeled as a function of $\sqrt{t}$. This curve fit is generally consistent for the data, although there is significant scatter. The data and fits for the $105^{\circ} \mathrm{C}$ (First series) are presented in the Figure 5 plots. These curves are typical of the data and fit that were achieved for the other samples. It was originally thought that oxidation rates at other temperatures could be estimated from these data. However, the ability to predict oxidation rates at other temperatures does not appear practical due to variations in the surface area, surface conditions, experimental error, temperature variations, etc.

The oxidation rate equations of both fine and coarse calcium metal are presented in Table III. The rate is strongly temperature dependent and should be reconciled with the particle size and consequently surface area of the particles to be more widely applicable. As it is, the data may be selectively used for a rough estimate of the oxidation rate of the calcium metal powders examined. Several representations of the kinetic data as a function of temperature and reciprocal temperature are shown in Figures $6 \mathrm{a}-6 \mathrm{f}$. These data suggest that the oxidation rates fall into two regimes. The two regimes are likely an artifact of the starting material and test protocol. There appears to be two lines near parallel lines that represent the different regimes as indicated by the lines in Figure $6 \mathrm{e}$ and $6 \mathrm{f}$. This condition may be due to the manner in which samples were prepared. There may be more or less fines in each of the tests since all of the samples were taken from the same vial. The data are also confounded by the presence of preexisting surface products.

To determine the form and amount of pre-existing $\mathrm{Ca}(\mathrm{OH})_{2}$ and $\mathrm{CaCO}_{3}$, samples of fine and coarse calcium metal powders were rapidly heated to $800^{\circ} \mathrm{C}$ with the results shown in Figures $7 \mathrm{a}$ and $7 \mathrm{~b}$. These samples exhibit phase transitions which correspond to the decomposition of $\mathrm{Ca}(\mathrm{OH})_{2}$ and $\mathrm{CaCO}_{3}$ at the lower $\left(\sim 450^{\circ} \mathrm{C}\right)$ and higher $\left(\sim 650^{\circ} \mathrm{C}\right)$ temperatures, respectively, in addition to oxidation weight gain. The relative amounts of $\mathrm{Ca}(\mathrm{OH})_{2}$ and $\mathrm{CaCO}_{3}$ present in the starting $\mathrm{Ca}$ metal were estimated from these tests. The $\mathrm{Ca}(\mathrm{OH})_{2}$ contents were $2.2 \%$ and $12.8 \%$ for large and small particles, respectively, while the $\mathrm{CaCO}_{3}$ contents were $1.3 \%$ and $2.8 \%$ for large and small particles, respectively. 
Table III. Curve fit for Ca metal oxidation at a number of temperatures.

\begin{tabular}{|l|l|r|r|r|r|r|}
\hline Temp $\left({ }^{\circ} \mathrm{C}\right)$ & wt $\propto$ time & \multicolumn{1}{|l|}{$\mathrm{R}^{2}$} & wt $\propto$ time & \multicolumn{1}{l|}{$\mathrm{R}^{2}$} & $\mathrm{Wt}^{2} \propto$ time & $\mathrm{R}^{2}$ \\
\hline 90 Coarse & $6 \times 10^{-7} \mathrm{t}+.0002$ & 0.9773 & $1 \times 10^{-4} \sqrt{\mathrm{t}-.003}$ & 0.9445 & $2 \times 10^{-10} \mathrm{t}-4 \times 10^{-7}$ & 0.9261 \\
\hline 105 Coarse & $1 \times 10^{-5} \mathrm{t}+.0184$ & 0.9565 & $.0014 \sqrt{\mathrm{t}-.0136}$ & 0.9977 & $4 \times 10^{-8} \mathrm{t}-2 \times 10^{-5}$ & 0.9984 \\
\hline 105 Coarse -2 & $3 \times 10^{-6} \mathrm{t}+0.0182$ & 0.958 & $0.0006 \sqrt{\mathrm{t}-0.0134}$ & 0.9979 & $8 \times 10^{-9} \mathrm{t}-2 \times 10^{-5}$ & 0.9982 \\
\hline 210 Coarse & $1 \times 10^{-6} \mathrm{t}+0.0029$ & 0.9888 & $.0003 \sqrt{\mathrm{t}}-.011$ & 0.9719 & $6 \times 10^{-8} \mathrm{t}-.0003$ & 0.957 \\
\hline 373 Coarse & $0.0002 \mathrm{t}+.1589$ & 0.9827 & $.0212 \sqrt{\mathrm{t}-.3213}$ & 0.9902 & $7 \times 10^{-6} \mathrm{t}-.0056$ & 0.9882 \\
\hline 220 Fine & $1 \times 10^{-6} \mathrm{t}+0.0091$ & 0.8685 & $.0087 \sqrt{\mathrm{t}+.0232}$ & 0.963 & $7 \times 10^{-9} \mathrm{t}+8 \times 10^{-6}$ & 0.9572 \\
\hline
\end{tabular}

\section{Characterization of $\mathrm{CaCO}_{3}$}

A sample of reagent grade $\mathrm{CaCO}_{3}$ was tested to determine the contribution of $\mathrm{CaCO}_{3}$ to the weight loss in the temperature range of interest. The TGA data are shown in Figure 8 . There was a weight loss attributable on heating from room temperature to $210^{\circ} \mathrm{C} \pm 5^{\circ} \mathrm{C}$ that ranged from 0.085 to $0.357 \%$. The $\mathrm{CaCO}_{3}$ decomposition temperature occurred at about $650^{\circ} \mathrm{C}$ for the impure $\mathrm{CaCO}_{3}$ present in the actual samples. The decomposition temperature increased to 765 and $791^{\circ} \mathrm{C}$ for reagent grade $\mathrm{CaCO}_{3}$ at heating rates of $10^{\circ} \mathrm{C} / \mathrm{min}$ and $30^{\circ} \mathrm{C} / \mathrm{min}$, respectively. This large variation in transition temperature can only be related to the purity and particle size of the samples.

\section{Characterization of $\mathrm{Ca}(\mathrm{OH})_{2}$}

Samples of reagent grade $\mathrm{Ca}(\mathrm{OH})_{2}$ were tested to determine the extent of moisture present (both physically adsorbed and chemically bound). Samples were tested at varying heating rates and for varying hold times at $210^{\circ} \mathrm{C}$. Multiple replicate samples were also tested. The reagent grade $\mathrm{Ca}(\mathrm{OH})_{2}$ exhibited two weight loss transitions. The first occurring at about $450^{\circ} \mathrm{C}$ is due to water being released from the hydroxide while the second about $650^{\circ} \mathrm{C}$ is due to carbon dioxide being released from $\mathrm{CaCO}_{3}$. Figure $9 \mathrm{a}$ shows the two transitions and the small weight loss on heating.

General observations indicated that on heating to $210^{\circ} \mathrm{C}$ there was often a small weight loss that can likely be attributed to moisture desorption. During an isothermal hold at $210^{\circ} \mathrm{C}$, the samples often exhibited a small weight gain. The cause of the weight gain when reagent grade $\mathrm{Ca}(\mathrm{OH})_{2}$ was held isothermally at $210^{\circ} \mathrm{C}$ needed an explanation. There were two possibilities: moisture or carbon dioxide pick-up from the air. It typically occurred only in the reagent grade materials. A set of experiments was run to determine if the gain was due to water or $\mathrm{CO}_{2}$. These tests utilized reagent grade $\mathrm{Ca}(\mathrm{OH})_{2}$ and different thermal histories. In the first case, a sample was heated to $210^{\circ} \mathrm{C}$, held for 30 minutes, heated to $900^{\circ} \mathrm{C}$, held for 5 minutes, then cooled to $210^{\circ} \mathrm{C}$, held for 180 minutes, cooled to room temperature, and then reheated to $900^{\circ} \mathrm{C}$ with a hold at $210^{\circ} \mathrm{C}$ for 30 minutes, as shown in Figure 9b. A control sample, shown in Figure 9c, was tested by heating at a constant rate $\left(10^{\circ} \mathrm{C} / \mathrm{min}\right)$ from room temperature to $900^{\circ} \mathrm{C}$. The final data set, shown in Figure $9 \mathrm{~d}$, was heated to $210^{\circ} \mathrm{C}$ held for 30 minutes then ramped to $900^{\circ} \mathrm{C}$. A comparison of the size of the hydroxide and carbonate decomposition peaks indicated the relative proportion of $\mathrm{Ca}(\mathrm{OH})_{2}$ and $\mathrm{CaCO}_{3}$ present in samples exposed to these two heating cycles. These data 
tentatively suggest (a difference of approximately $1 \%$ is apparent) that the weight gain at $210^{\circ} \mathrm{C}$ is due primarily to $\mathrm{CO}_{2}$ pick-up. Tests to confirm which species actually form will require a complex gas delivery system. The weight changes on heating, holding, and final heating are presented in Table IV. These data show similar moisture contents but quite different weight changes on heating from 210 to $380^{\circ} \mathrm{C}$ with the constantly heated sample gaining about $1 / 3$ of the weight that sample that was isothermally held at $210^{\circ} \mathrm{C}$ did (italicized value in Table IV).

Table IV. Weight changes and associated temperature ranges for moisture and decomposition products of $\mathrm{Ca}(\mathrm{OH})_{2}$; data are shown in Figure $9 \mathrm{~b}$ and $9 \mathrm{~d}$.

\begin{tabular}{|c|c|c|c|c|}
\hline Transition & Sample & Temperature $\left({ }^{\circ} \mathrm{C}\right)$ & Weight (mg) & Weight (\%) \\
\hline Moisture & \multirow{6}{*}{$\mathbf{A}$} & RT-229 & 0.171 & 1.12 \\
\hline Isothermal & & $233-253$ & -0.0469 & -0.308 \\
\hline Ramp & & $243-385$ & -0.0772 & -0.507 \\
\hline $\mathrm{Ca}(\mathrm{OH})_{2}$ & & 450 & 3.232 & 21.2 \\
\hline Ramp 2 & & $489-539$ & 0.0183 & 0.120 \\
\hline $\mathrm{CaCO}_{3}$ & & 646 & 0.543 & 3.57 \\
\hline Moisture & \multirow{4}{*}{ B } & RT-212 & 0.115 & 0.728 \\
\hline Ramp & & $212-393$ & -0.0283 & -0.180 \\
\hline $\mathrm{Ca}(\mathrm{OH})_{2}$ & & 451 & 3.399 & 21.6 \\
\hline $\mathrm{CaCO}_{3}$ & & 645 & 0.404 & 2.56 \\
\hline
\end{tabular}

Note: (-) values indicate weight gains using the TA instrument convention. Sample " $A$ " was heated using the following cycle: RT $-210^{\circ} \mathrm{C}$ at $10^{\circ} \mathrm{C} / \mathrm{min} ; 210^{\circ} \mathrm{C}$ hold 30 minutes; $210-900^{\circ} \mathrm{C}$ at $10^{\circ} \mathrm{C} / \mathrm{min}$ while sample " $\mathrm{B}$ " was subjected to the following heating cycle: $\mathrm{RT}-900^{\circ} \mathrm{C}$ at $10^{\circ} \mathrm{C} / \mathrm{min}$ without intermediate holds.

To determine the amount of adsorbed and chemically bound water and $\mathrm{CO} 2$ present on thermally formed $\mathrm{CaO}$, an experiment was run using fines of calcium metal. The sample was rapidly heated to $800^{\circ} \mathrm{C}$ to oxidize, then cooled, and re-heated to determine the final form of the reaction products. The data plot is shown in Figure 7c. It is clear that the oxidation of calcium is very rapid above about $450^{\circ} \mathrm{C}$. On re-heating after oxidation, there was a small peak for $\mathrm{Ca}(\mathrm{OH})_{2}$ decomposition (less than $1 \%$ ) and a peak that represents about $4.3 \%$ weight loss due to $\mathrm{CO}_{2}$ evolution. The water and $\mathrm{CO}_{2}$ peaks were used to estimate that there was about $12.7 \% \mathrm{Ca}(\mathrm{OH})_{2}$ and $2.8 \% \mathrm{CaCO}_{3}$ on the fine calcium metal. The oxidation of the remaining calcium can be determined by assuming that that the balance (initial mass less $\mathrm{Ca}(\mathrm{OH})_{2}$ and $\mathrm{CaCO}_{3}$ ) of the powder is calcium metal. The final weight indicated that $88.5 \%$ of the available calcium was converted to $\mathrm{CaO}$ after exposure to $800^{\circ} \mathrm{C}$. An alternative method to calculate the amount of calcium converted is to consider that the weight gain is due solely to oxygen pick-up and then add the weight gains between the decomposition temperature and heating to the final temperature. Using this method, indicated that $55.9 \%$ was oxidized to $\mathrm{CaO}$. The discrepancy between the two methods arises because the oxidation of calcium and resultant weight gains are masked by weight losses due to decomposition and the likely presence of some $\mathrm{Ca}(\mathrm{OH})_{2}$ and $\mathrm{CaCO}_{3}$ in the starting material. 
To better understand the decomposition of thermally-formed, non-reagent grade $\mathrm{Ca}(\mathrm{OH})_{2}$ under heating conditions, the sample formed from oxidizing calcium metal, shown in Figure $7 \mathrm{c}$, and described above, was tested after being exposed to laboratory air for four days. The sample was heated at a rate of $10^{\circ} \mathrm{C} / \mathrm{min}$ with a $210^{\circ} \mathrm{C}$ hold for 30 minutes and subsequently heated to $900^{\circ} \mathrm{C}$. This test was conducted to determine the adsorbed moisture, $\mathrm{Ca}(\mathrm{OH})_{2}$, and $\mathrm{CaCO}_{3}$ content in a material that is formed in manner similar to the $\mathrm{CaO}$ present in SSC. The results from this stability test are shown in Figure 10 for the sample that was heated to $900^{\circ} \mathrm{C}$ using the following heating cycle: room temperature -210 at $10^{\circ} \mathrm{C} / \mathrm{min}, 30 \mathrm{~min}$ hold at $210^{\circ} \mathrm{C}, 210$ $900^{\circ} \mathrm{C}$ at $10^{\circ} \mathrm{C} / \mathrm{min}$, and then cooled. The sample exhibited the weight changes shown in Table $\mathrm{V}$. There was about $2 \%$ water adsorbed on the surface and there may have been as much as $0.44 \%$ weight change due to oxidation of residual calcium metal. However, based on the previously described experiments, heating in this temperature range may promote the formation of $\mathrm{CaCO}_{3}$ in addition to oxidizing residual $\mathrm{Ca}$ metal.

Table V. Moisture products and reaction temperatures for $\mathrm{CaO}$ formed by oxidizing Ca metal.

\begin{tabular}{|l|l|l|l|}
\hline Transition & Temp & Weight (mg) & Weight (\%) \\
\hline Moisture & rt-216 & 0.161 & 1.93 \\
\hline Isothermal & 216 & & \\
\hline $\mathrm{CaOx}$ & $216-390$ & -0.029 & -0.349 \\
\hline $\mathrm{Ca}(\mathrm{OH})_{2}$ decomposition & 435 & 1.38 & 16.6 \\
\hline $\mathrm{CaOx}$ & $457-515$ & -0.0076 & -0.0909 \\
\hline $\mathrm{CaCO}$ decomposition & 665 & 0.796 & 9.57 \\
\hline Remainder & 696 & 6.01 & 72.3 \\
\hline
\end{tabular}

Note: (-) values indicate weight gains using the TA instrument convention. Sample was heated using the following cycle: RT $-210^{\circ} \mathrm{C}$ at $10^{\circ} \mathrm{C} / \mathrm{min} ; 210^{\circ} \mathrm{C}$ hold 30 minutes; $210-900^{\circ} \mathrm{C}$ at $10^{\circ} \mathrm{C} / \mathrm{min}$.

Characterization of $\mathrm{PuO}_{2}$

Samples of $\mathrm{PuO} 2$ from FB-line were tested. The samples were exposed to a number of different moisture content environments. The samples were tested using the same heating cycle as was used for the previously described work. No weight changes on heating were attributed to phase transitions, however, weight losses due to moisture evolution were apparent. The weight loss rate was observed to decrease significantly at the end of the 30 -minute hold at $210^{\circ} \mathrm{C}$. Weight loss was observed to continue until a temperature of about $500^{\circ} \mathrm{C}$, as shown in Figure 11 . Table VI indicates the weight losses at approximately $210^{\circ} \mathrm{C}$ and $500^{\circ} \mathrm{C}$. Representative data are presented in Figure 11 showing the loss as a function of temperature while Figure 12 show the loss as a function of time. The rate of weight loss after the hold decreased and was near zero by the end of the hold period. The percent of weight loss that occurred after the $210^{\circ} \mathrm{C}$ isothermal exposure for 30 minutes is indicated for both the raw data and the buoyancy and heat effects corrected data (Table IV). The fraction of the moisture removed by the isothermal hold at $210^{\circ} \mathrm{C}$ based on the minimum weight at $500^{\circ} \mathrm{C}$ varied from 35 to $50 \%$ based on the corrected data. The buoyancy and heat correction impacted the fraction of moisture removed by as little as $1 \%$ to nearly $20 \%$. 
Table VI. Weight loss due to moisture evolution on heating to approximately $210^{\circ} \mathrm{C}$ and $500^{\circ} \mathrm{C}$.

\begin{tabular}{|l|r|r|l|l|l|l|l|r|r|r|}
\hline Run & Sample ID & $\begin{array}{l}\text { Temp } \\
\left({ }^{\circ} \mathrm{C}\right)\end{array}$ & $\begin{array}{l}\text { Raw } \\
210^{\circ} \mathrm{C} \\
(\%)\end{array}$ & $\begin{array}{l}\text { Corrected } \\
210^{\circ} \mathrm{C} \\
(\%)\end{array}$ & $\begin{array}{l}\text { Temp } \\
\left({ }^{\circ} \mathrm{C}\right)\end{array}$ & $\begin{array}{l}\text { Raw } \\
500^{\circ} \mathrm{C} \\
(\%)\end{array}$ & $\begin{array}{l}\text { Corrected } \\
500^{\circ} \mathrm{C} \\
(\%)\end{array}$ & \multicolumn{2}{|l|}{$\begin{array}{l}\text { Fraction of moisture } \\
\text { lost at 210 }\end{array}$} \\
\hline & & & & & & & Raw & Corrected \\
\hline 12 & $\mathrm{FB}$ line $\mathrm{PuO}_{2}$ & 211 & 0.22 & 0.43 & 499 & 0.63 & 1.24 & 34.24 & $\mathbf{3 5 . 1 3}$ \\
\hline 19 & $\mathrm{PuO}_{2}$ as Received & 210 & 0.53 & 0.75 & 500 & 0.70 & 1.26 & 68.37 & $\mathbf{5 2 . 3 9}$ \\
\hline 75 & $\mathrm{FB}$ line $\mathrm{PuO}_{2}$ & 210 & 0.42 & 0.63 & 500 & 0.74 & 1.30 & 56.61 & 48.46 \\
\hline 87 & Dried $\mathrm{PuO}_{2}$ & 198 & 0.68 & 0.89 & 500 & 1.23 & 1.81 & $\mathbf{5 5 . 3 9}$ & $\mathbf{4 9 . 0 7}$ \\
\hline 97 & $\mathrm{PuO}_{2}+100 \% \mathrm{RH}$ & 225 & 2.31 & 2.52 & 500 & 2.91 & 3.41 & 79.38 & 73.90 \\
\hline
\end{tabular}

Characterization of $\mathrm{L}$ series and $\mathrm{H} 7 \mathrm{SS} \mathrm{C}$

Four RFETS SSC samples that contained low percentages of $\mathrm{PuO}_{2}$ and one that had a high percentage of $\mathrm{PuO}_{2}$ were tested to determine the weight loss from room temperature to $900^{\circ} \mathrm{C}$. The scans for the five samples and two replicates are shown in Figure 13. The samples typically exhibited the following weight changes, as shown in Figure 14:

$>$ a weight loss on heating to $210^{\circ} \mathrm{C}$ due to moisture evolution

$>$ a weight gain during the isothermal hold

$>$ a weight gain during heating to $400^{\circ} \mathrm{C}$

$>$ a weight loss during the $\mathrm{Ca}(\mathrm{OH})_{2}$ to $\mathrm{CaO}$ transition

$>$ a weight gain from $450-550^{\circ} \mathrm{C}$ likely due to oxidation of remaining calcium metal (or possibly plutonium fines) to $\mathrm{CaO}$ (or $\mathrm{PuO}_{2}$ ) or a conversion of $\mathrm{CaO}$ to $\mathrm{CaCO}_{3}$

$>$ a weight loss at $650^{\circ} \mathrm{C}$ due to $\mathrm{CaCO}_{3}$ to $\mathrm{CaO}$ transition.

Several of the samples also exhibited a weight gain transition at about $700^{\circ} \mathrm{C}$. This final transition was not characterized in this work. Annotated data plots for the L-1 and repeated samples are shown in Figure 14.

The moisture, calcium, $\mathrm{Ca}(\mathrm{OH})_{2}, \mathrm{Ca}(\mathrm{OH})_{2}$, and $\mathrm{Mg}(\mathrm{OH})_{2}$ contents can be estimated from the data and are presented in Table VII. Only the L-3 sample of SSC exhibited any residual $\mathrm{Mg}(\mathrm{OH})_{2}$ and the total amount was a few tenths of a percent. Figure 15 exhibits this transition using a blown up scale for both the temperature and the weight. It is possible that this $\mathrm{Mg}(\mathrm{OH})_{2}$ was from an area of the SSC that did not see an adequately high temperature (greater than $360^{\circ} \mathrm{C}$ ) during bomb reduction or from glovebox sweepings of unreacted material. The data from calcination experiments indicate that once $\mathrm{Mg}(\mathrm{OH})_{2}$ is converted to $\mathrm{MgO}$, the $\mathrm{MgO}$ will not reform $\mathrm{Mg}(\mathrm{OH})_{2}$ in relatively short periods of time and actually has not during the 15-20 year storage periods at RFETS. 
Table VII. Composition of RFETS SSC samples determined by weight loss and attributed to the species defined in the table.

\begin{tabular}{|l|r|r|r|r|r|r|r|}
\hline Sample & $\begin{array}{l}\text { Total sample } \\
(\mathrm{mg})\end{array}$ & $\begin{array}{l}\text { Moisture } \\
(\%)\end{array}$ & $\begin{array}{l}\text { Ca metal } \\
(\%)\end{array}$ & $\begin{array}{l}\mathrm{Ca}(\mathrm{OH})_{2} \\
(\%)\end{array}$ & $\begin{array}{l}\mathrm{CaCO}_{3} \\
(\%)\end{array}$ & $\begin{array}{l}\mathrm{Mg}(\mathrm{OH})_{2} \\
(\%)\end{array}$ & $\begin{array}{l}\text { Total Ca } \\
(\%)\end{array}$ \\
\hline H7 & 17.50 & 0.40 & 2.13 & 24.86 & 3.66 & 0 & 17.03 \\
\hline H7-R & 15.95 & 0.20 & 2.01 & 23.84 & 6.62 & 0 & 17.54 \\
\hline L-1 & 15.78 & 1.70 & 3.92 & 19.41 & 2.24 & 0 & 15.31 \\
\hline L-1 R2 & 15.47 & 0.66 & 1.04 & 17.86 & 1.48 & 0 & 11.35 \\
\hline L-3 & 15.13 & 0.24 & 0.75 & 11.67 & 2.79 & 0.21 & 8.17 \\
\hline L-4 & 16.93 & 0.12 & 4.34 & 4.10 & 5.98 & 0 & 8.95 \\
\hline L-5 & 18.35 & 0.10 & 2.07 & 7.50 & 2.99 & 0 & 7.32 \\
\hline
\end{tabular}

Note: The moisture is based on the weight loss on heating to $200^{\circ} \mathrm{C}$. The calcium metal content is based on the oxidation of calcium metal that occurs during heating of the sample from room temperature to $900^{\circ} \mathrm{C}$. The oxidation product was assumed to be $\mathrm{CaO}$ with only oxygen being consumed. The amounts of $\mathrm{Ca}(\mathrm{OH})_{2}$ and $\mathrm{CaCO}_{3}$ are based on stoichiometry and the assumption that the weight losses are due to the evolution of $\mathrm{H}_{2} \mathrm{O}$ and $\mathrm{CO}_{2}$, respectively.

Discussion: Determination of the relative contributions of the SSC constituents to moisture.

The weight change that was measured using a single data point at $210^{\circ} \mathrm{C}$ for 30 minutes is a composite number. The value consists of concurrent weight loss and weight gain reactions. The weight losses were due to adsorbed moisture on $\mathrm{MgO}$ sand and crucible material, $\mathrm{PuO}_{2}$, $\mathrm{Ca}(\mathrm{OH})_{2}, \mathrm{CaCO}_{3}, \mathrm{CaO}$, and calcium. The weight gains were due to the oxidation of any species such as calcium or plutonium, the conversion of $\mathrm{CaO}$ to $\mathrm{Ca}(\mathrm{OH})_{2}$, the conversion of $\mathrm{CaO}$ to $\mathrm{CaCO}_{3}$, and the conversion of $\mathrm{Ca}(\mathrm{OH})_{2}$ to $\mathrm{CaCO}_{3}$ and water.

This work suggests that calcined RFETS MgO sand and crucible will contain little if any adsorbed moisture. This conclusion is based on the observation that uncalcined RFETS MgO had less than $0.1 \%$ water that was evolved on heating to $210^{\circ} \mathrm{C}$. Samples of reagent grade $\mathrm{Mg}(\mathrm{OH})_{2}$ also did not exhibit any weight changes due to the desorption of water at $210^{\circ} \mathrm{C}$. The only weight change observed was at approximately $360^{\circ} \mathrm{C}$ where $\mathrm{Mg}(\mathrm{OH})_{2}$ is converted to $\mathrm{MgO}$ and water.

The contribution of adsorbed moisture on $\mathrm{Ca}(\mathrm{OH})_{2}$ was difficult to ascertain since the behavior of reagent grade $\mathrm{Ca}(\mathrm{OH})_{2}$ was different from thermally formed $\mathrm{Ca}(\mathrm{OH})_{2}$. The reagent grade material exhibited a weight loss followed by a weight gain on heating to and holding at $210^{\circ} \mathrm{C}$. The thermally formed $\mathrm{Ca}(\mathrm{OH})_{2}$ exhibited only a weight loss due to moisture desorption. Partially calcined $\mathrm{Ca}(\mathrm{OH})_{2}$ formed $\mathrm{CaCO}_{3}$ in preference to $\mathrm{Ca}(\mathrm{OH})_{2}$. The reagent grade $\mathrm{Ca}(\mathrm{OH})_{2}$ had a maximum of about $1 \%$ water adsorbed. With an isothermal hold at $210^{\circ} \mathrm{C}$, a $0.3 \%$ weight increase was observed. The majority of this increase was attributed to $\mathrm{CaCO}_{3}$ formation. The behavior of samples of $\mathrm{Ca}(\mathrm{OH})_{2}$ formed by oxidation of calcium metal revealed slightly different results. This sample exhibited a weight loss of approximately $2 \%$ due to adsorbed moisture on heating to $210^{\circ} \mathrm{C}$, no weight gain during the isothermal hold at $210^{\circ} \mathrm{C}$, and a higher percentage of $\mathrm{CO}_{2}$ evolution than was observed in the reagent grade $\mathrm{Ca}(\mathrm{OH})_{2}$. 
Reagent grade $\mathrm{CaCO}_{3}$ exhibited an apparent weight loss of $0.01 \%$ on holding at $210^{\circ} \mathrm{C}$ and a gain of $0.37 \%(29 \mu \mathrm{g})$ on heating to $600^{\circ} \mathrm{C}$. The gain was due in part to buoyancy and instrument heating. The weight loss represented approximately $1.2 \mu \mathrm{g}$ and may be a "real" observation. The weight variation from thermal drift and buoyancy is on the order of 50 to $70 \mu \mathrm{g}$ based on previous work. This amount of interference from the balance overpowers the weight change by a factor of 2 .

Based on the tests that were conducted, it is difficult to ascribe the relative contributions to total moisture content of each of the individual species present. Some bounding limits can be determined based on a number of assumptions. The ranges of moisture contents determined at $210^{\circ} \mathrm{C}$ as determined from the data above are summarized in Table VIII. The average and standard deviations were calculated from the original samples and replicates. There were a minimum of two and a maximum of six samples for each value except for the thermally formed $\mathrm{Ca}(\mathrm{OH})_{2}$ which had only a single sample. The contributions due to thermal effects on the electronics and the buoyancy effects were not taken into account. These corrections can have an effect on the outcome of the data as was shown in Table VI where the impact ranged from about a 50 to $100 \%$ difference in the weight change.

Table VIII. Average and standard deviation of weight losses due to moisture (not corrected) detected after 30 minutes at $210^{\circ} \mathrm{C}$.

\begin{tabular}{|l|l|l|l|l|}
\hline Component & $\begin{array}{l}\text { Largest weight } \\
\text { loss observed (\%) }\end{array}$ & $\begin{array}{l}\text { Average + } \\
3 \sigma *\end{array}$ & $\begin{array}{l}\text { Estimated } \\
\text { moisture } \\
2 \text { x observed }\end{array}$ & $\begin{array}{l}\text { Number of } \\
\text { runs }\end{array}$ \\
\hline $\begin{array}{l}\text { MgO (sand and } \\
\text { crucible) }\end{array}$ & $\mathbf{0 . 0 9 6}$ & $\mathbf{0 . 1 5}$ & $\mathbf{0 . 1 9}$ & $\begin{array}{l}7 \text { (sand } \\
\text { only) }\end{array}$ \\
\hline Ca metal & $\mathbf{0 . 4 3}$ & $\mathbf{0 . 6 6}$ & $\mathbf{0 . 8 6}$ & $\mathbf{6}$ \\
\hline $\mathbf{P u O}_{2}(\mathbf{F B ~ L i n e )}$ & $\mathbf{2 . 3 1}$ & $\mathbf{3 . 3 6 1}$ & $\mathbf{4 . 6 2}$ & $\mathbf{5}$ \\
\hline $\begin{array}{l}\mathrm{Ca}(\mathrm{OH})_{2}+\mathrm{CaCO}_{3} \\
(\mathrm{Thermally} \mathrm{formed)})\end{array}$ & $\mathbf{2 . 0}$ & $* *$ & $\mathbf{4 . 0}$ & $\mathbf{1}$ \\
\hline $\begin{array}{l}\mathrm{Ca}(\mathrm{OH})_{2} \\
(\mathrm{Reagent} \text { grade) }\end{array}$ & 1.12 & 1.49 & 2.2 & 4 \\
\hline $\begin{array}{l}\mathrm{CaCO} \\
\text { (Reagent grade) }\end{array}$ & 0.36 & 0.63 & 0.71 & 3 \\
\hline Empty pan & $0.008619 \mathrm{mg}$ & $\begin{array}{l}\text { Thermal drift to } 210^{\circ} \mathrm{C}(0.043-0.057 \% \\
\text { relative error for } 15-20 \mathrm{mg} \text { samples) }\end{array}$ \\
\hline
\end{tabular}

* The average and standard deviations for moisture content for the number of runs indicated in the table were determined. These data were then used to calculate the values in this column. ** no value was calculated for this since only one or two samples were run. More definitive statistics would use the student $t$ test or a similar modification to the data. 
WSRC-TR-99-00275

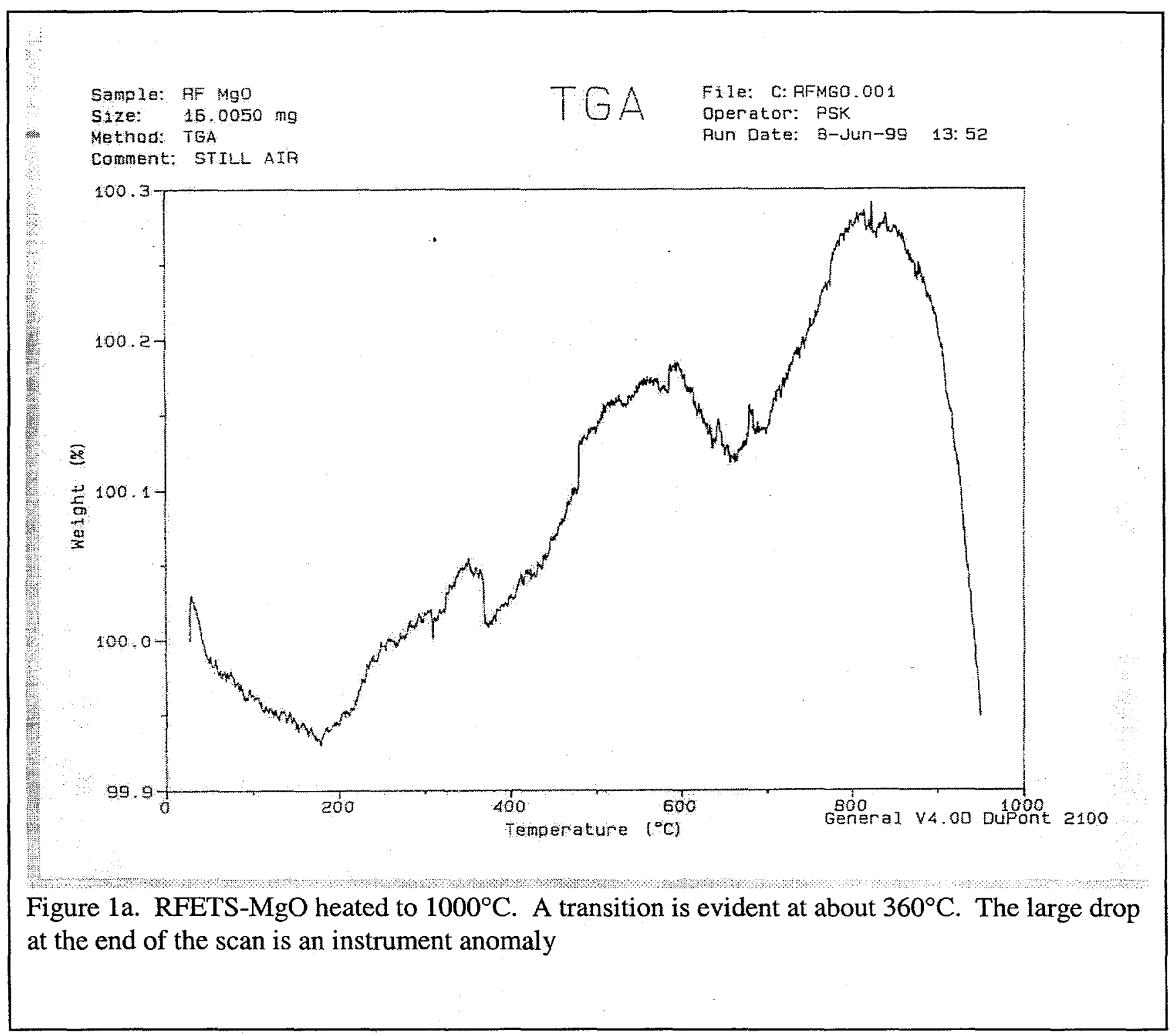




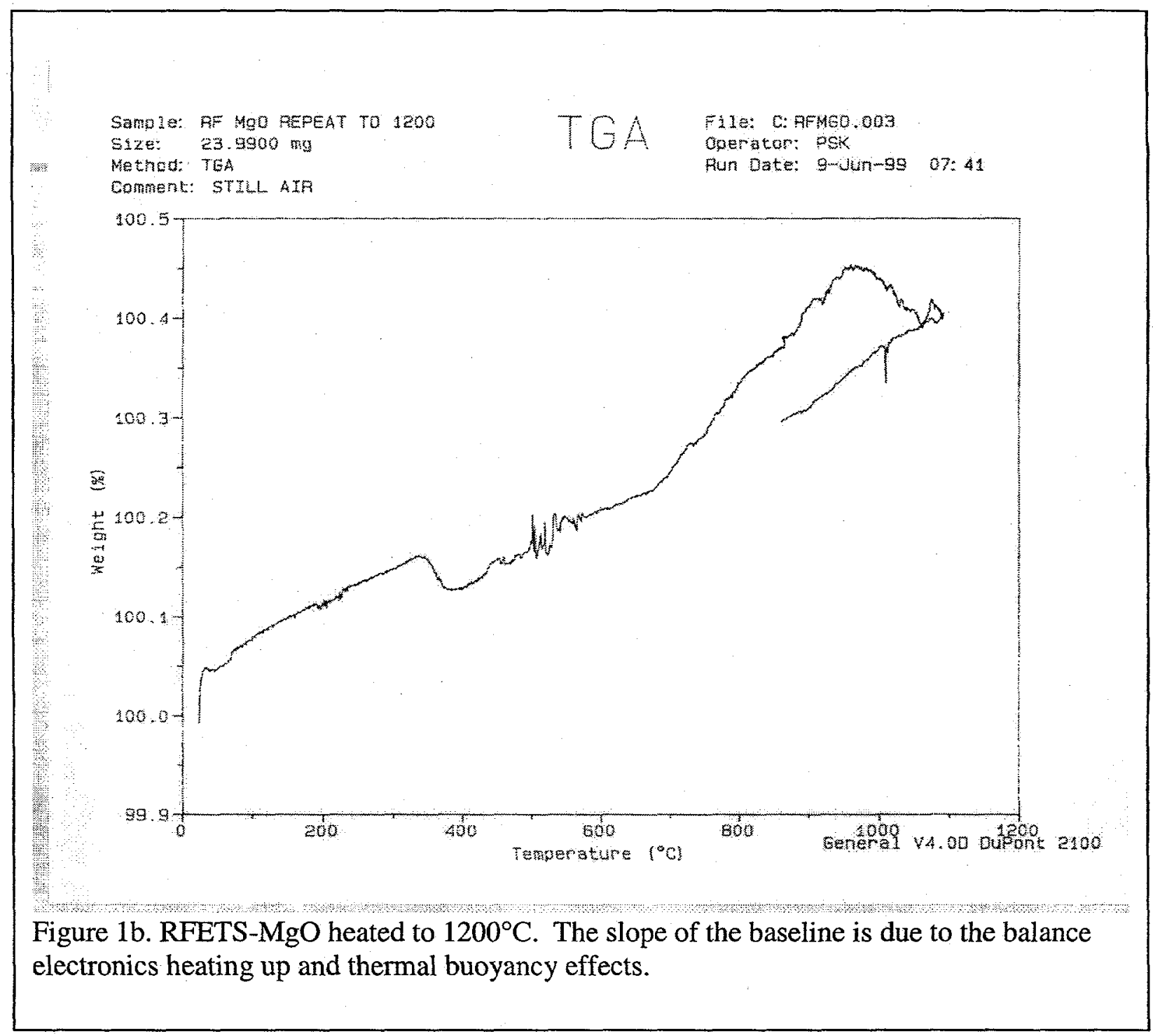


WSRC-TR-99-00275

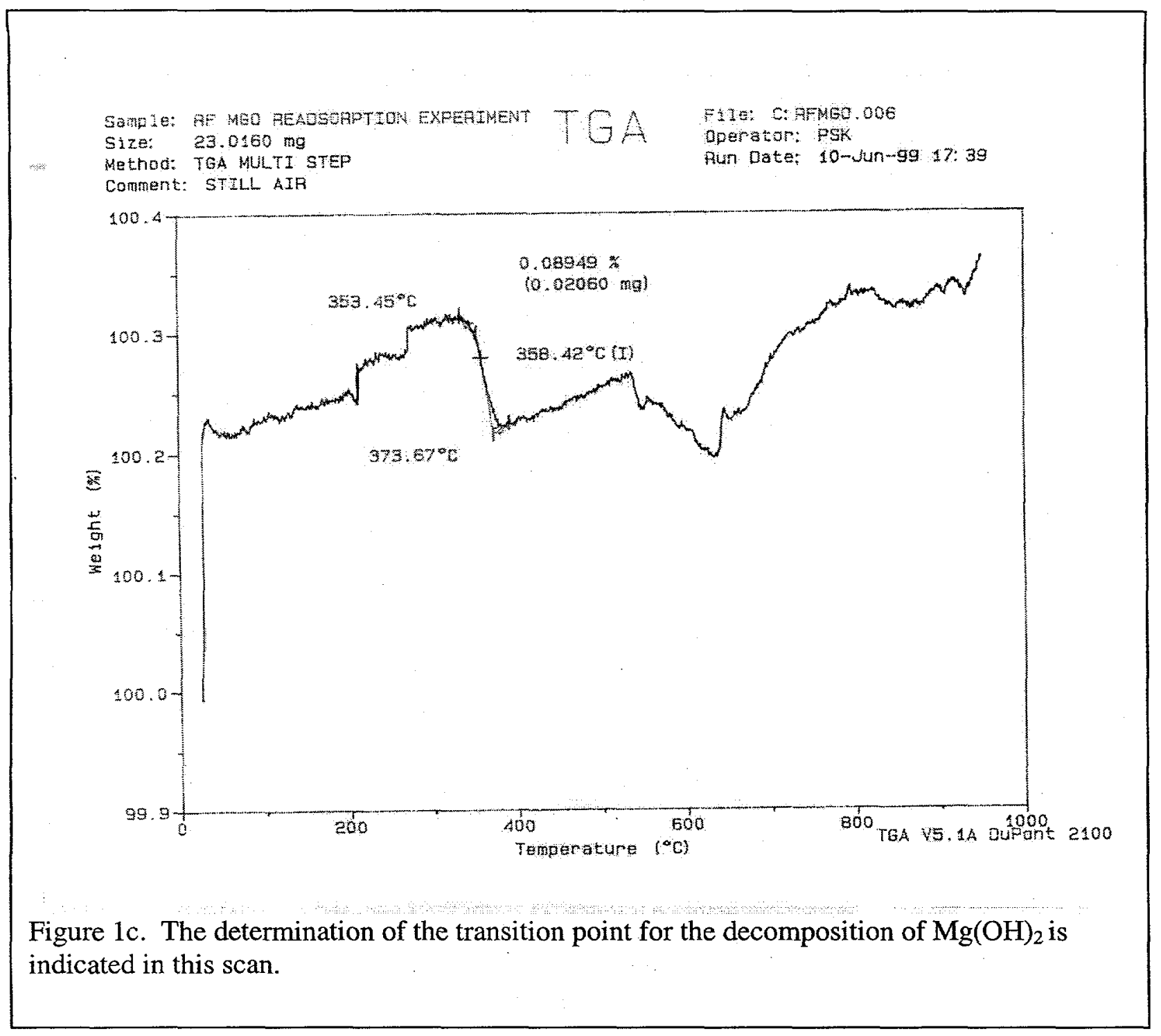


WSRC-TR-99-00275

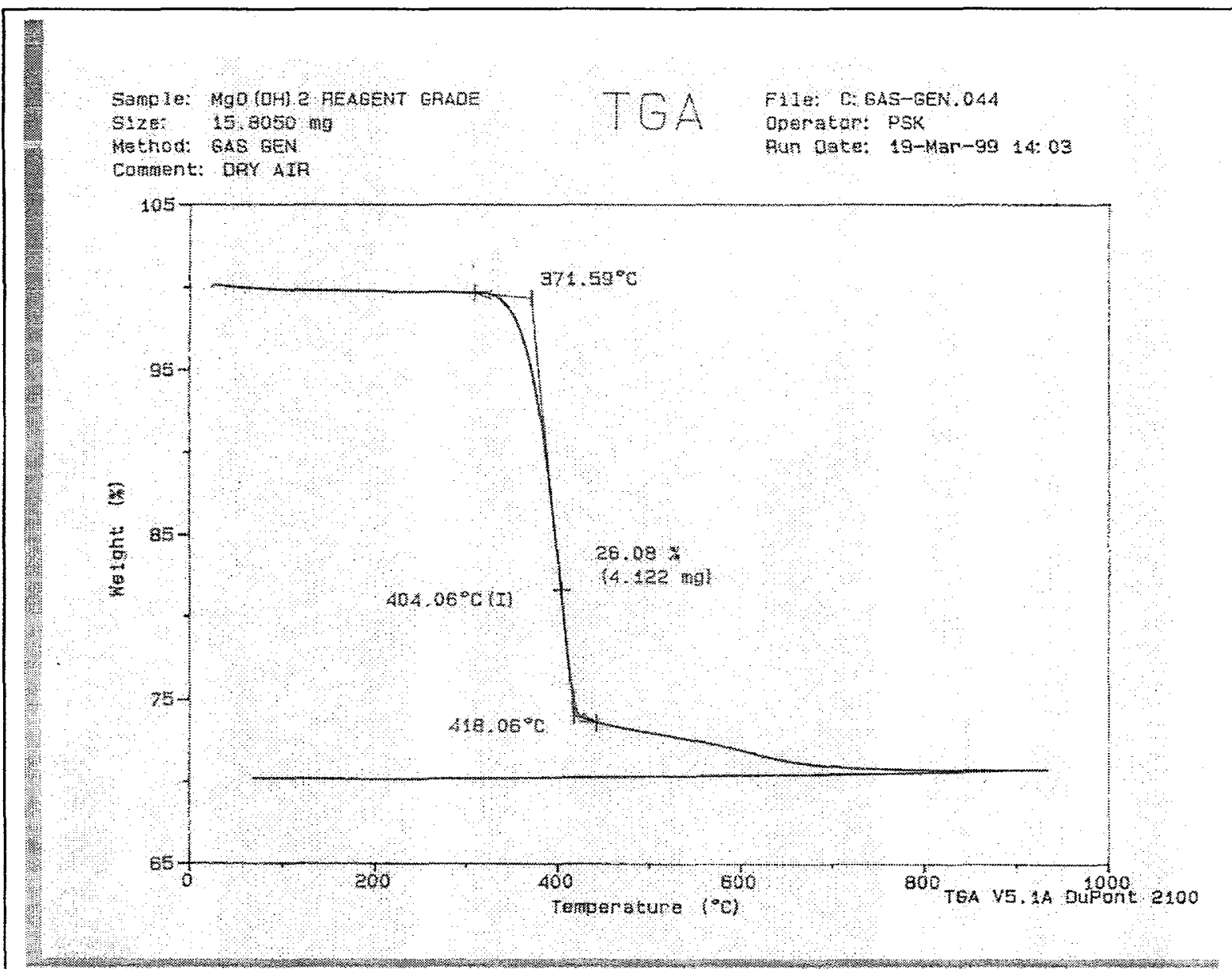

Figure 1d. Decomposition of reagent grade $\mathrm{Mg}(\mathrm{OH})_{2}$ at a heating rate $10^{\circ} \mathrm{C} / \mathrm{min}$. 
WSRC-TR-99-00275

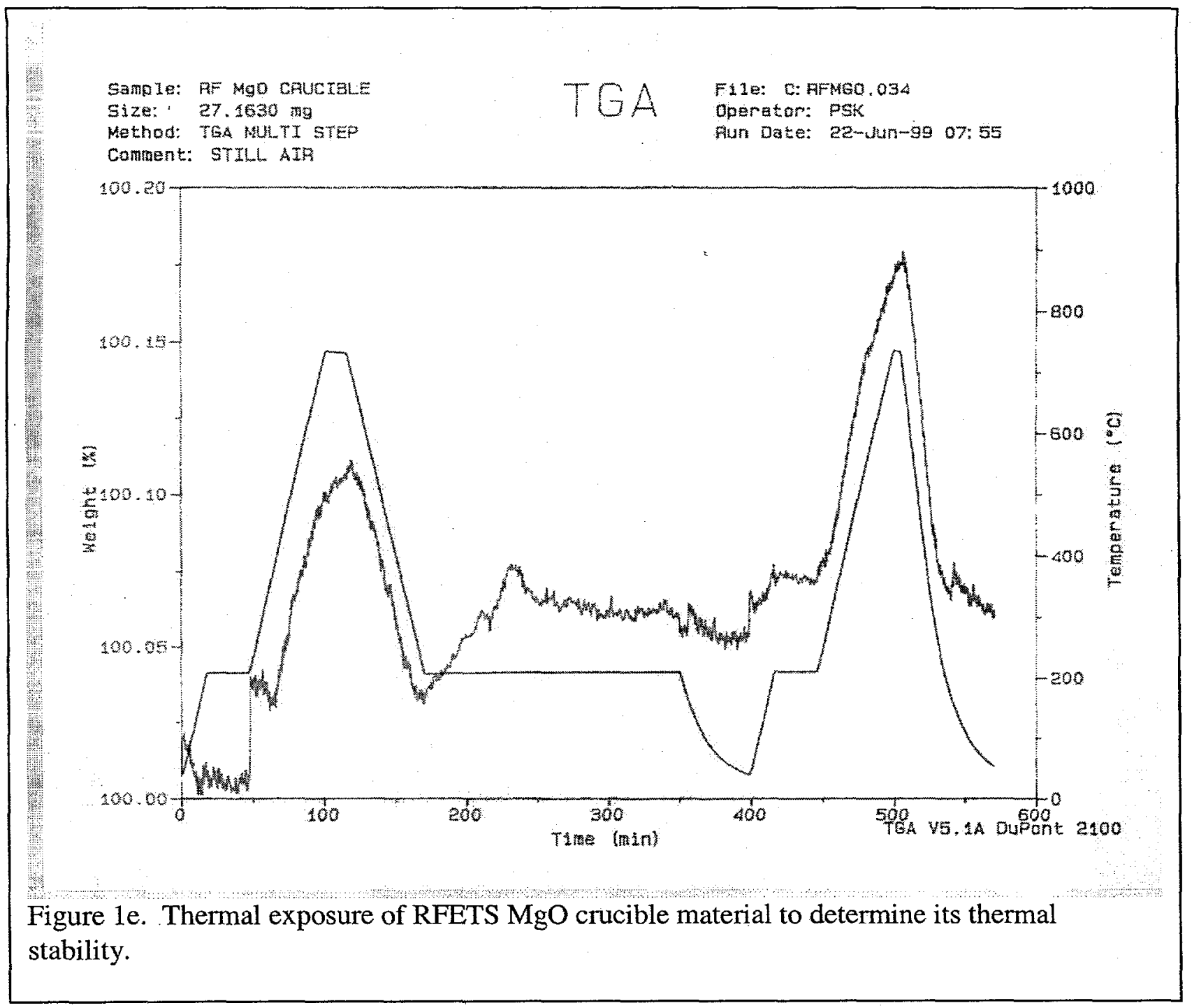


WSRC-TR-99-00275
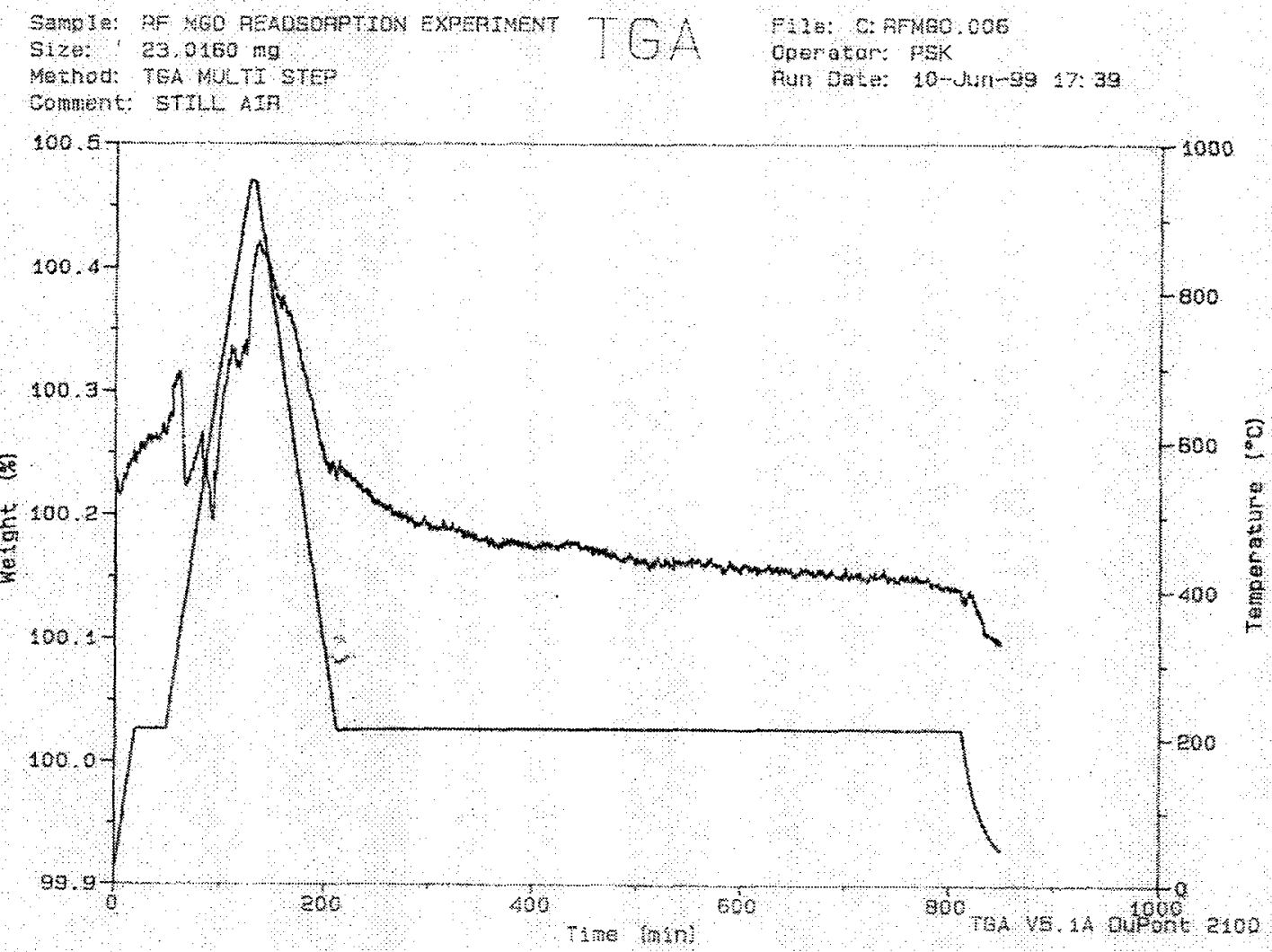

Figure 2a. Thermal cycle to decompose any residual $\mathrm{Mg}(\mathrm{OH})_{2}$ in RFETS $\mathrm{MgO}$ and a soak to try to reform it after exposure at $1000^{\circ} \mathrm{C}$. 


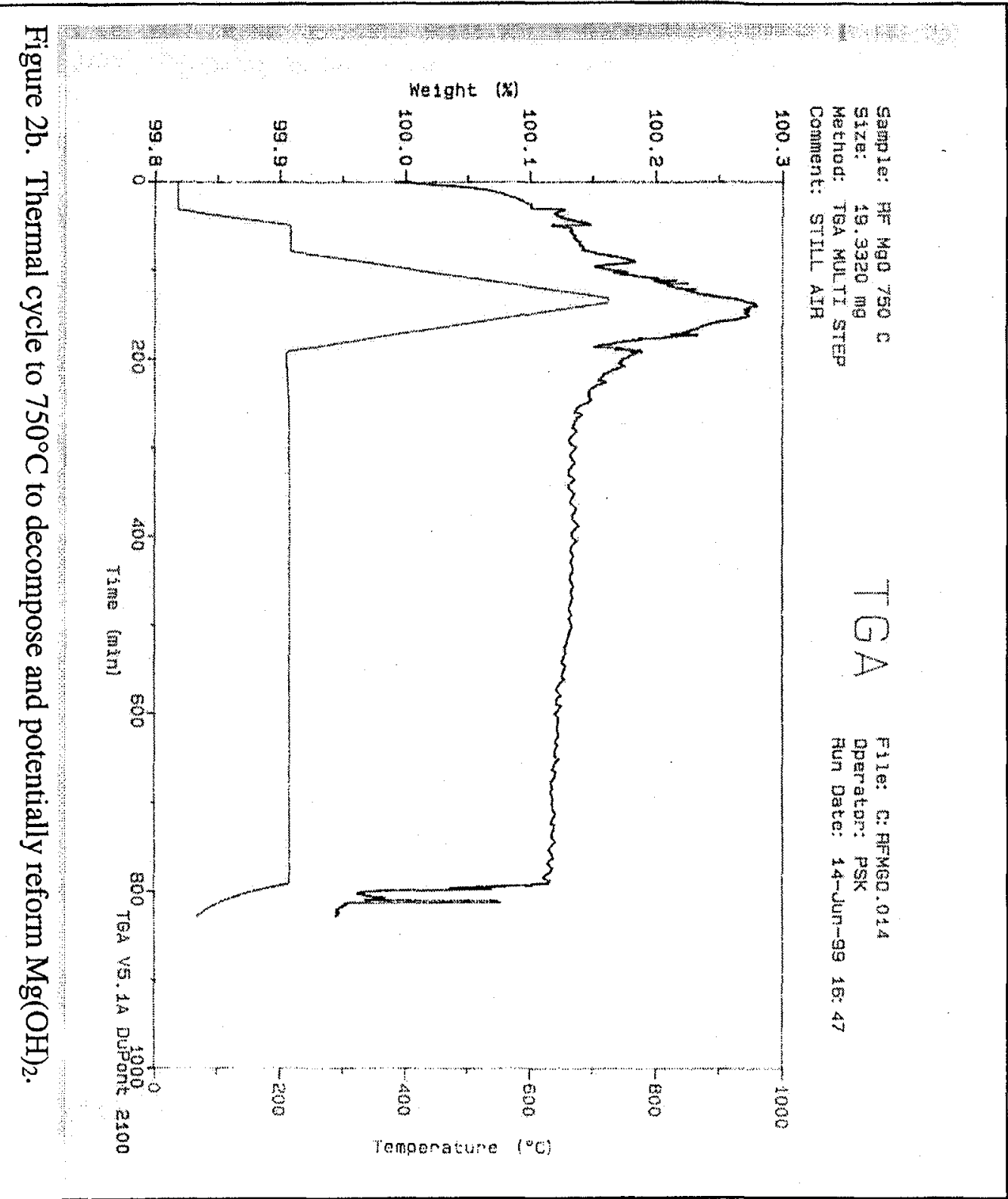


WSRC-TR-99-00275




WSRC-TR-99-00275

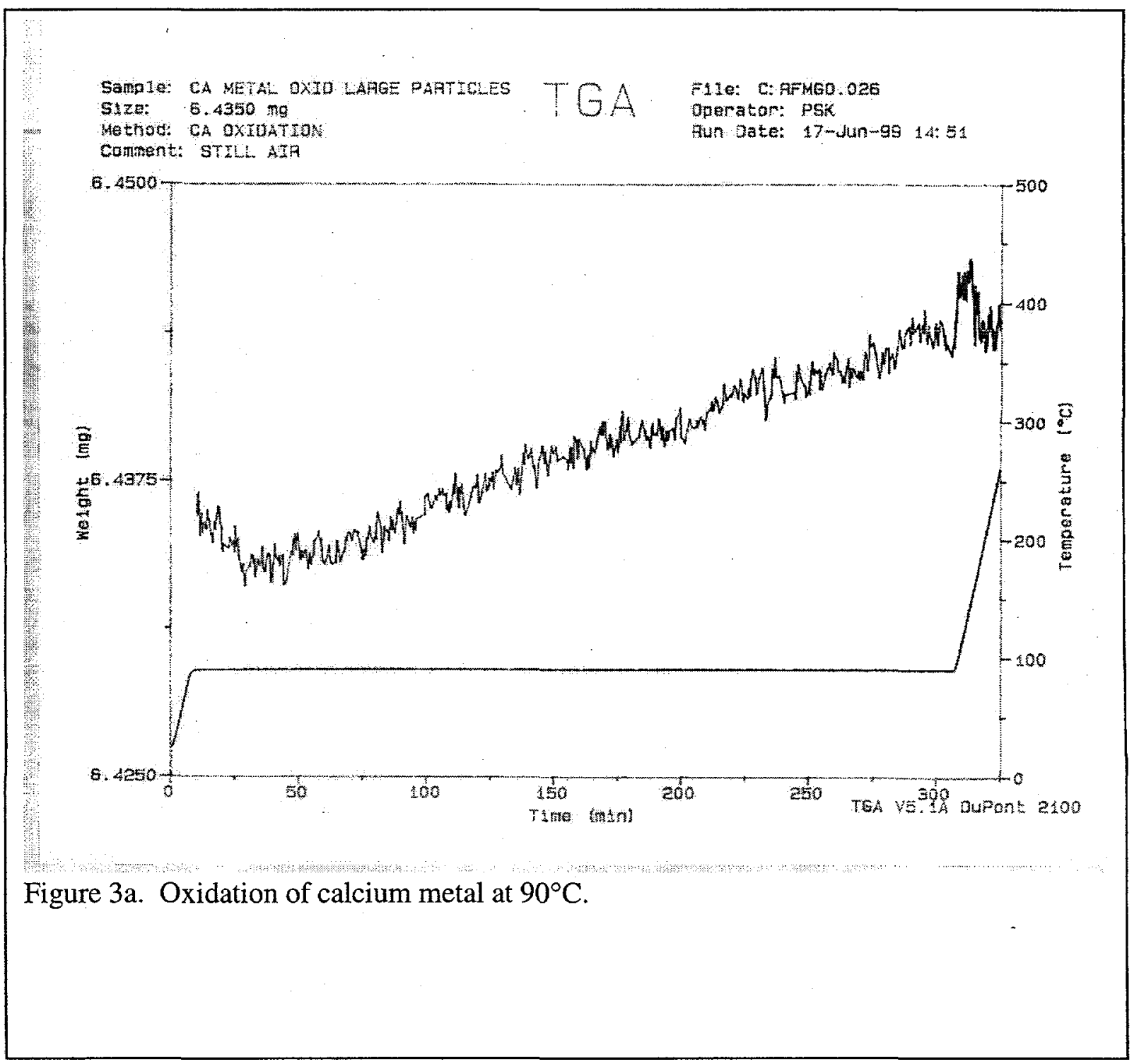


WSRC-TR-99-00275

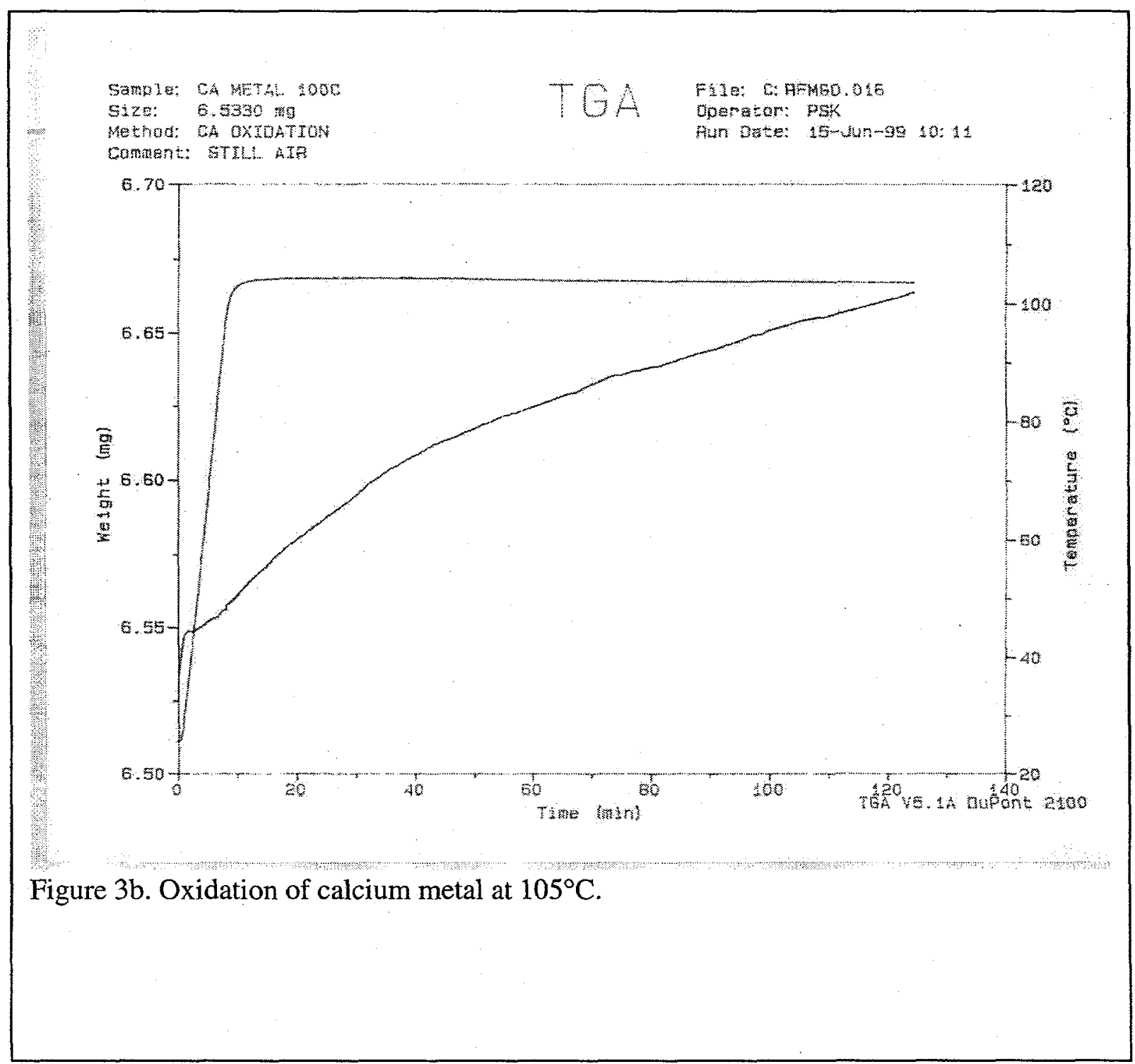


WSRC-TR-99-00275

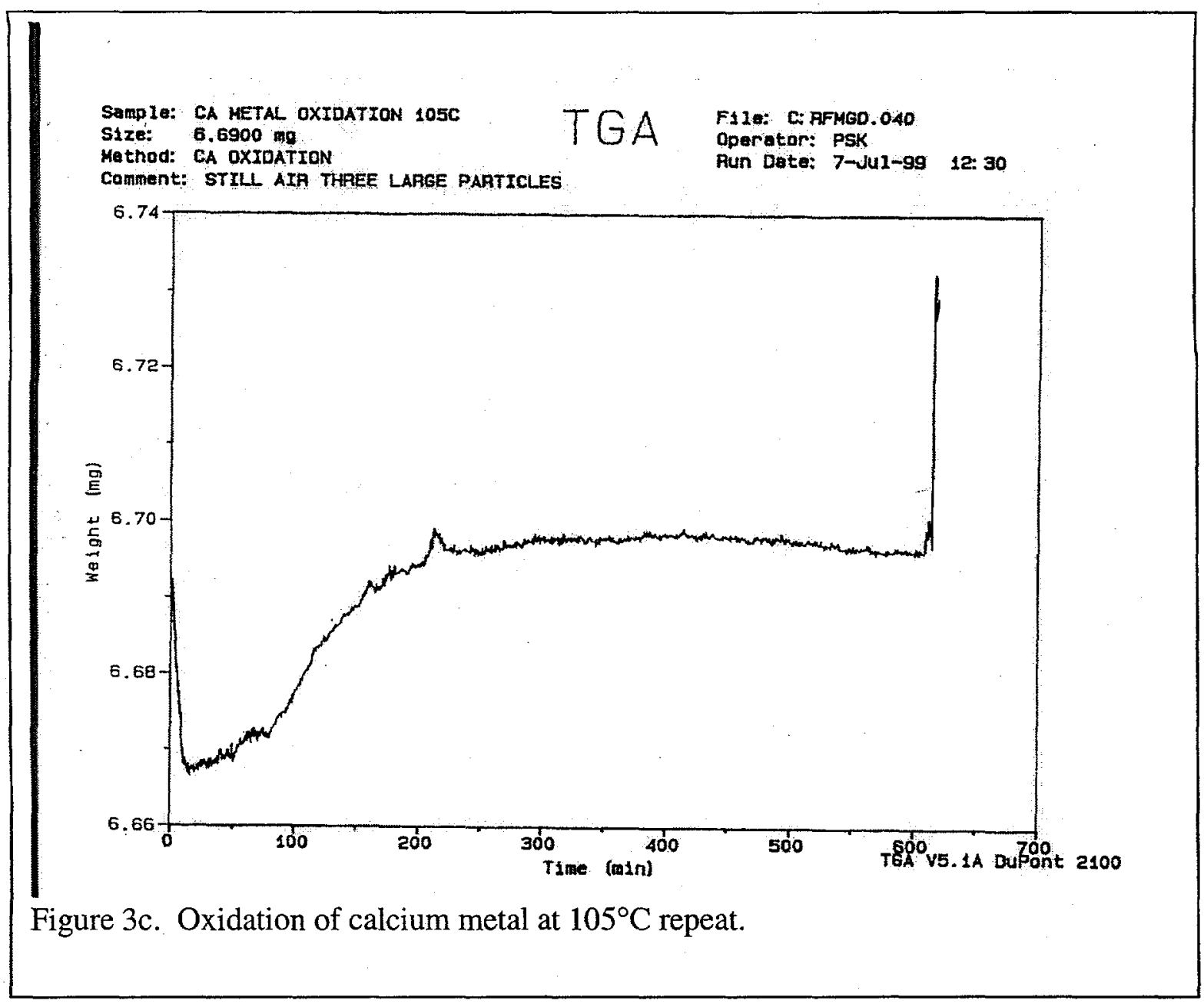


WSRC-TR-99-00275

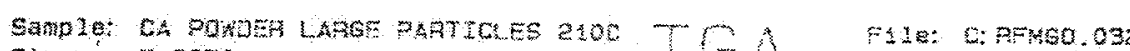

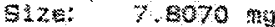

Qpepatom: pox

Sethod: WA OKTOAYSOW

Fun Date: 2u-jum-9s $13: 10$

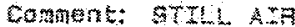

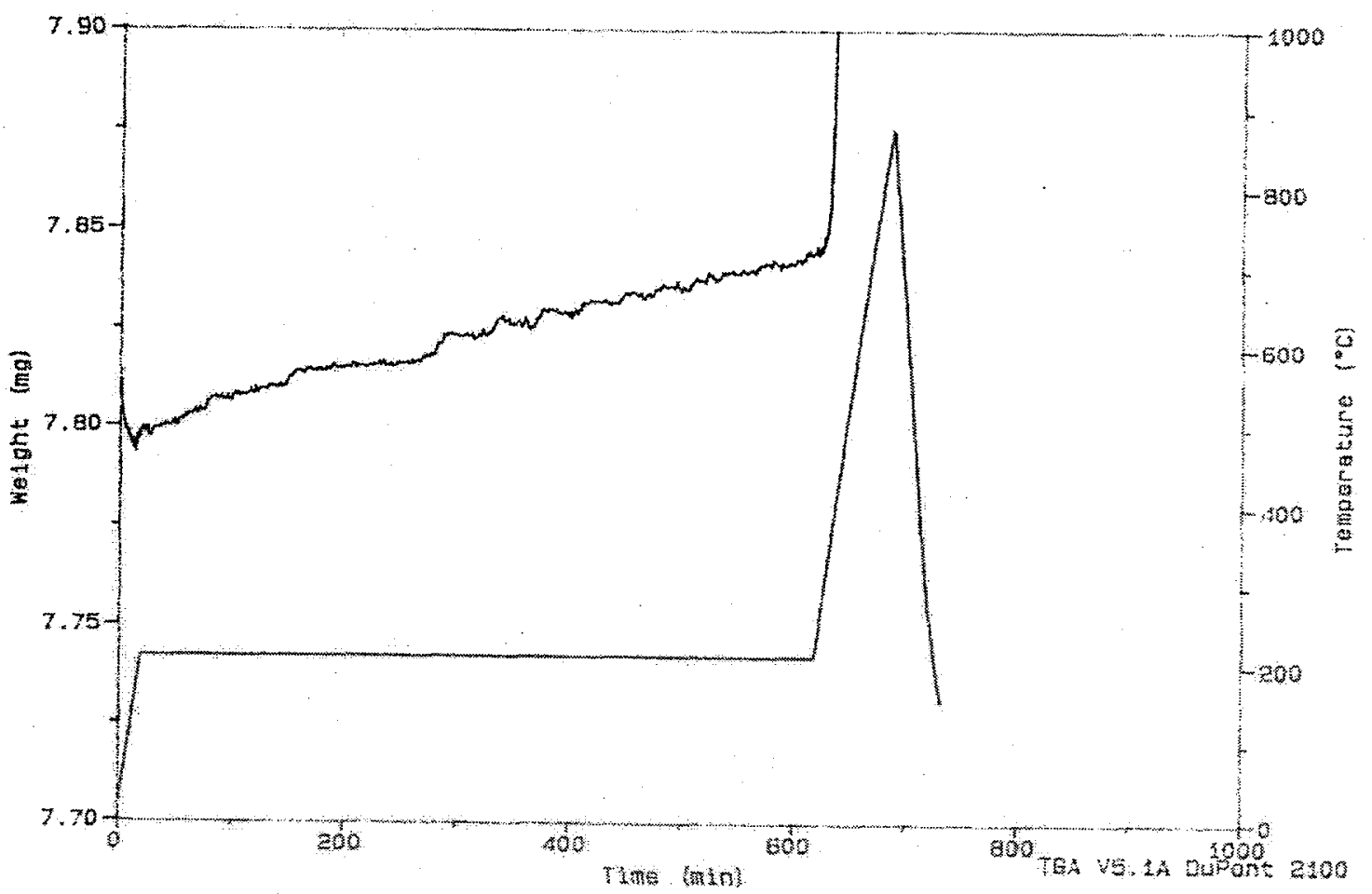

Figure 3d. Oxidation of calcium metal at $210^{\circ} \mathrm{C}$. 
WSRC-TR-99-00275

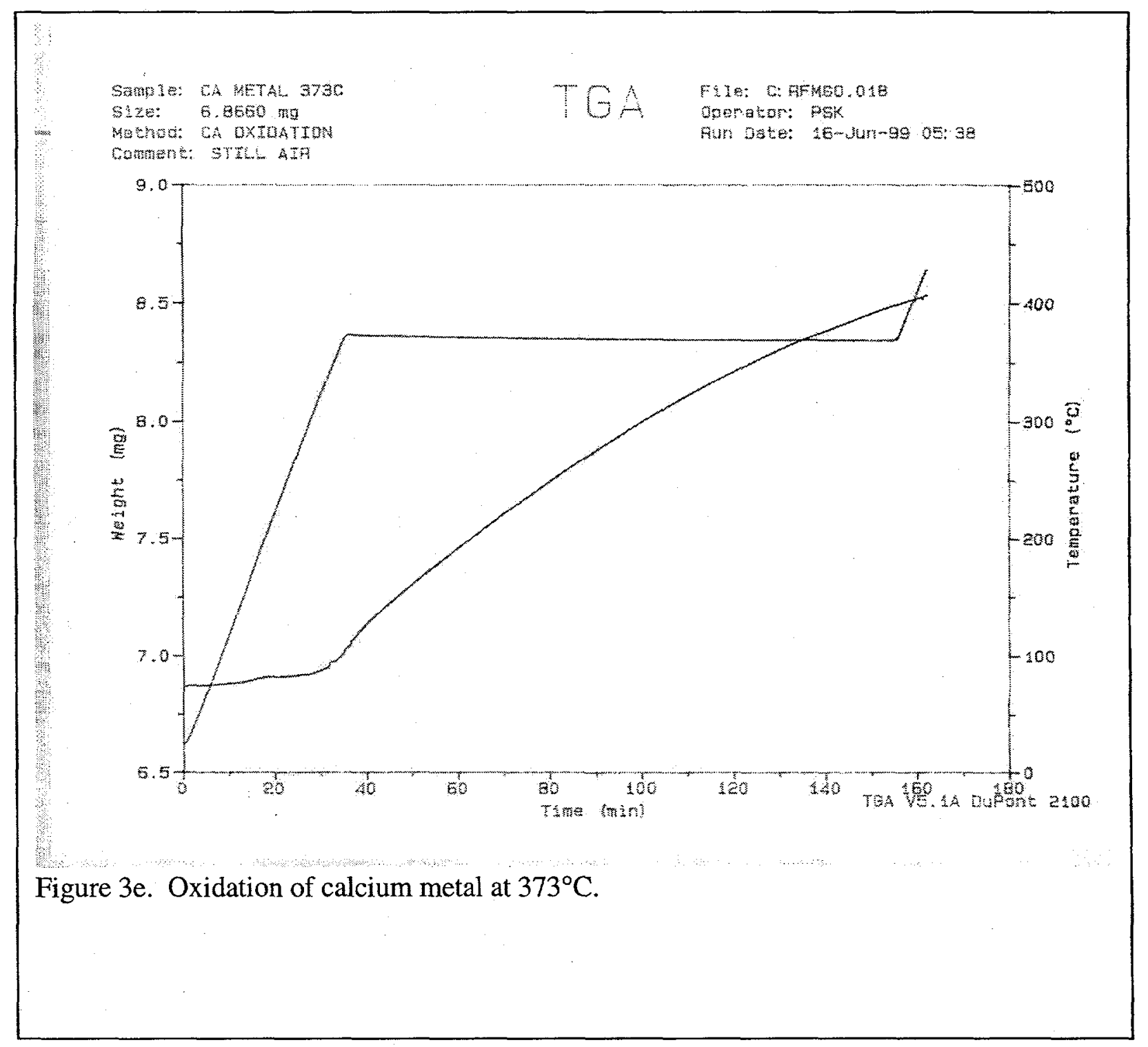


WSRC-TR-99-00275

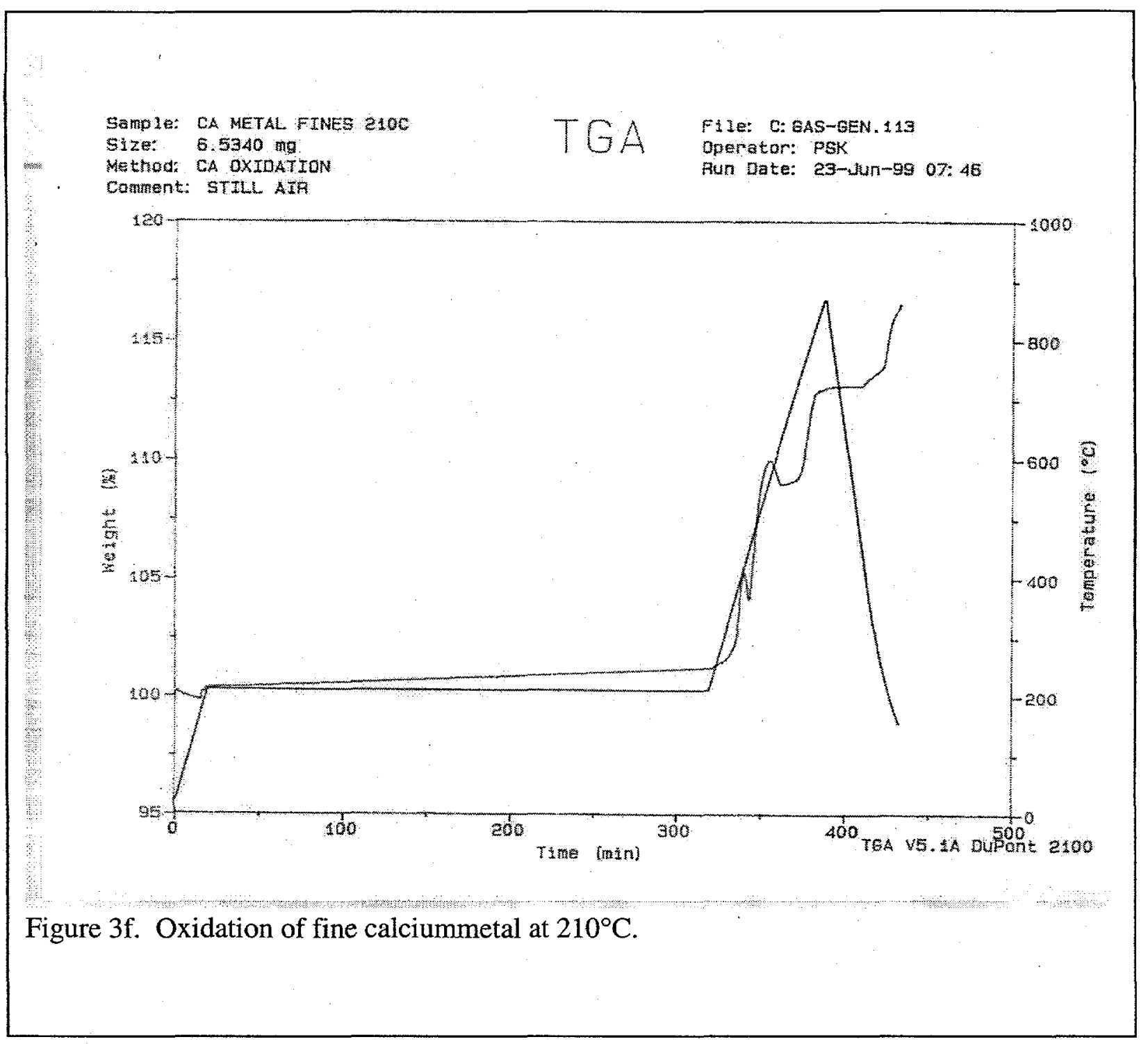


WSRC-TR-99-00275

\section{Oxidation of Ca Metal}

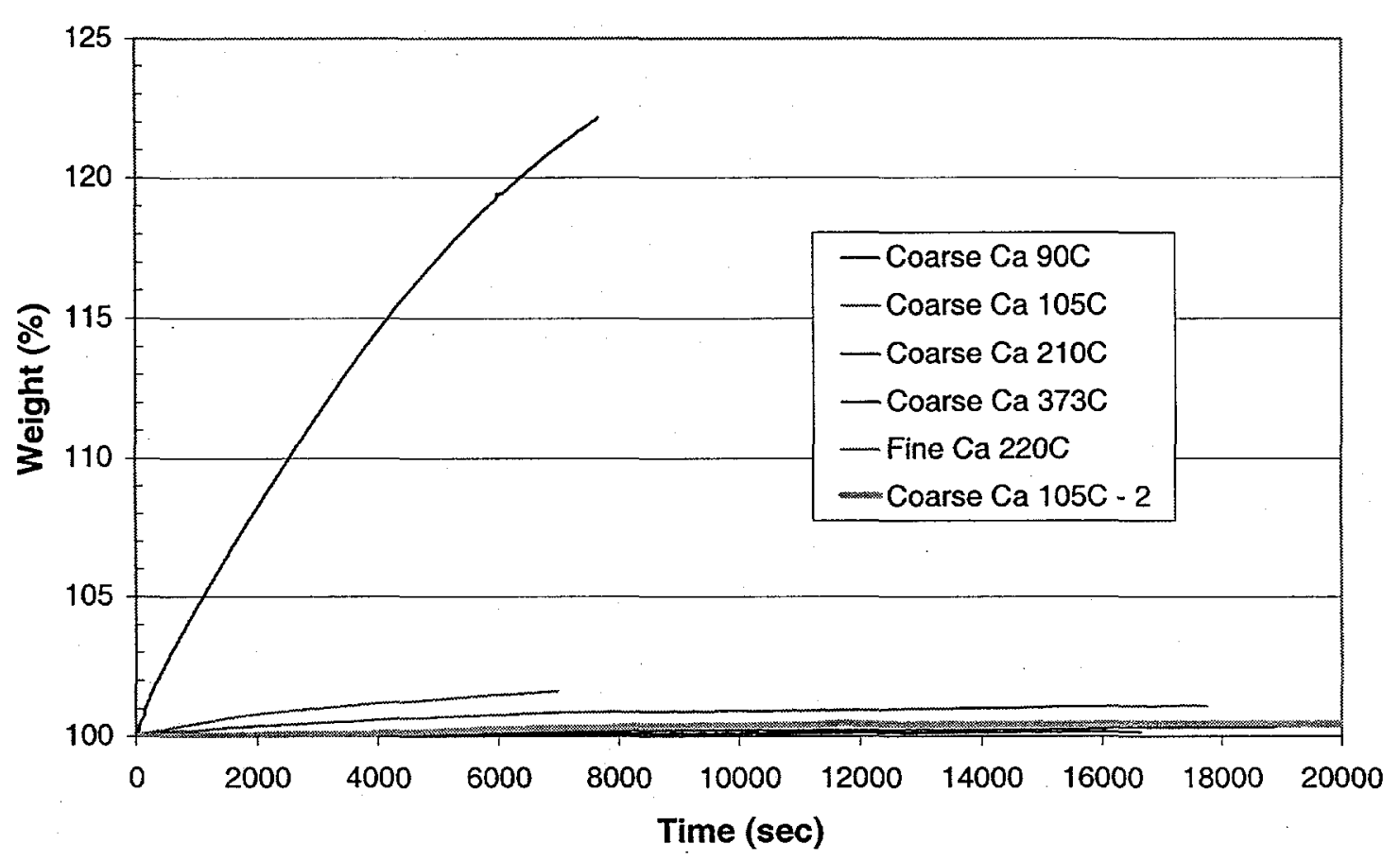

Figure 4a. Summary plot of the weight change data for calcium metal showing data for all four temperatures. 
WSRC-TR-99-00275

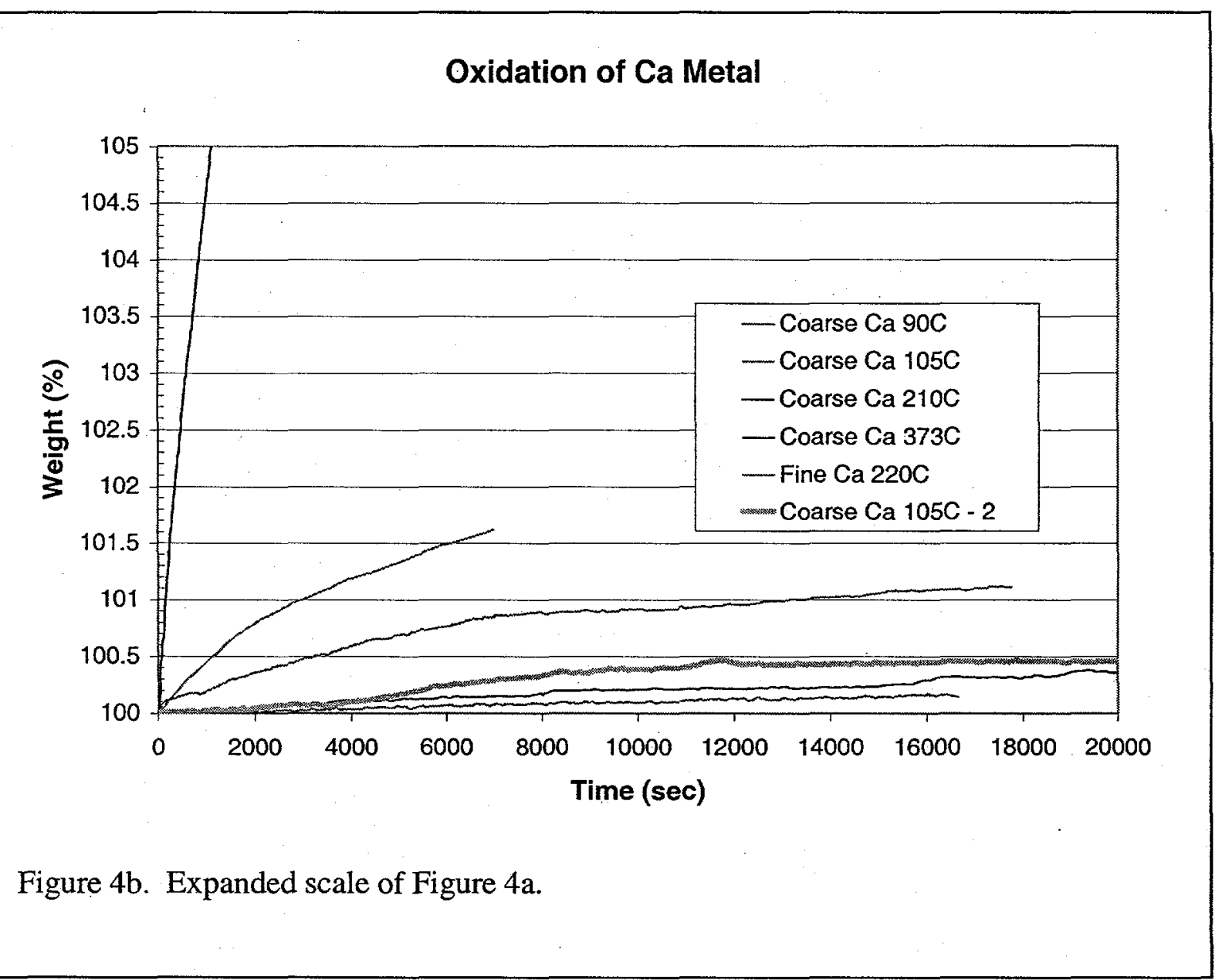




\section{Oxidation of Ca Metal at $105 \mathrm{C}$}

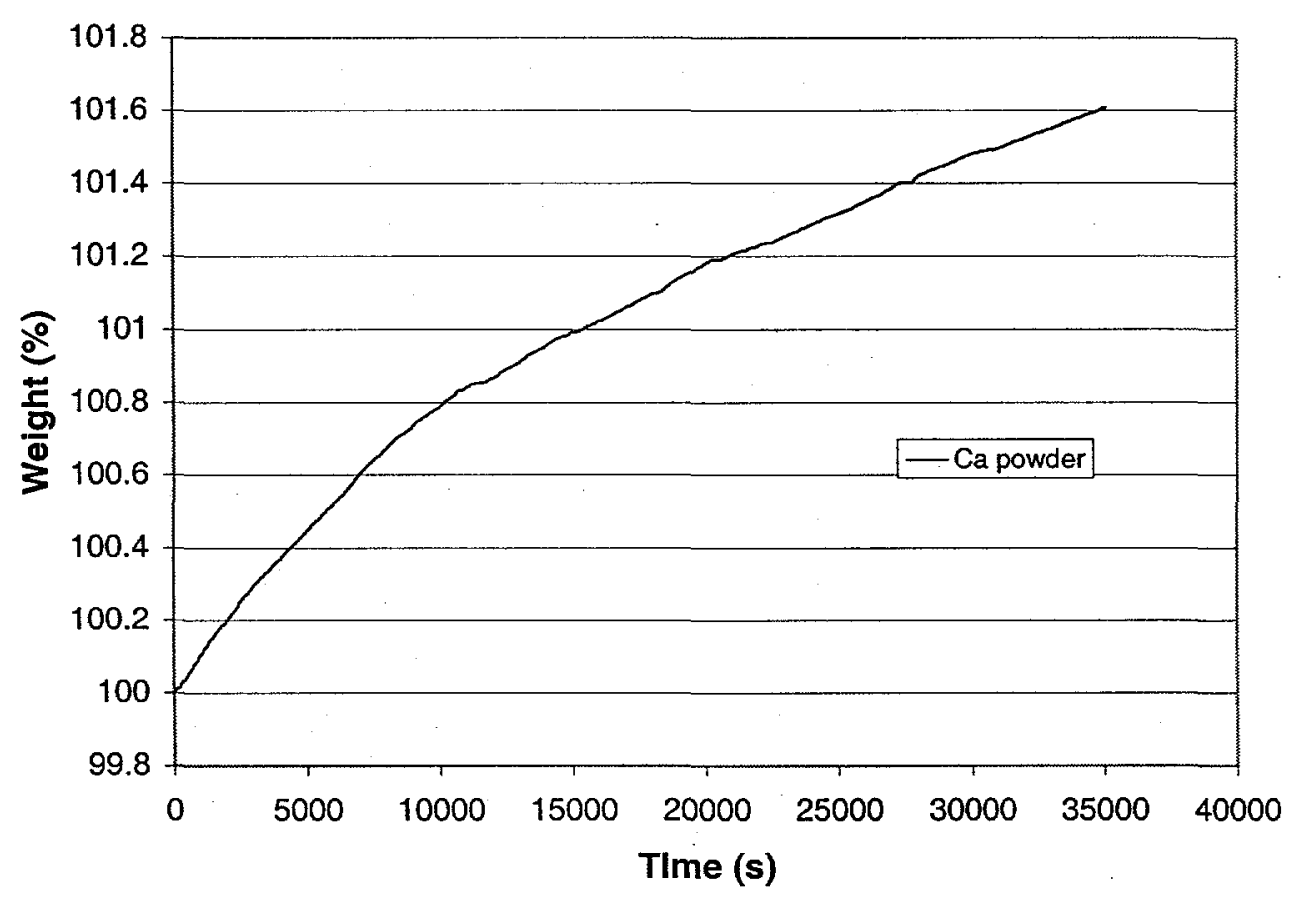

Figure 5a. Weight gain data for a sample exposed at $105^{\circ} \mathrm{C}$. 
WSRC-TR-99-00275

\section{Oxidation of Ca Metal at 105C}

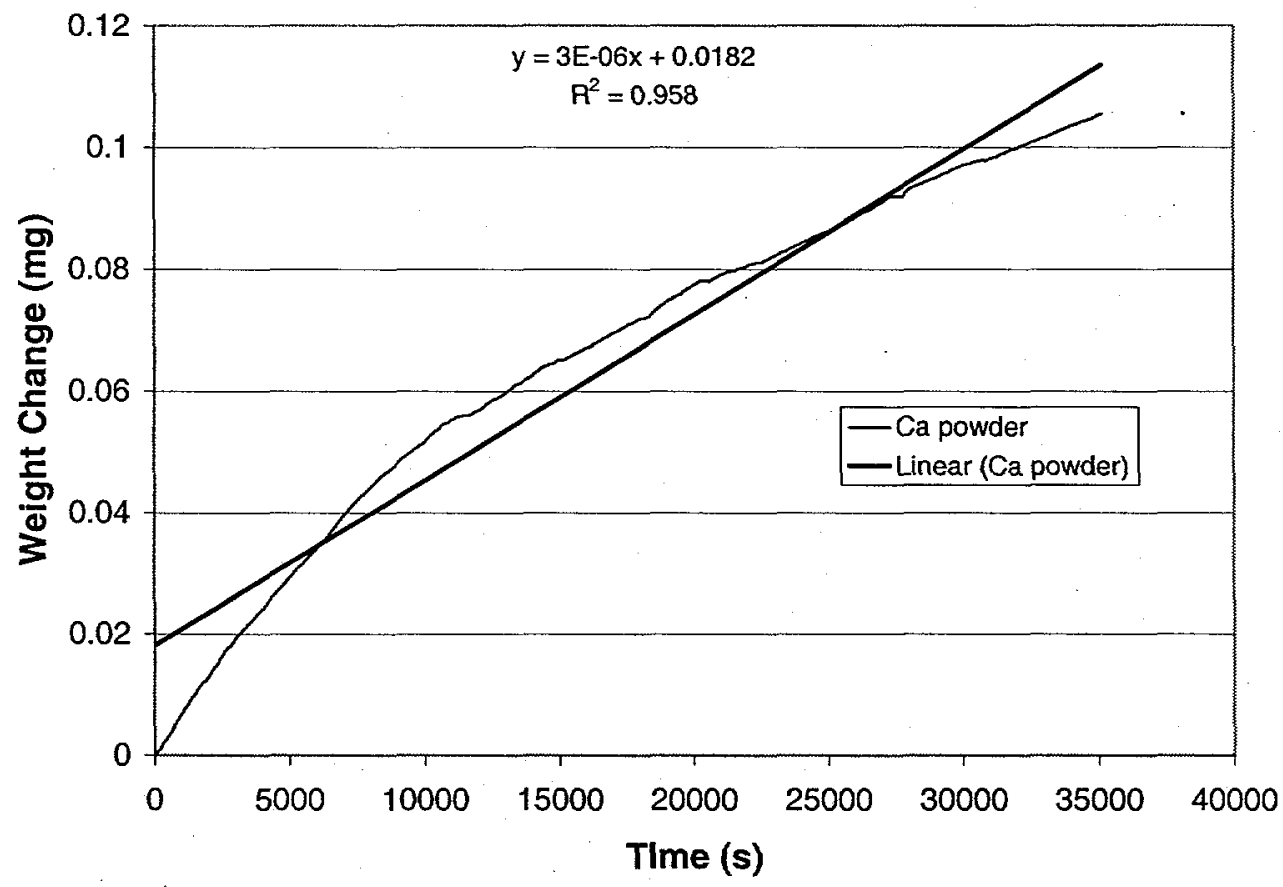

Figure $5 \mathrm{~b}$. Linear data fit for the weight gain data. 


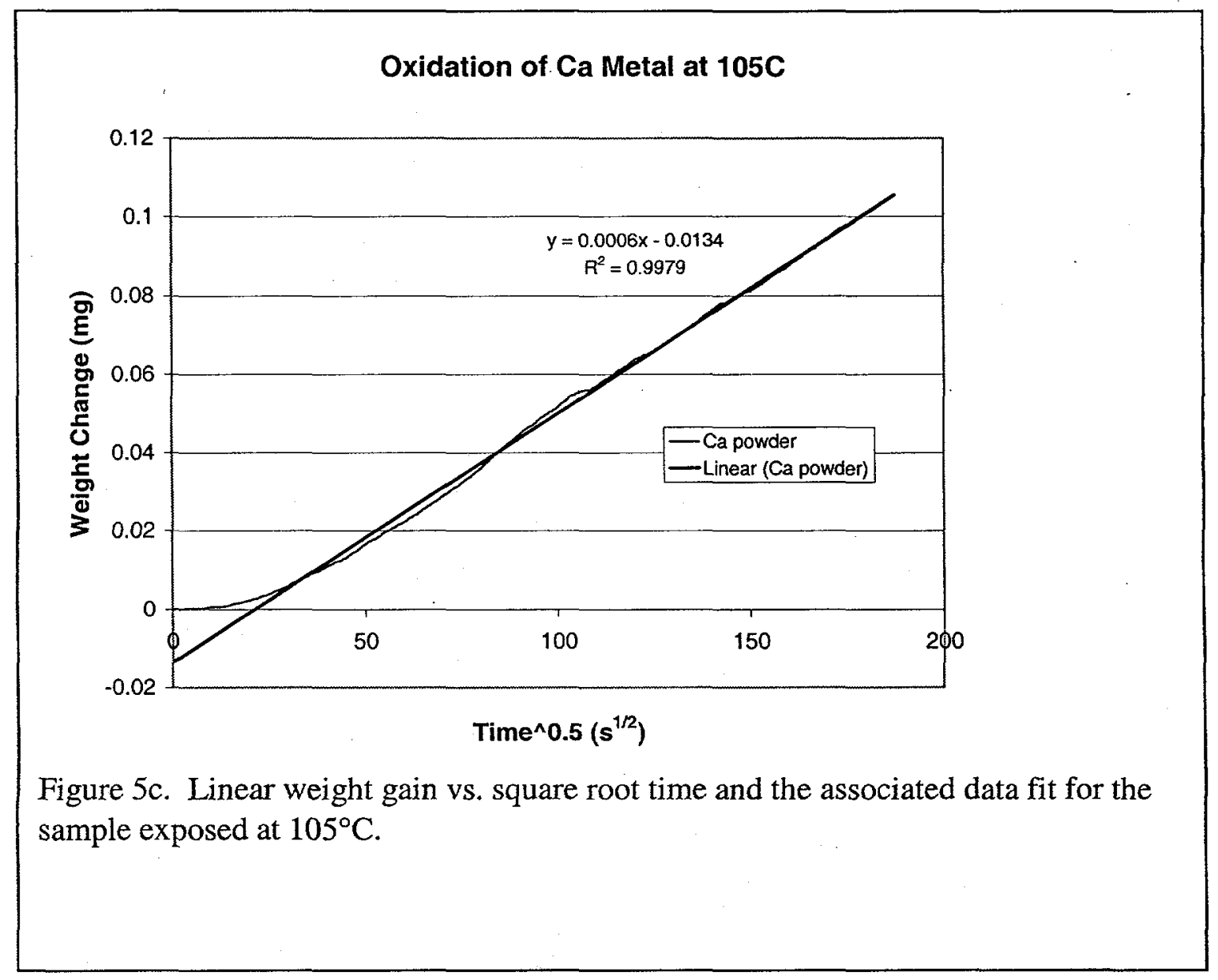


WSRC-TR-99-00275

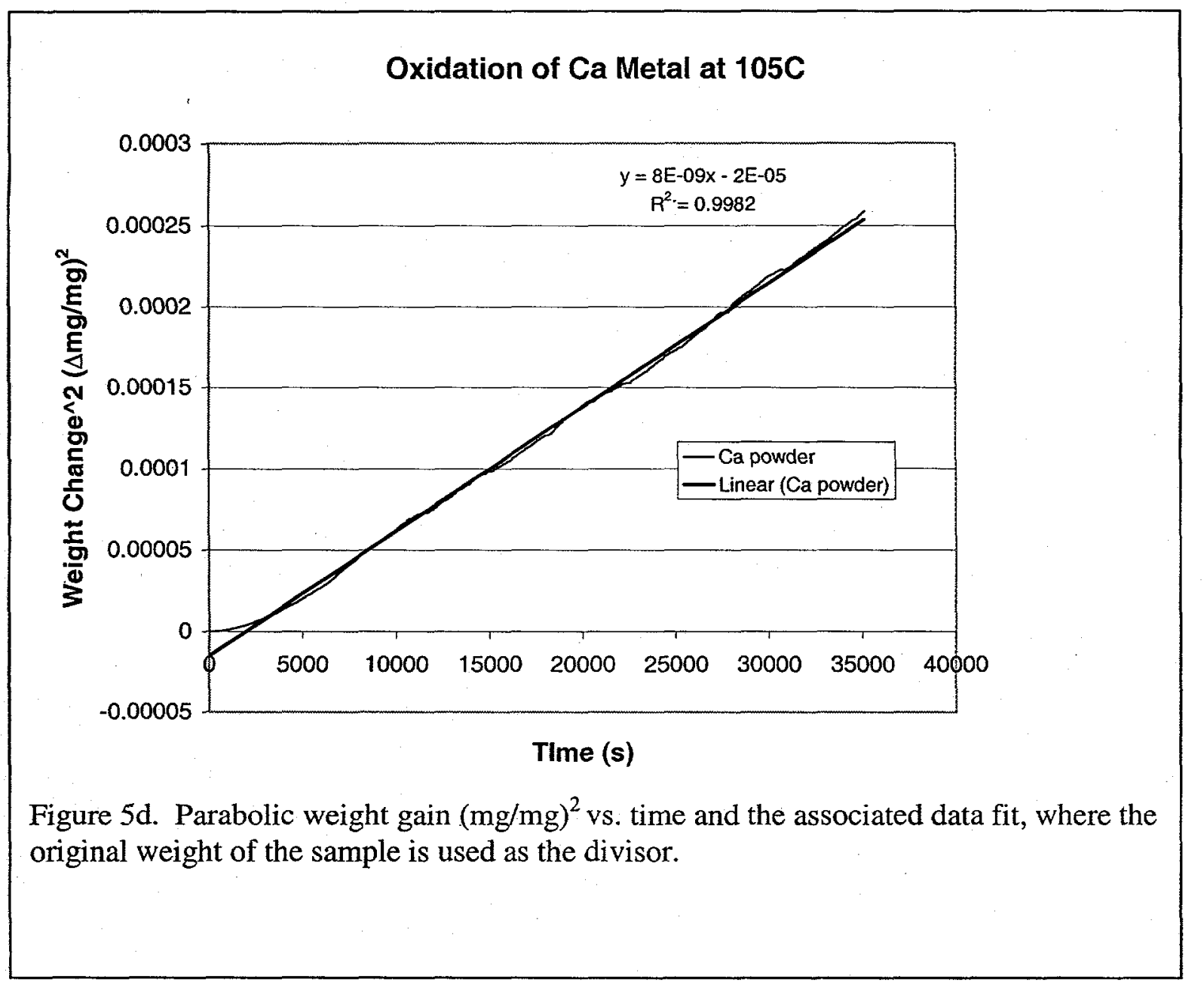




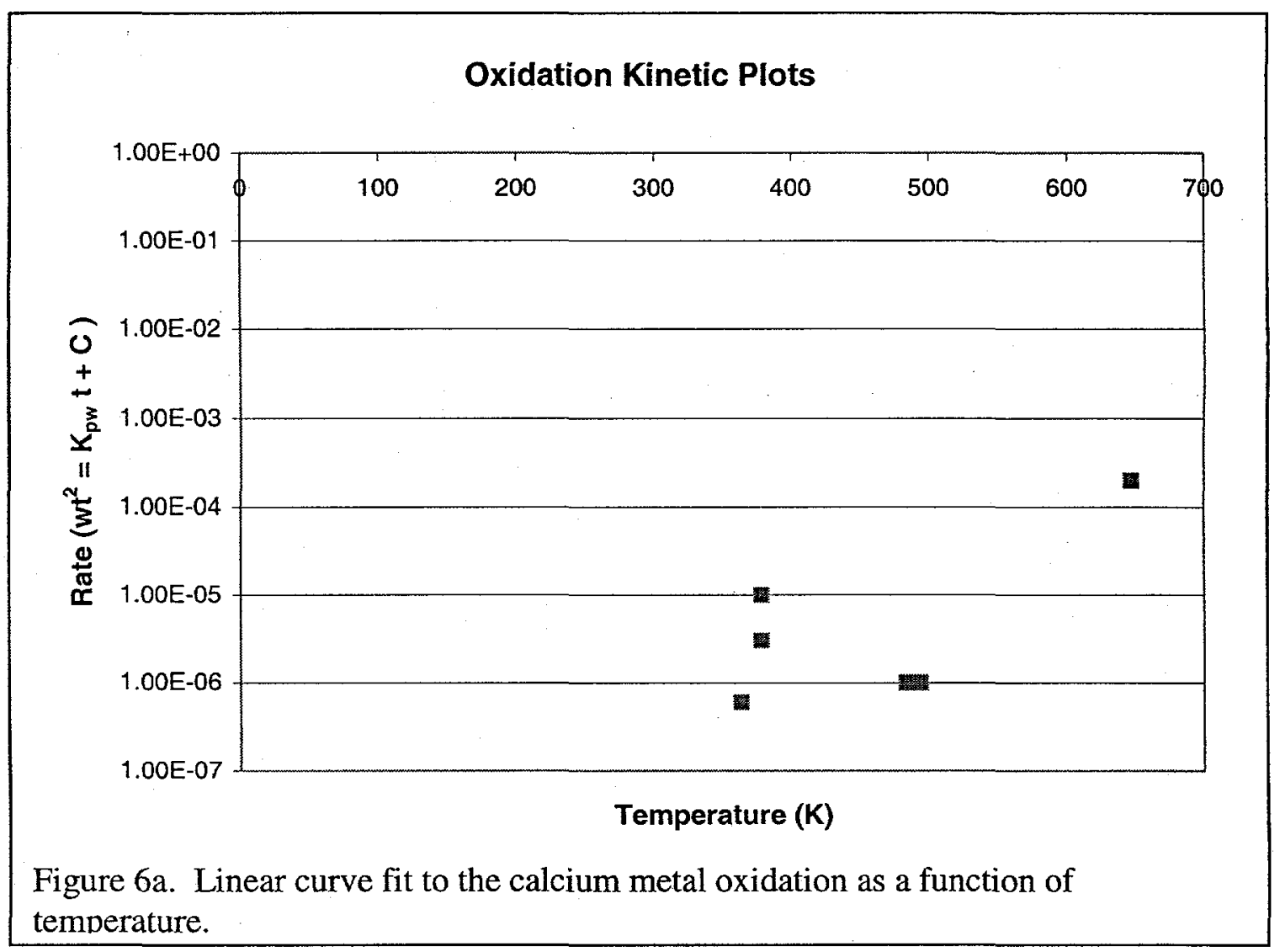




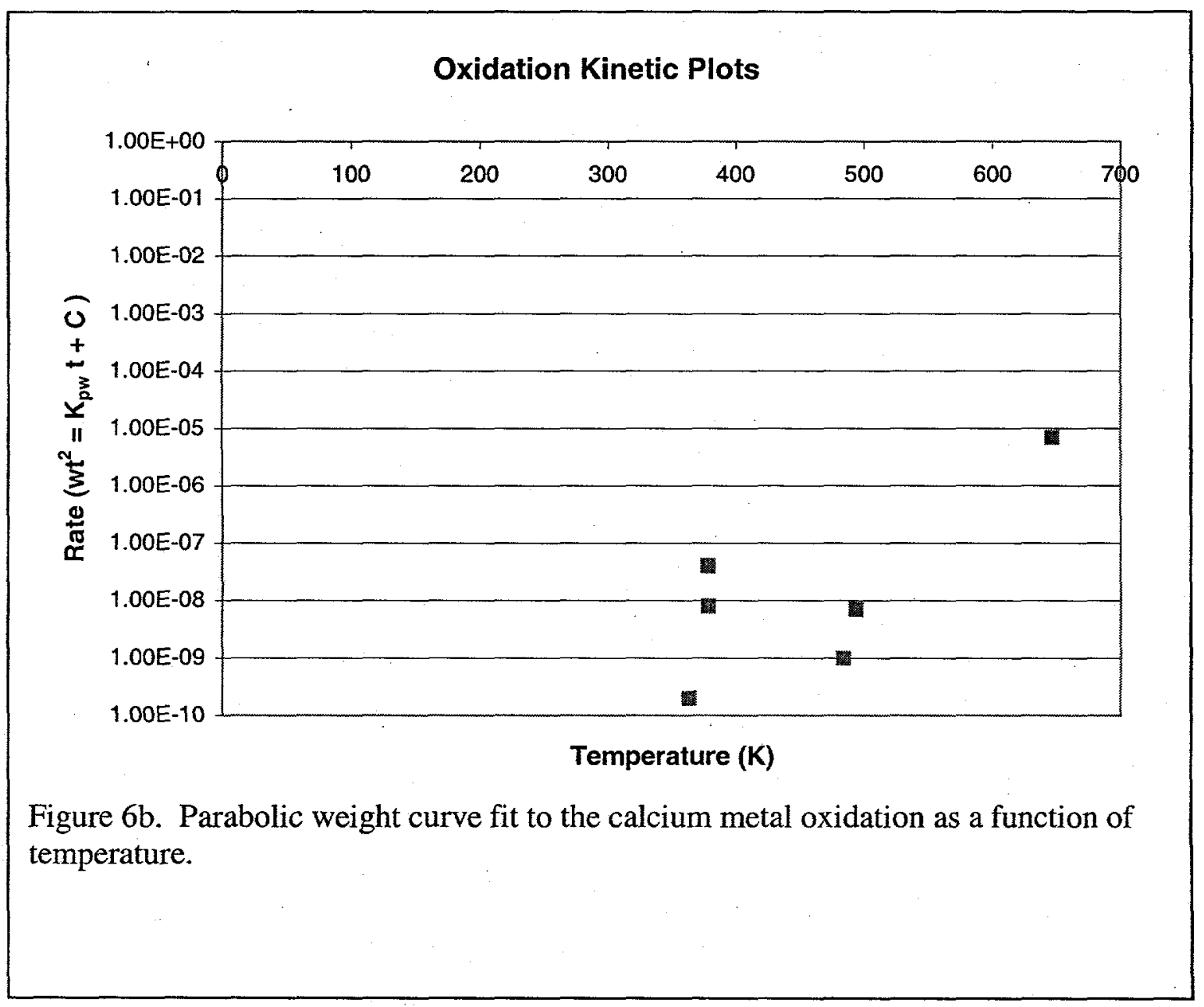




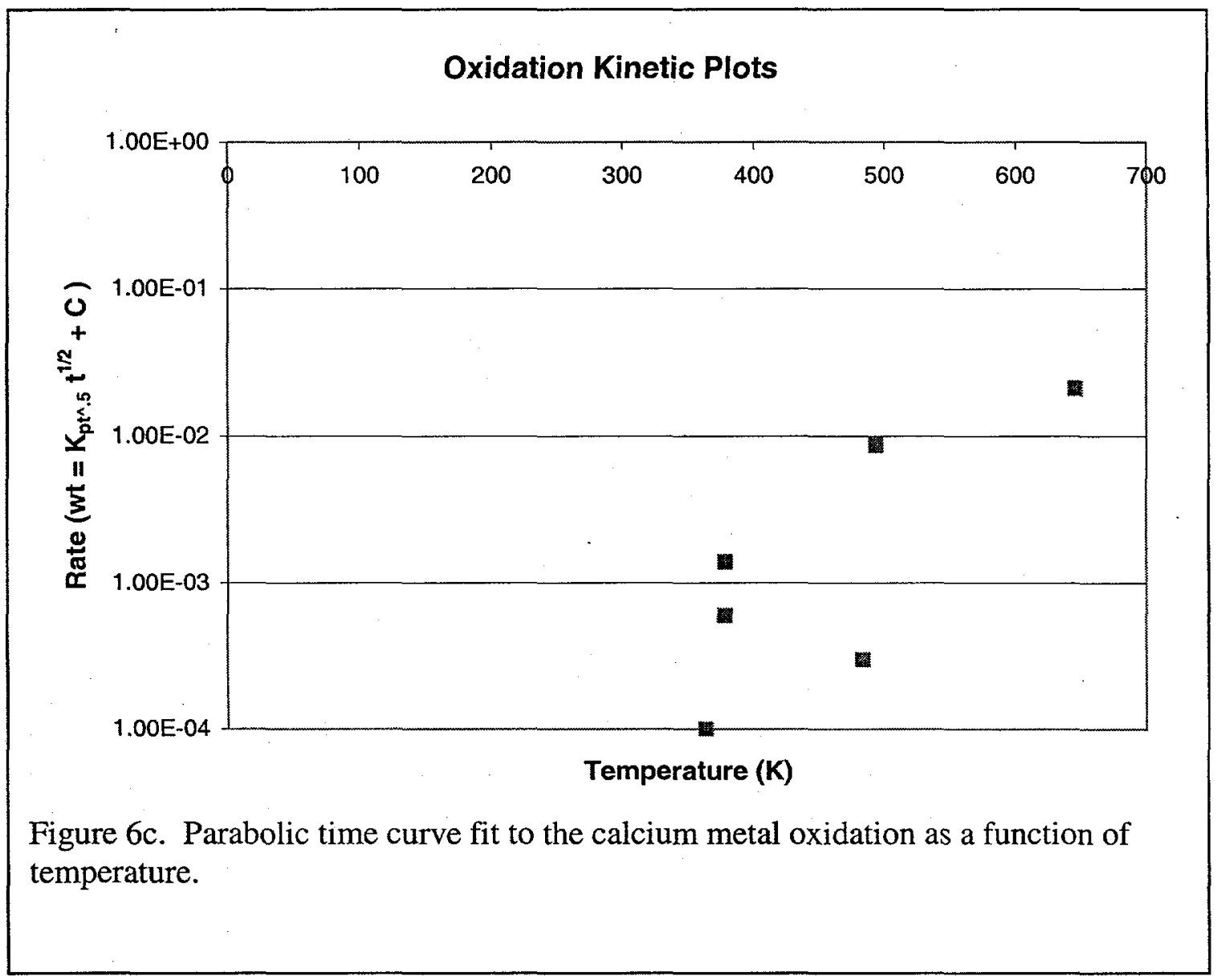


WSRC-TR-99-00275

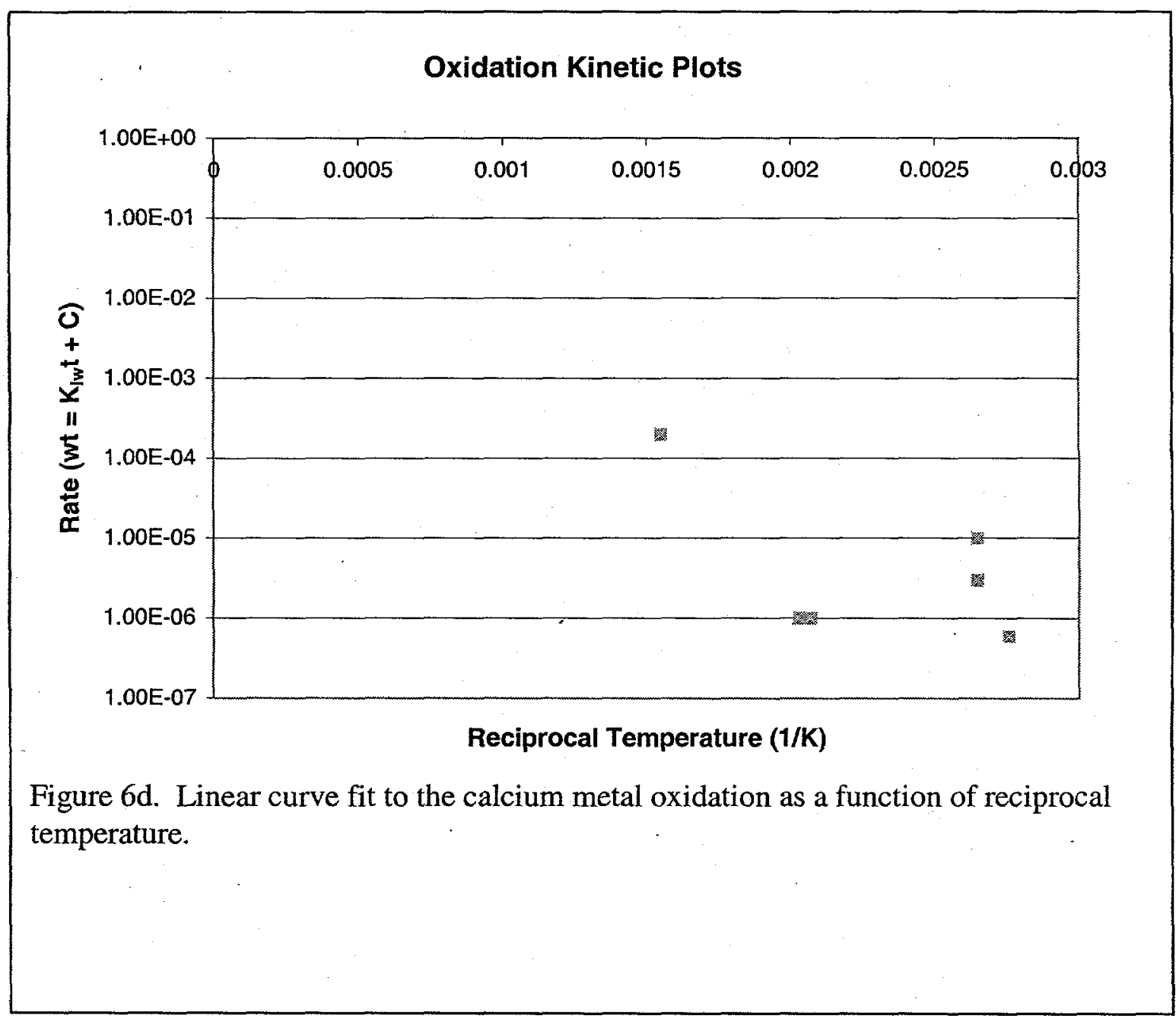


WSRC-TR-99-00275

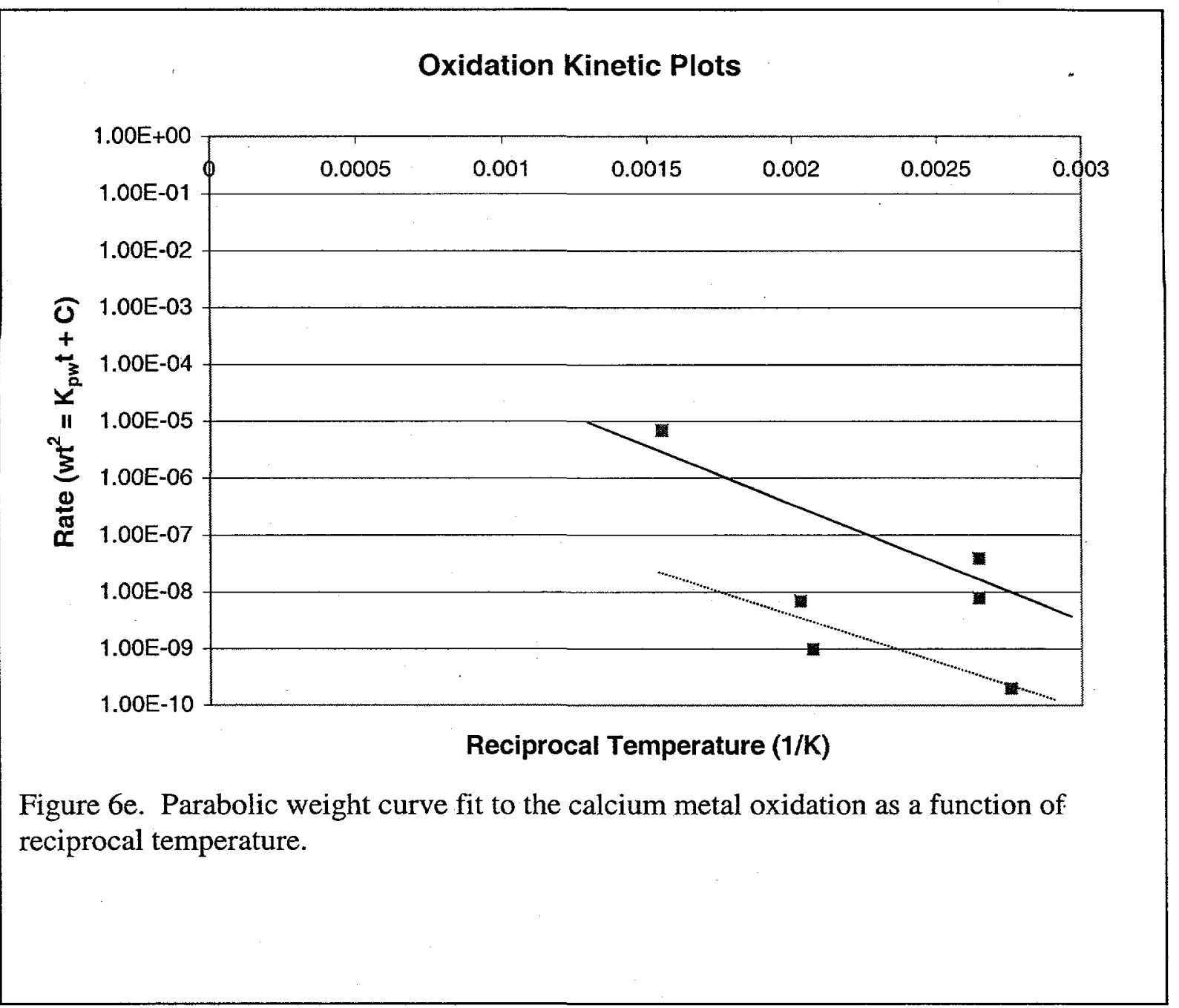




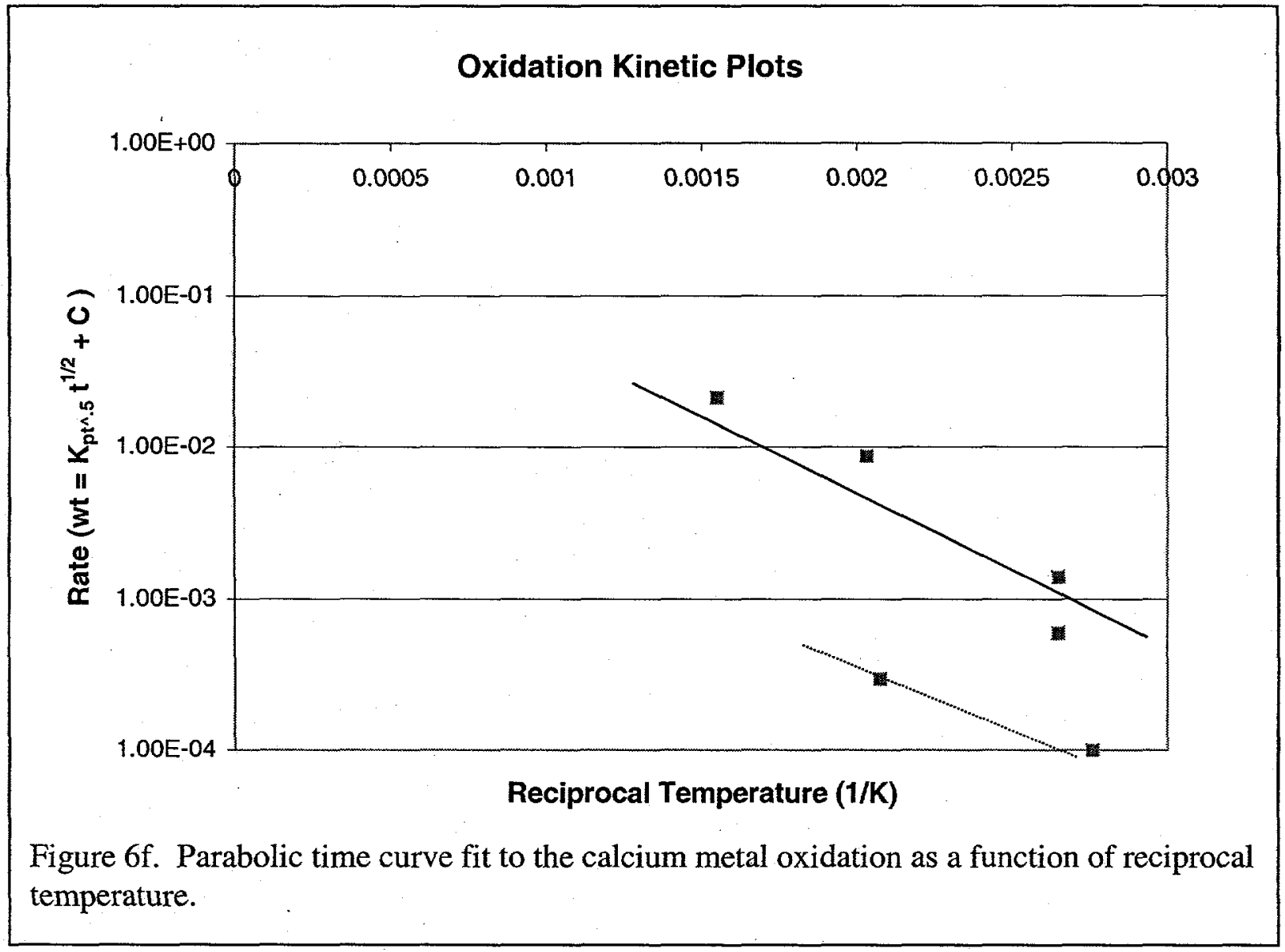


WSRC-TR-99-00275

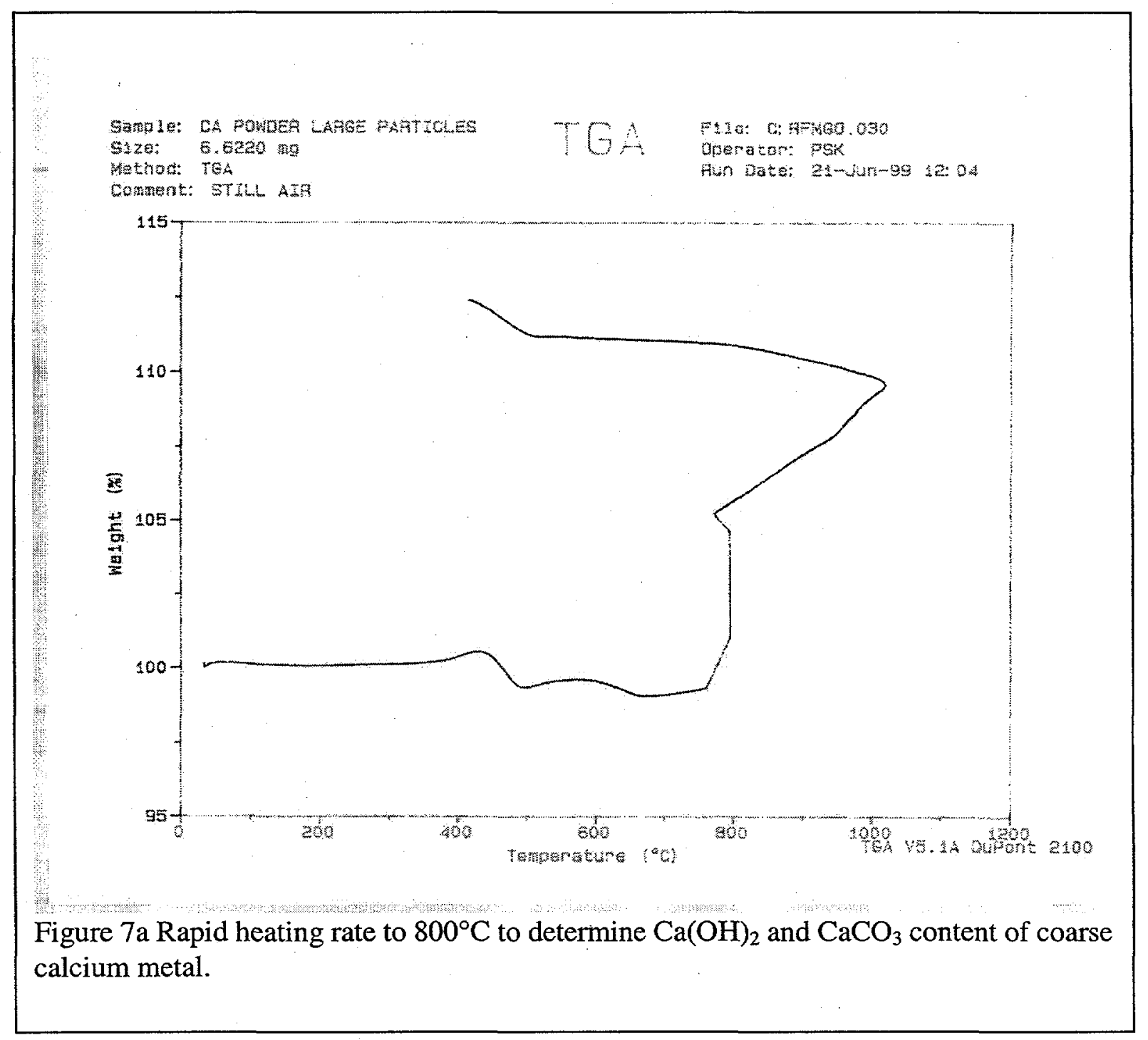




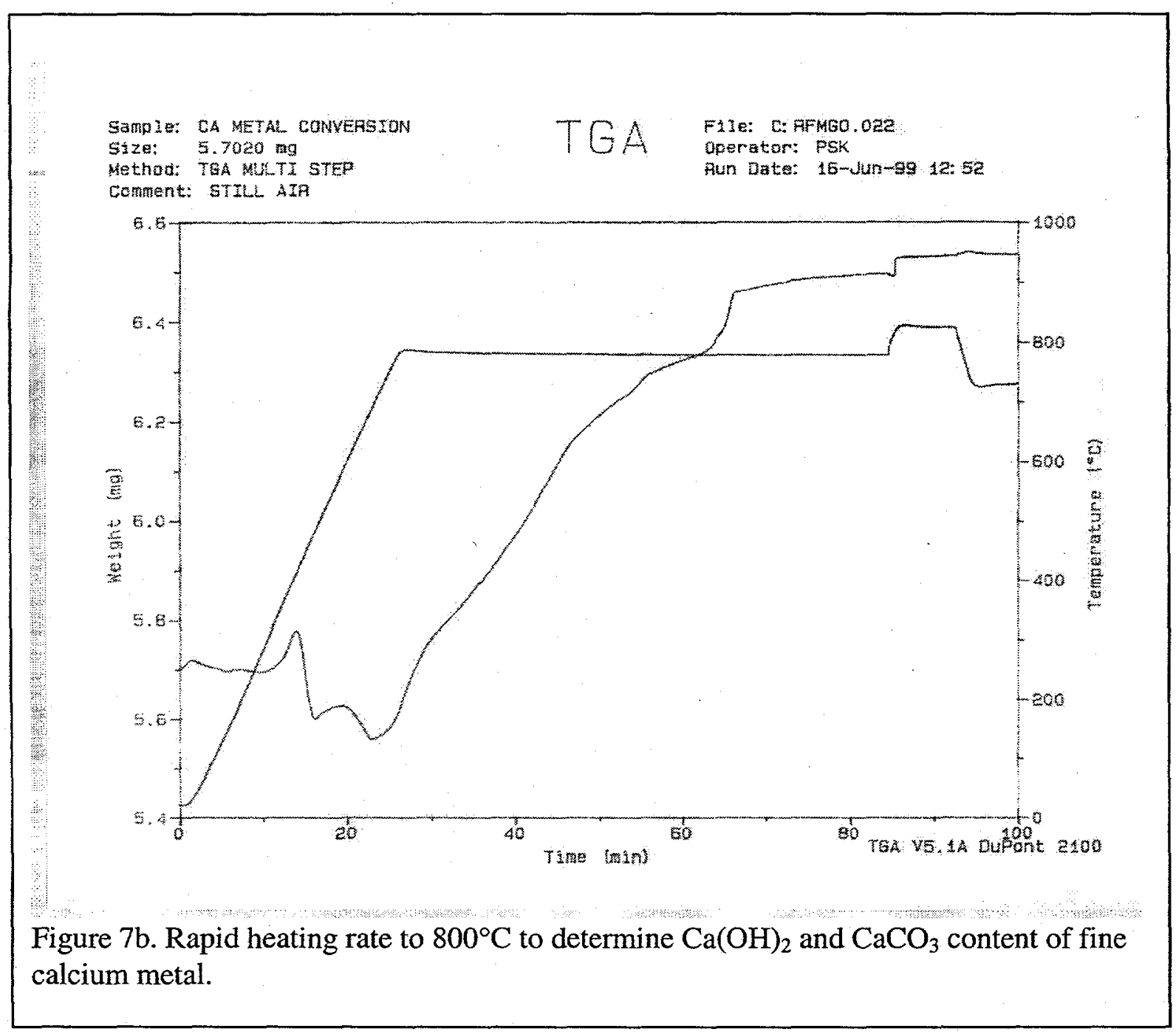


WSRC-TR-99-00275

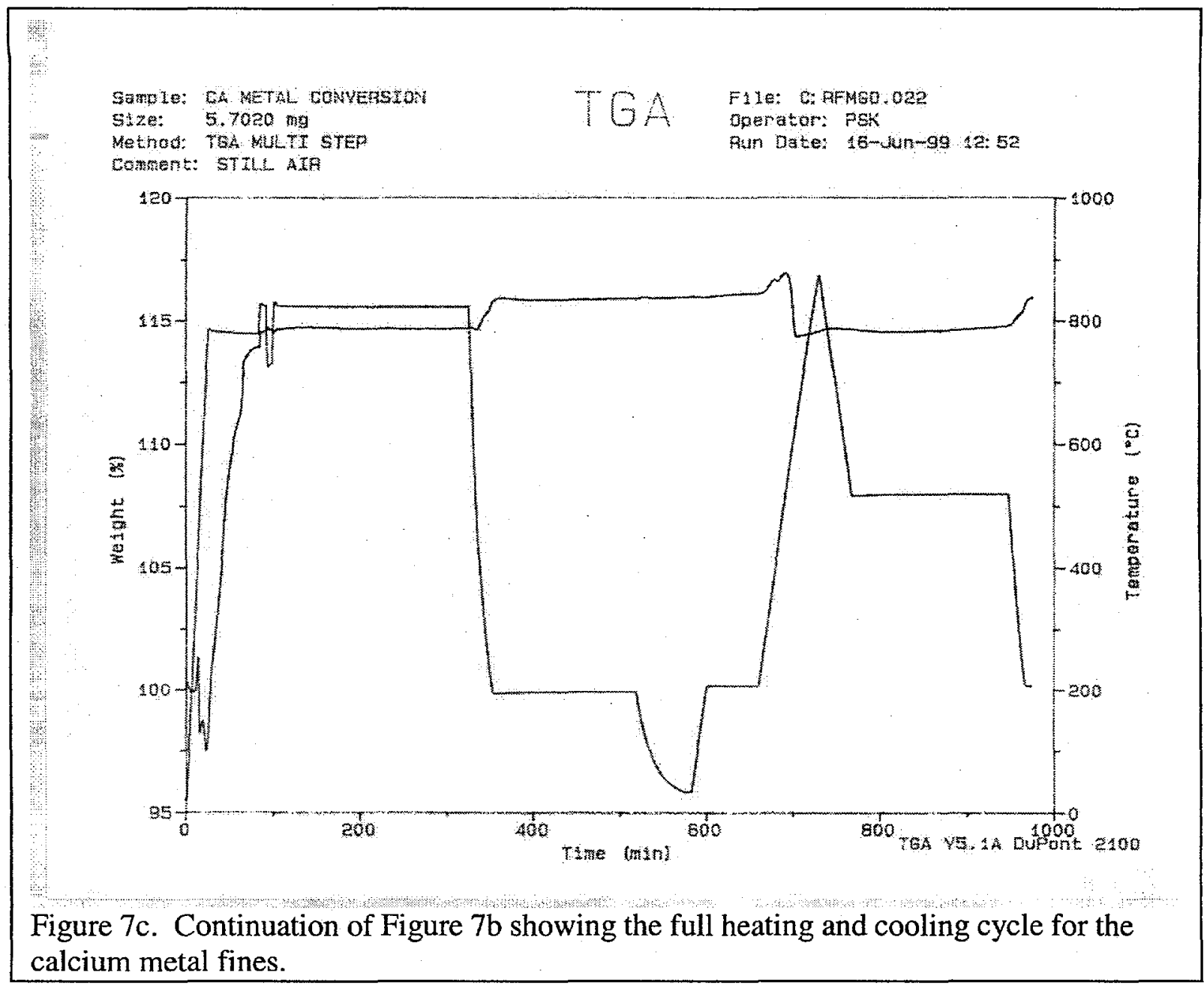




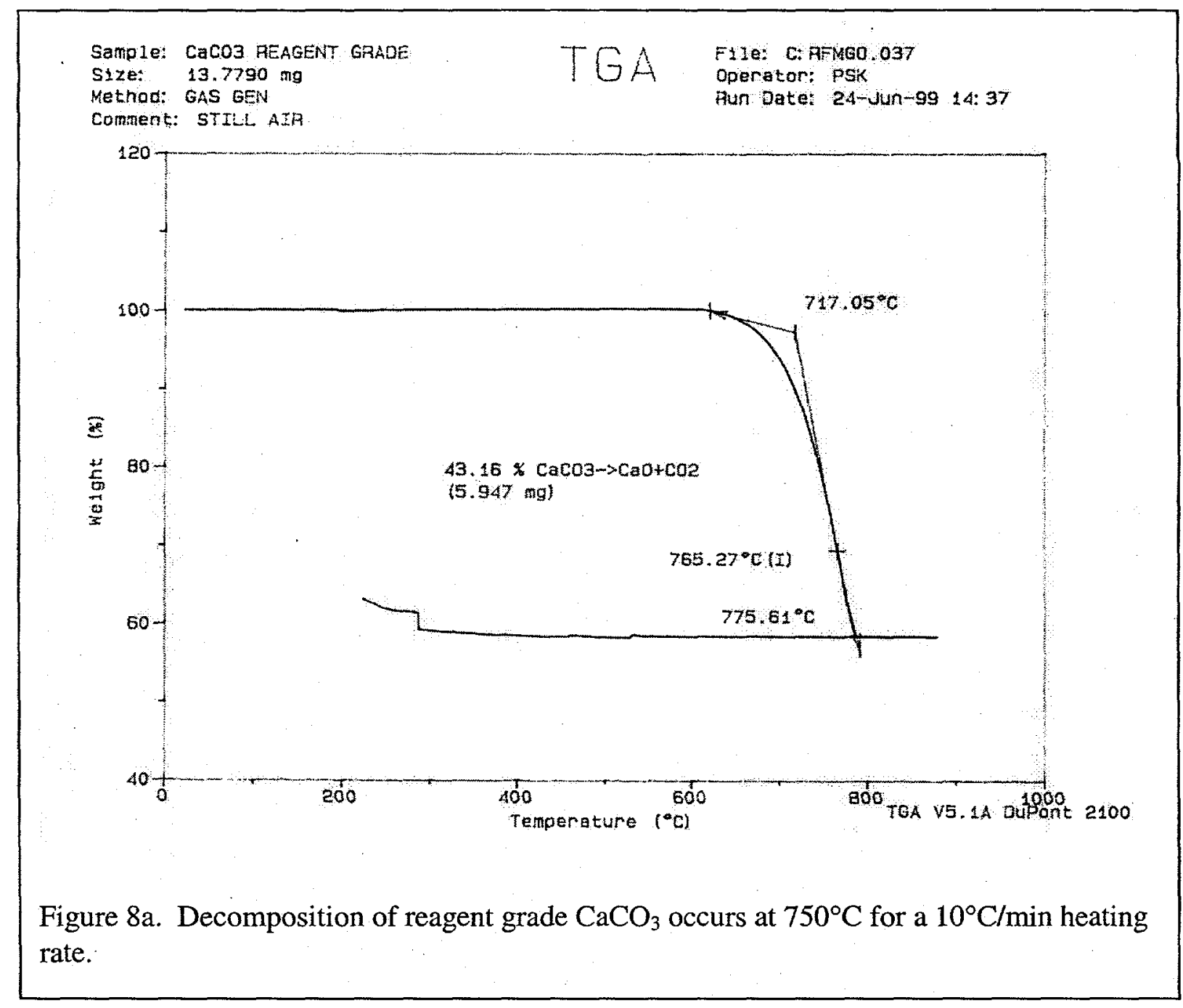


WSRC-TR-99-00275

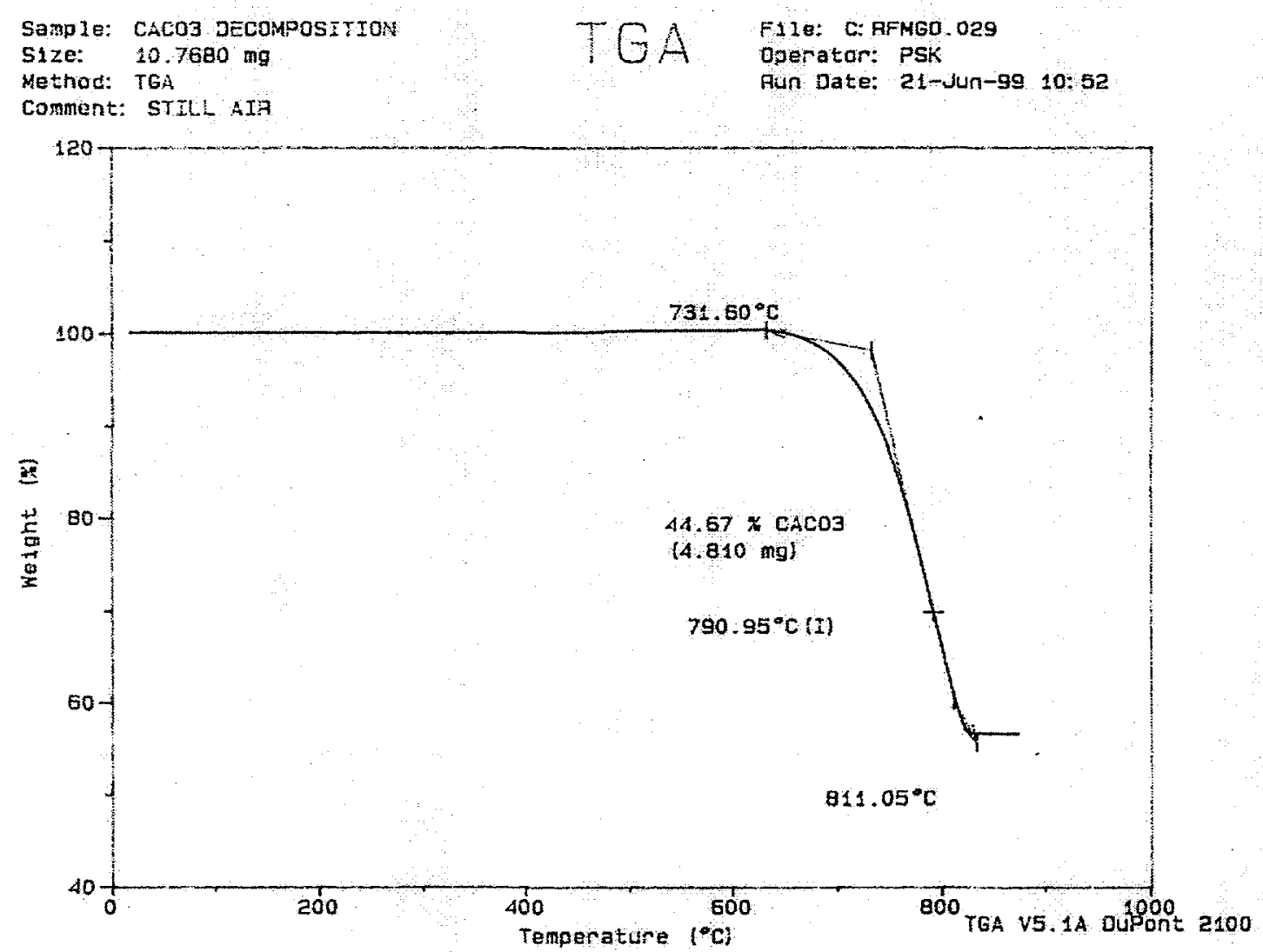

Figure 8 b. Decomposition of reagent grade $\mathrm{CaCO}_{3}$ occurs at $790^{\circ} \mathrm{C}$ for a $30^{\circ} \mathrm{C} /$ min heating rate. 
WSRC-TR-99-00275

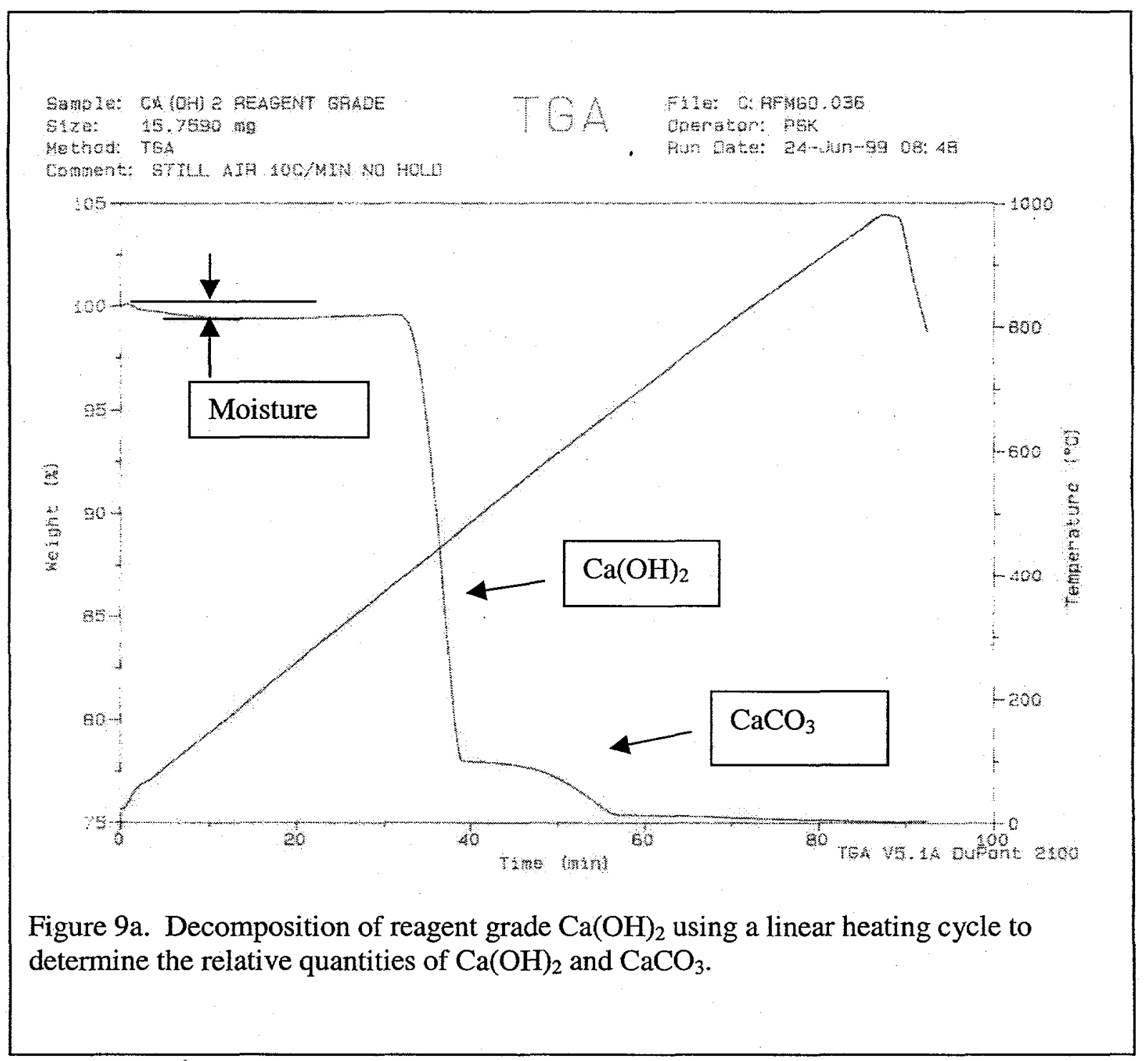


Sample: Ca (OH) 2 REAGENT GRADE

Size: $\quad 12.4300 \mathrm{mg}$

TOA FIIE: C: RFMGO.038

Method: TGA MULTI STEP

operator: PSK

comment: STILL AIP

Run Date: 24-Jun-99 17: 12

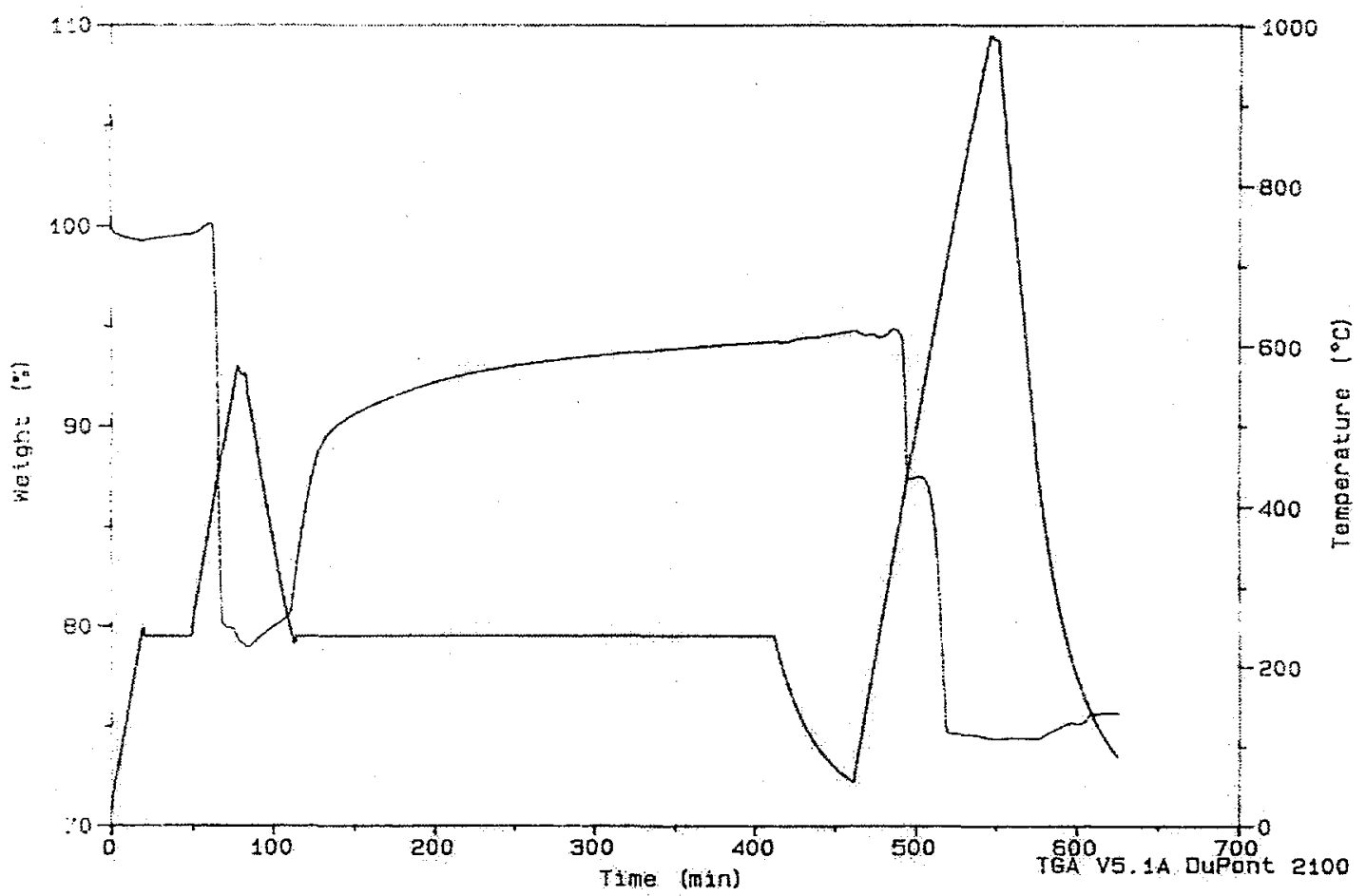

Figure $9 \mathrm{~b}$. Decomposition of reagent grade $\mathrm{Ca}(\mathrm{OH})_{2}$ using a complex heating cycle to decompose the hydroxide then cool to determine re-adsorption product(s). 


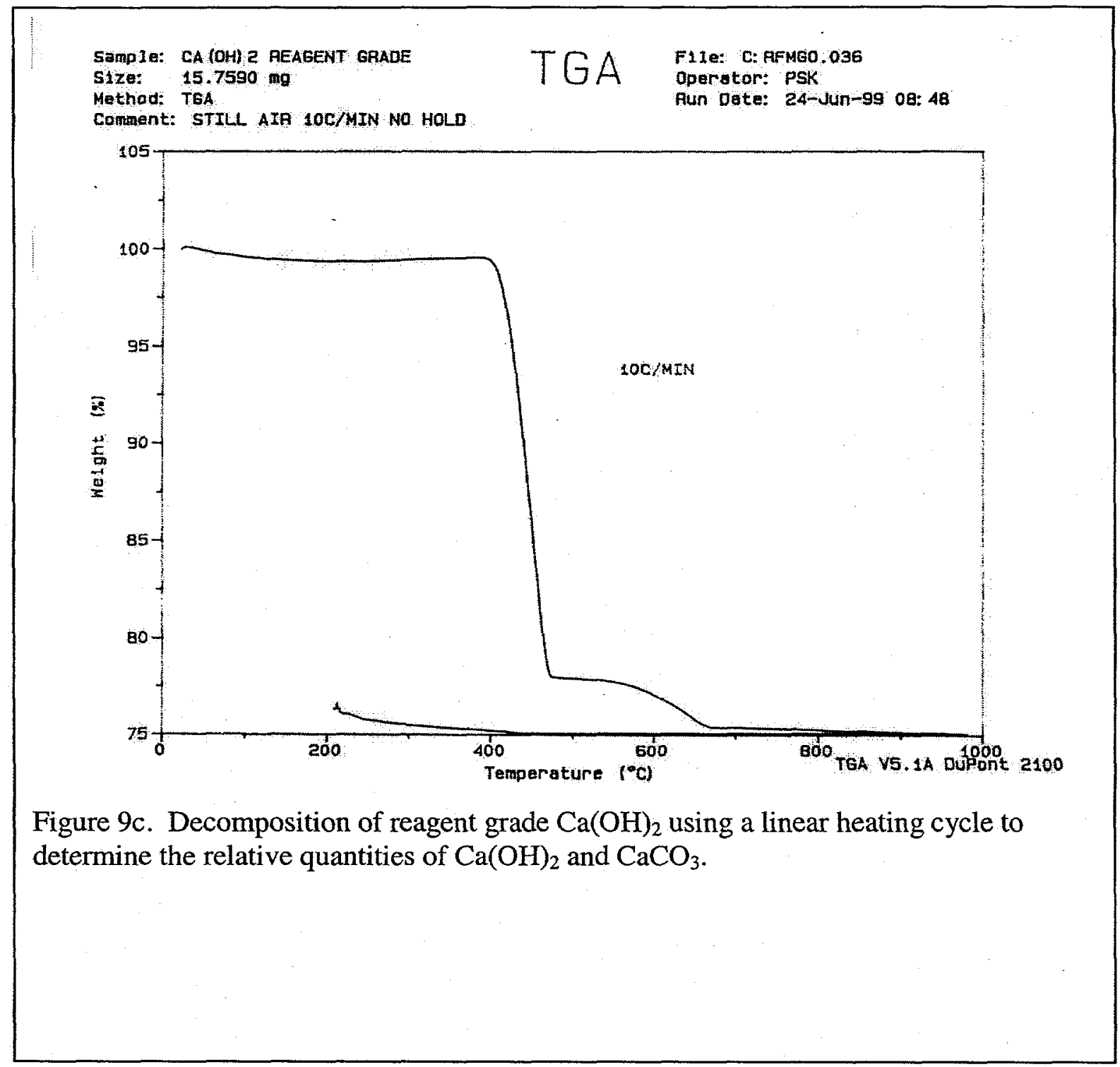


WSRC-TR-99-00275

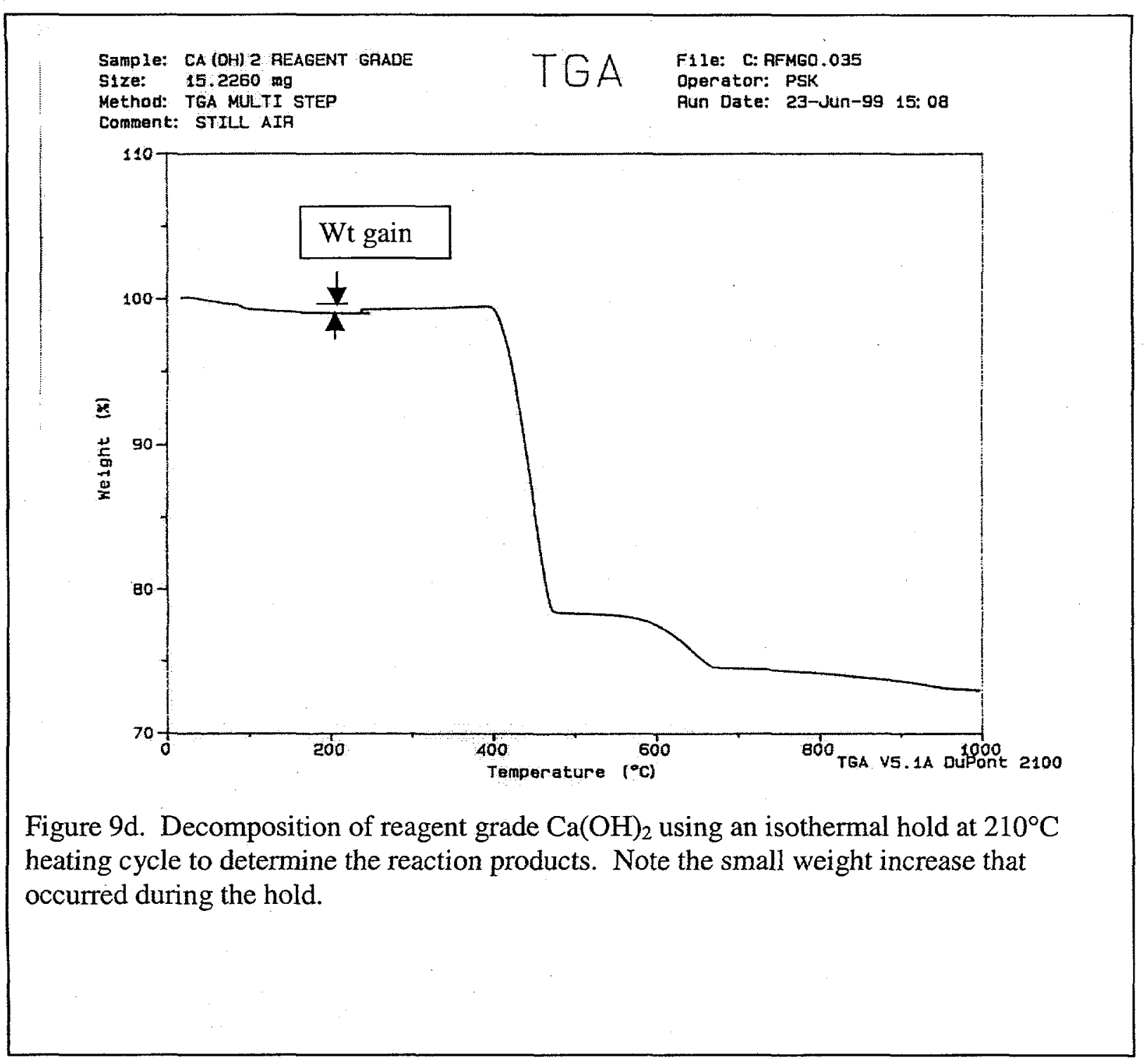


WSRC-TR-99-00275

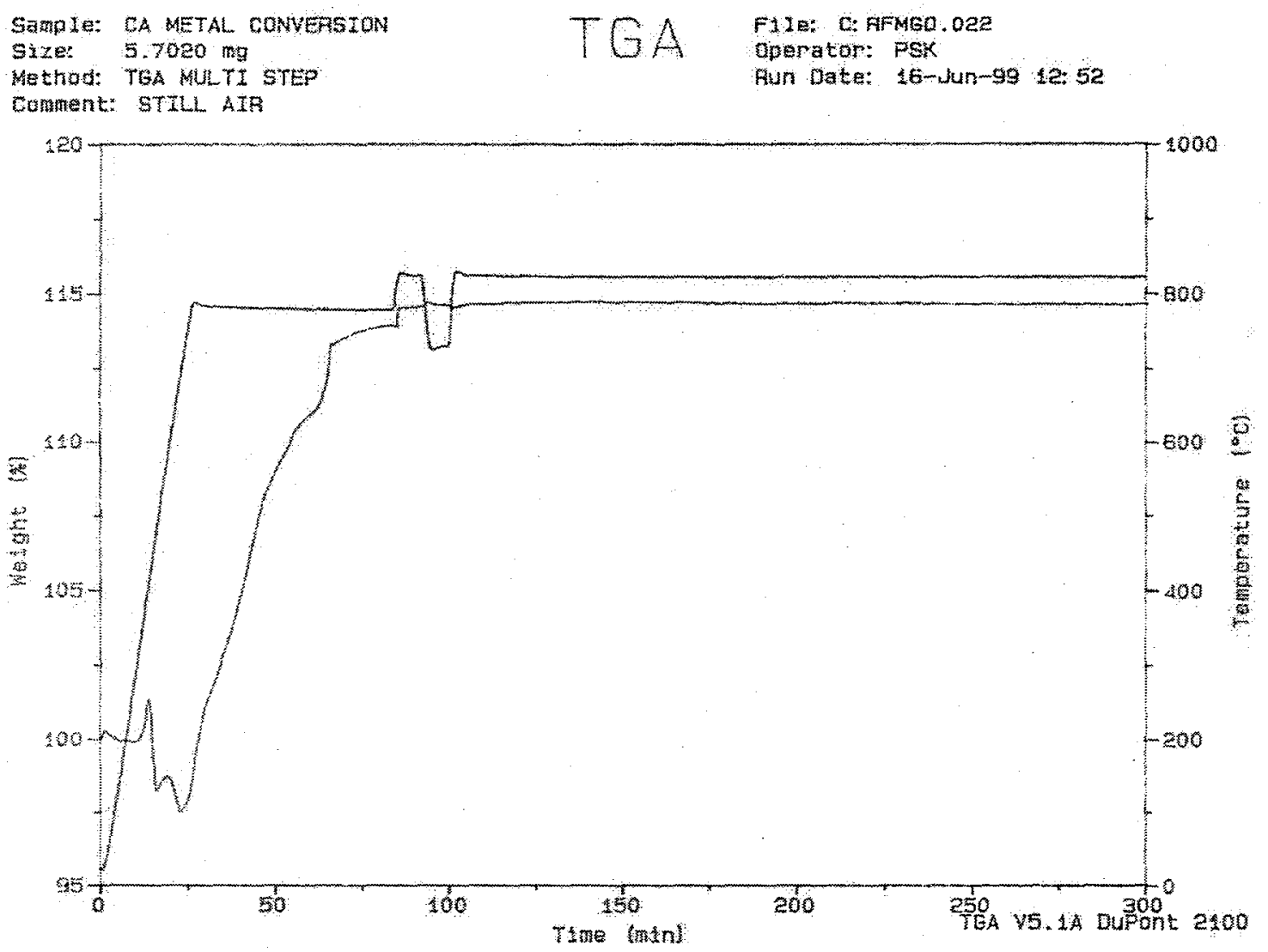

Figure 10a. Fine calcium metal that was oxidized at $800^{\circ} \mathrm{C}$ until no appreciable weight gain was apparent. 




Figure 10b. Thermal exposure of $\mathrm{Ca}(\mathrm{OH})_{2}$ that was formed by oxidizing the Ca metal exhibited in Figure 10a. The sample was exposed to laboratory air for four days. The $\mathrm{CaCO}_{3}$ peak is more prominent than that observed for reagent grade $\mathrm{Ca}(\mathrm{OH})_{2}$. 


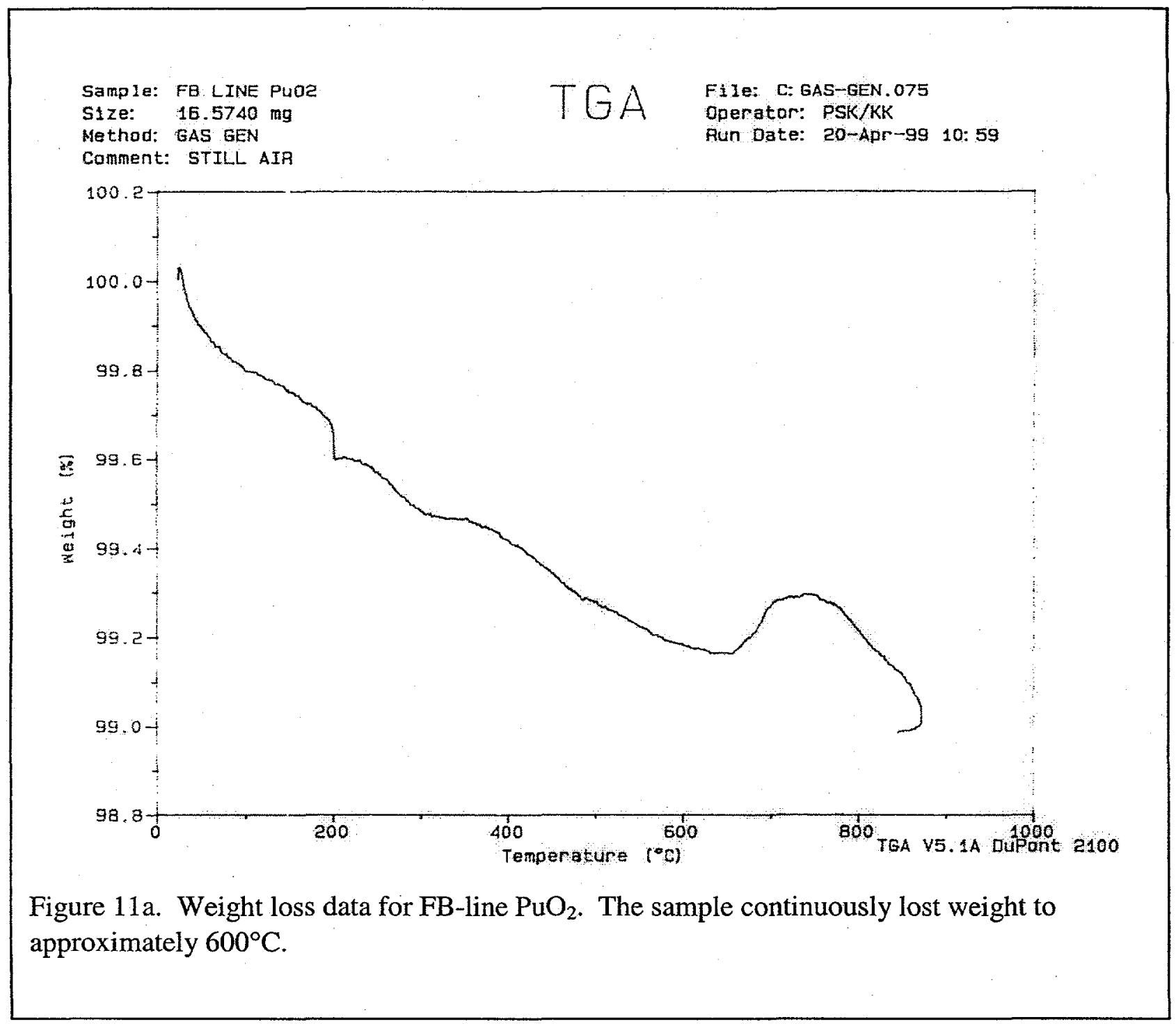




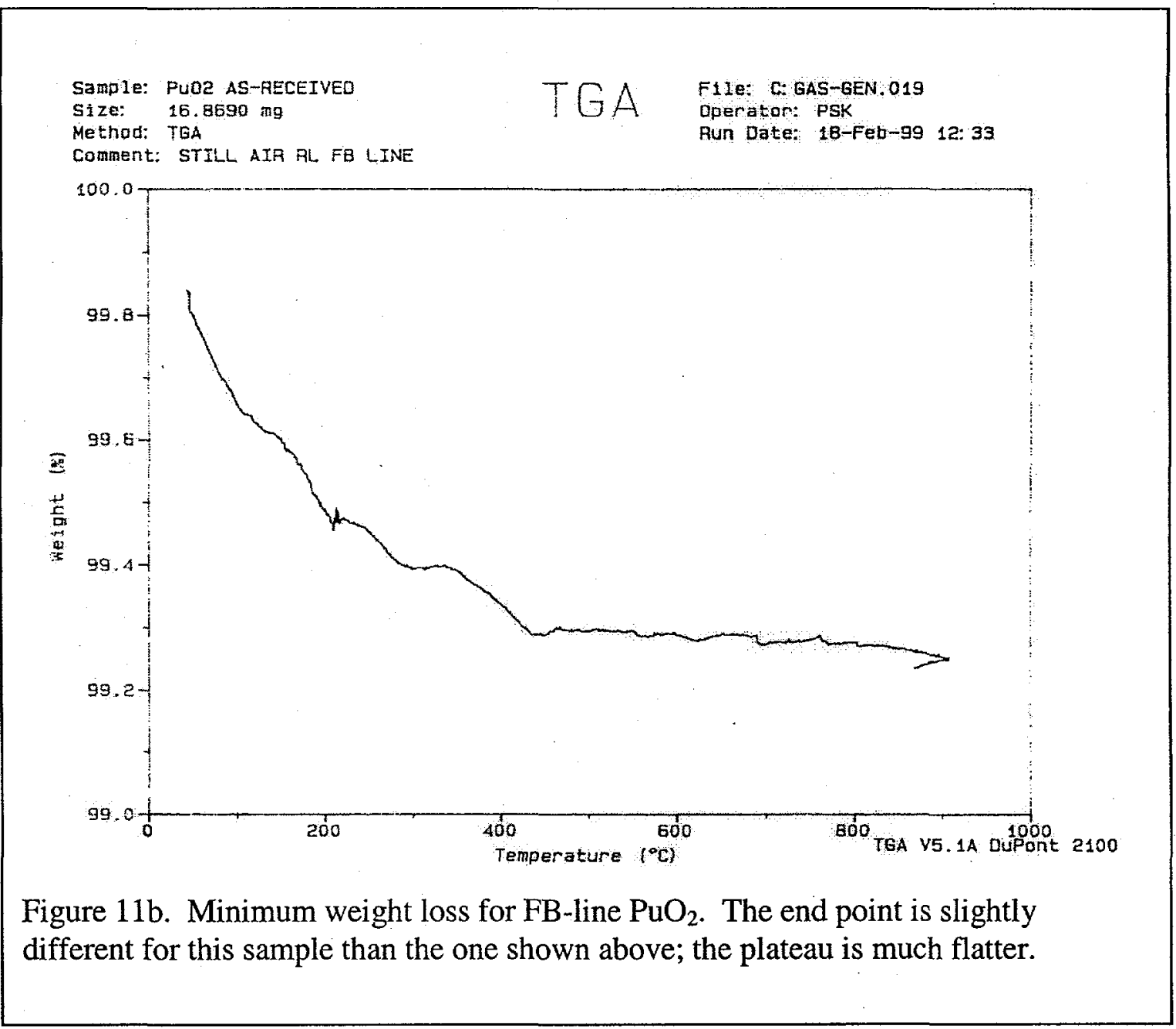




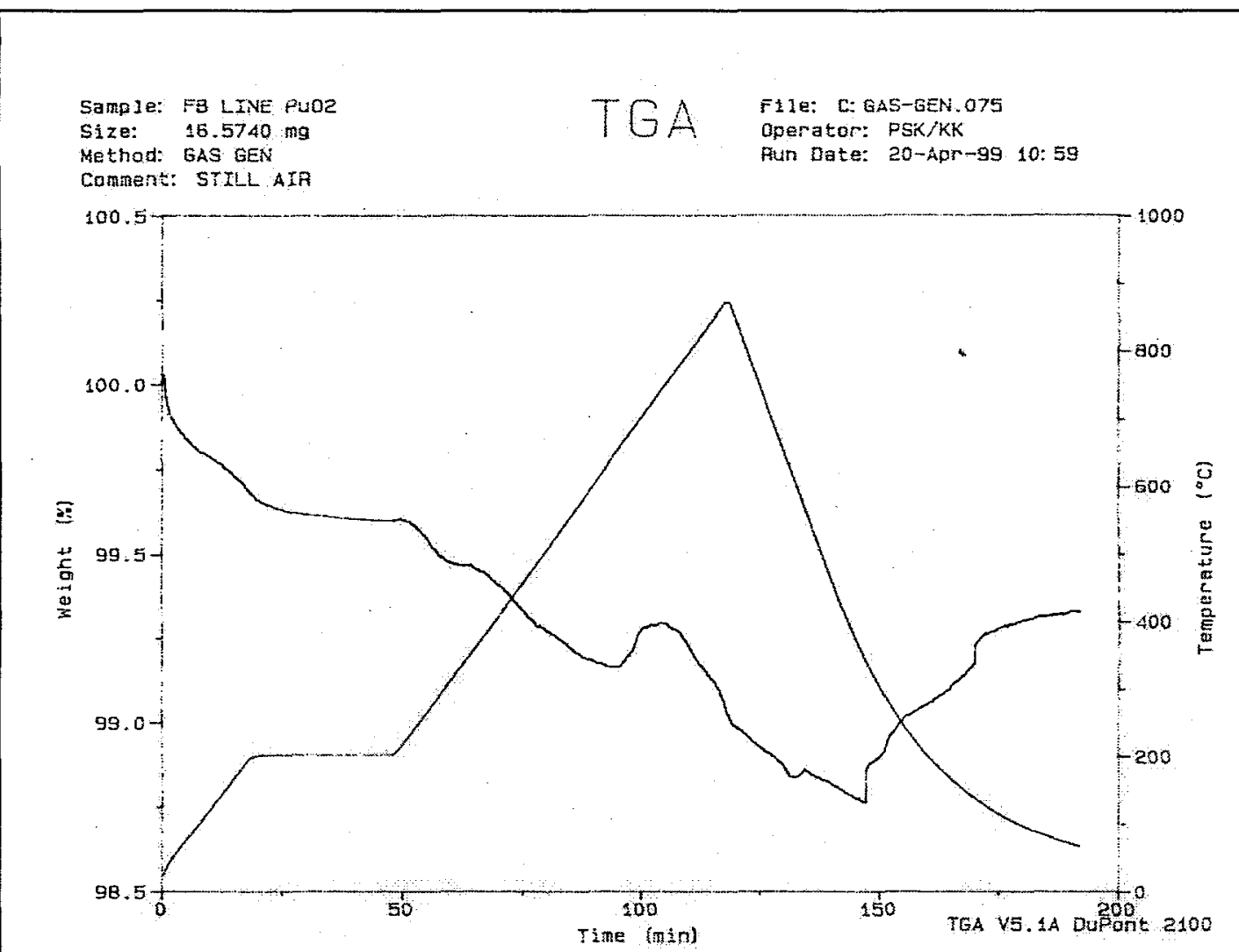

Figure 12a. A plot of the weight change vs. time for the sample shown in Figure 11a. The slope at $210^{\circ} \mathrm{C}$ after 30 minutes is nearly zero. 
WSRC-TR-99-00275

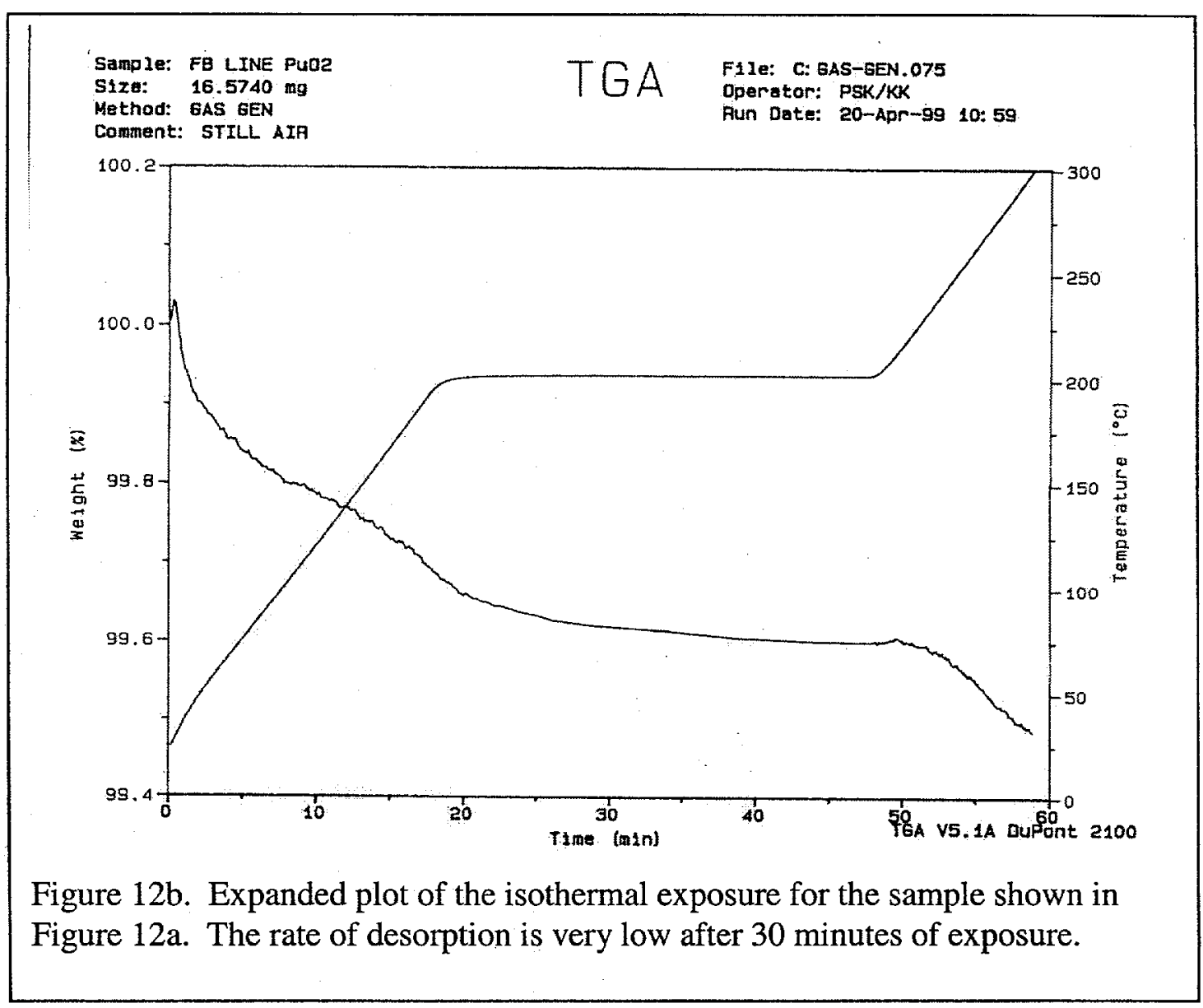




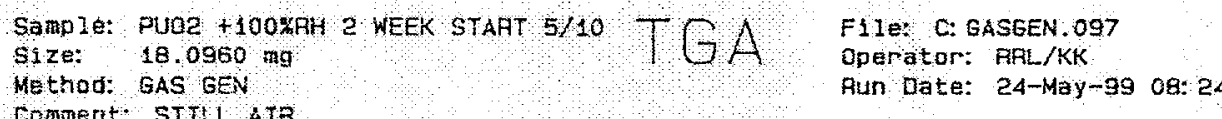

Cominert: STILL ATR

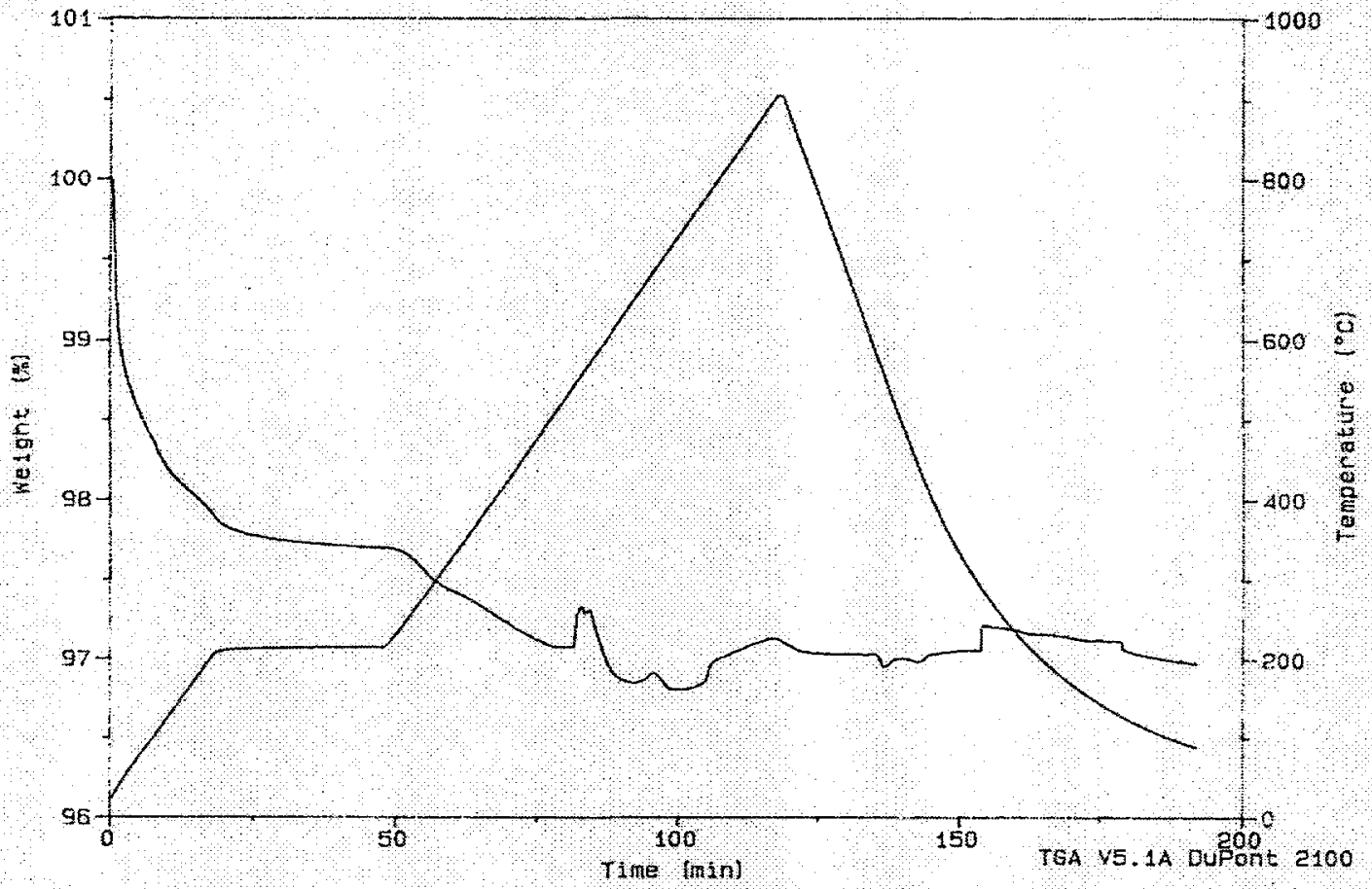

Figure 12c. A plot of the weight change vs. time, the slope at $210^{\circ} \mathrm{C}$ after 30 minutes is nearly zero but the total moisture content is higher than $12 \mathrm{a}$. 
WSRC-TR-99-00275

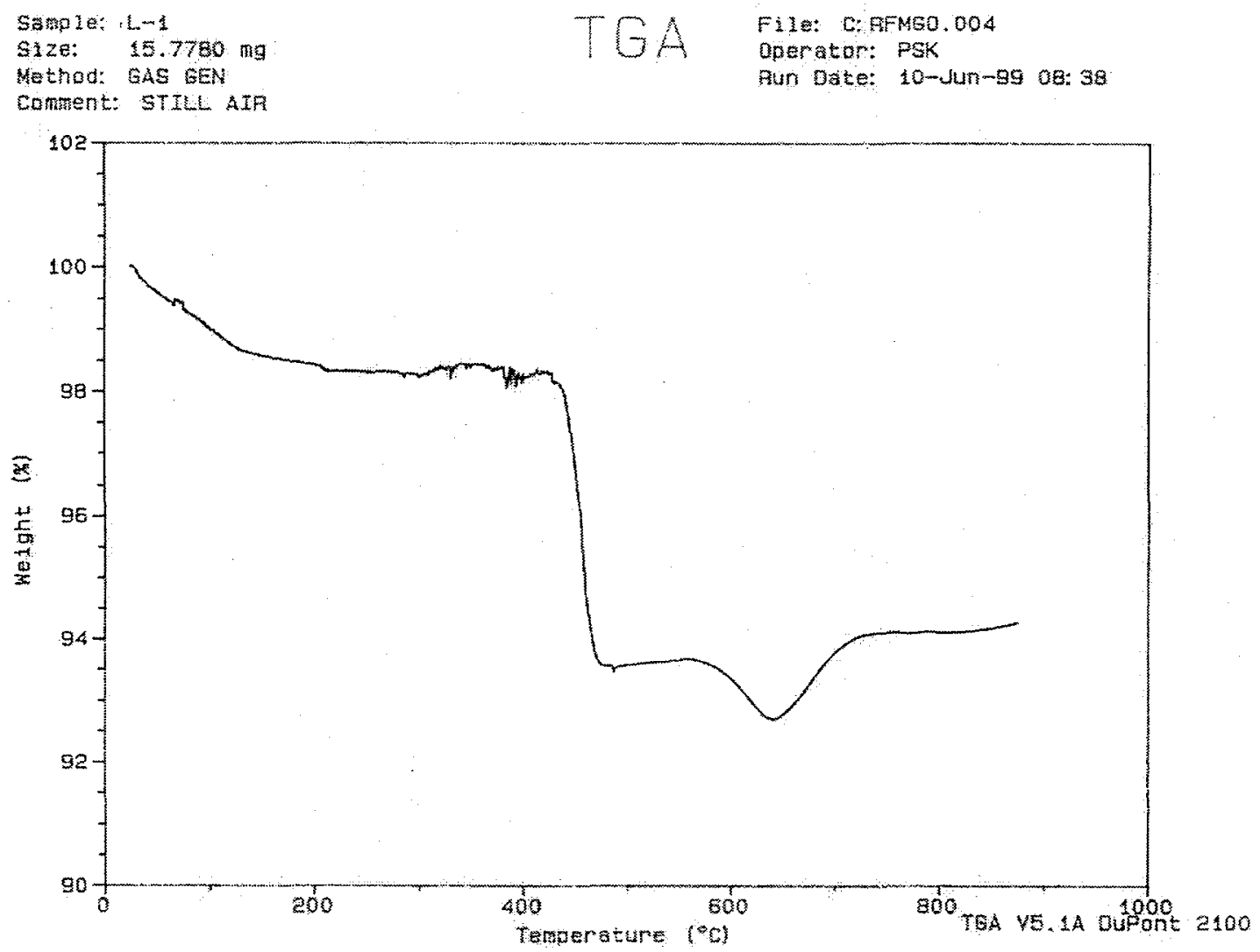

Figure 13a. Thermal exposure and related weight changes for sample L-1. 
WSRC-TR-99-00275

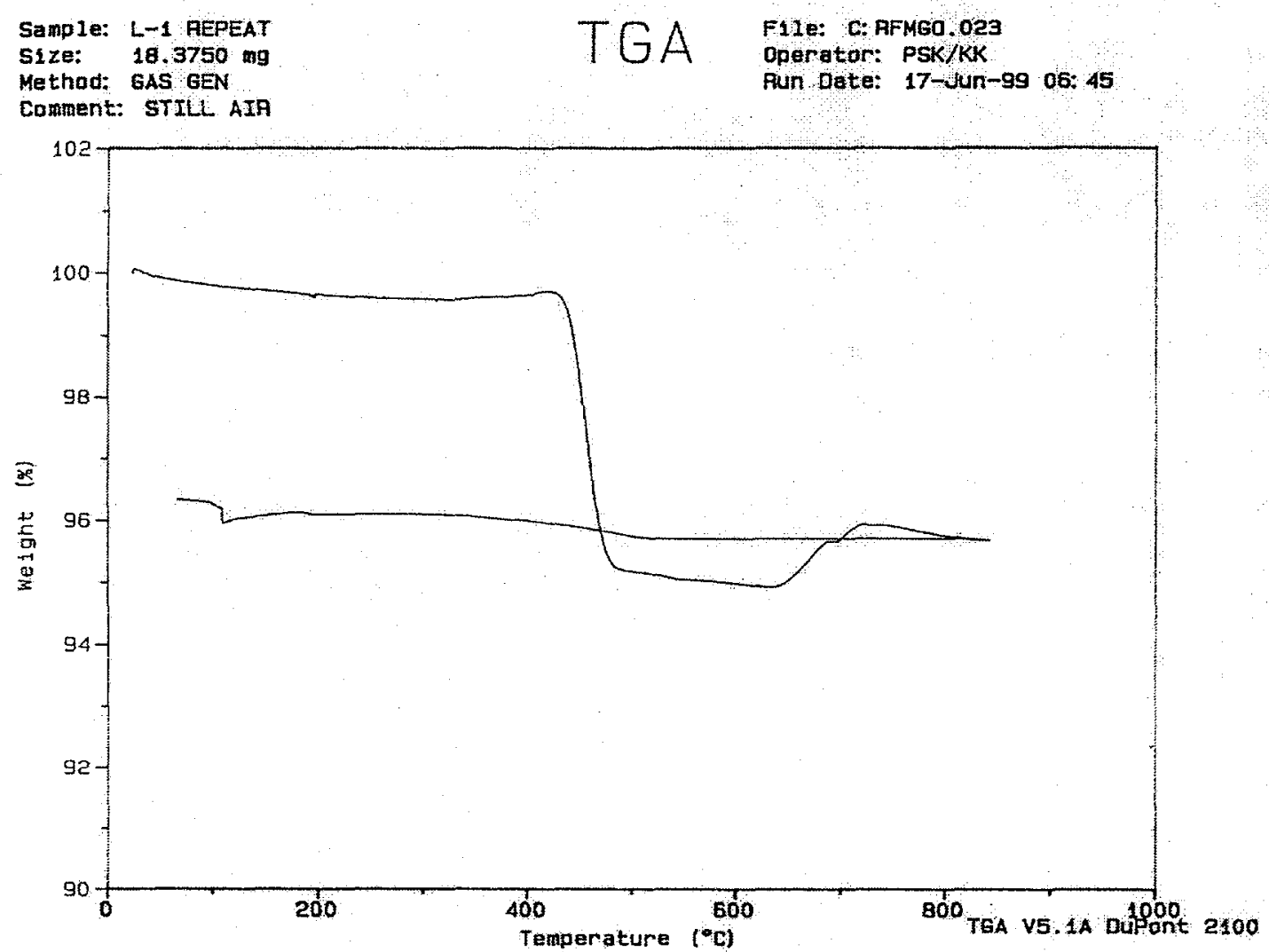

Figure 13b. Thermal exposure and related weight changes for sample L-1 repeat. 
WSRC-TR-99-00275

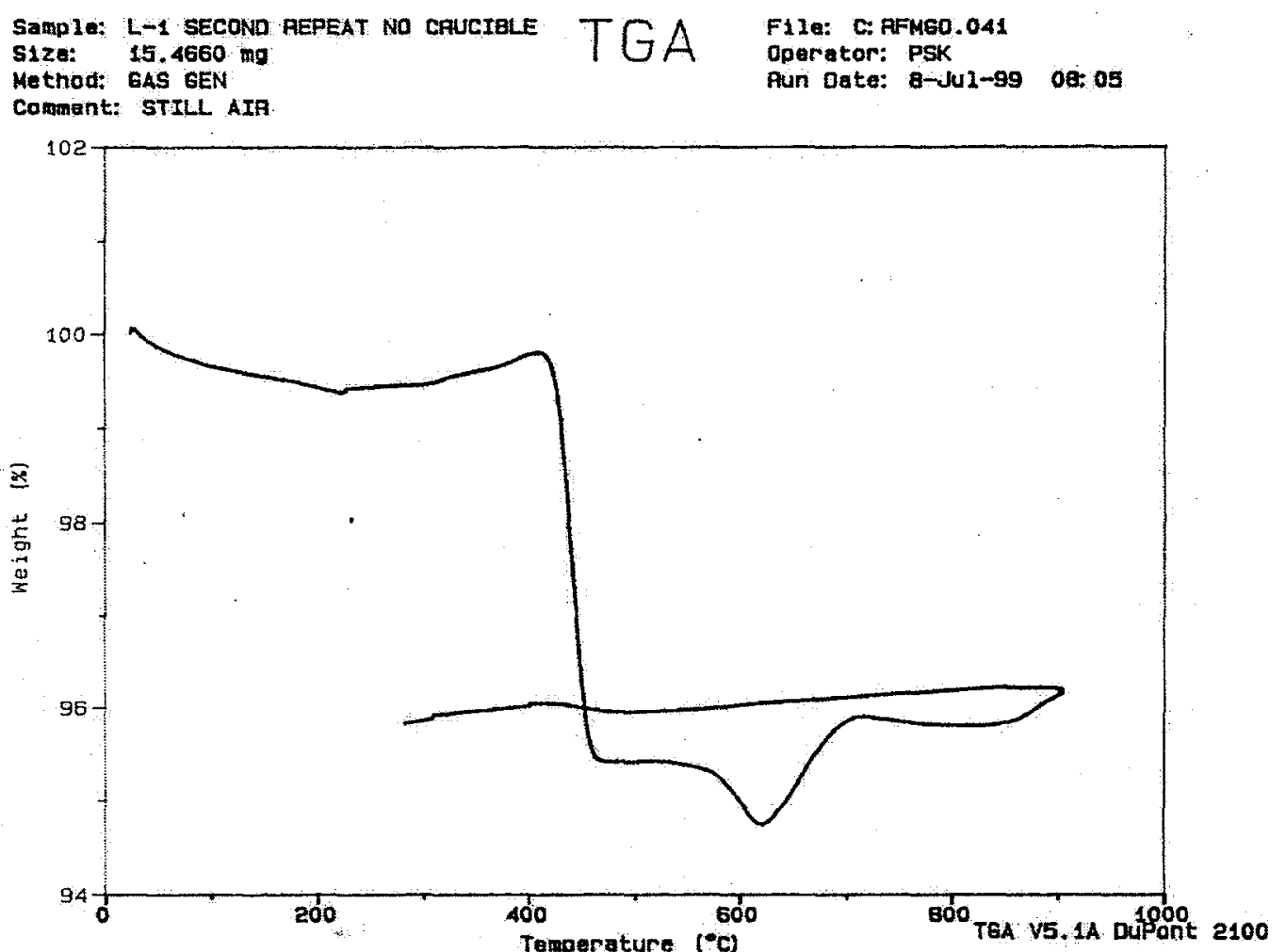

Figure 13c. Thermal exposure and related weight changes for sample L-1 second repeat. 


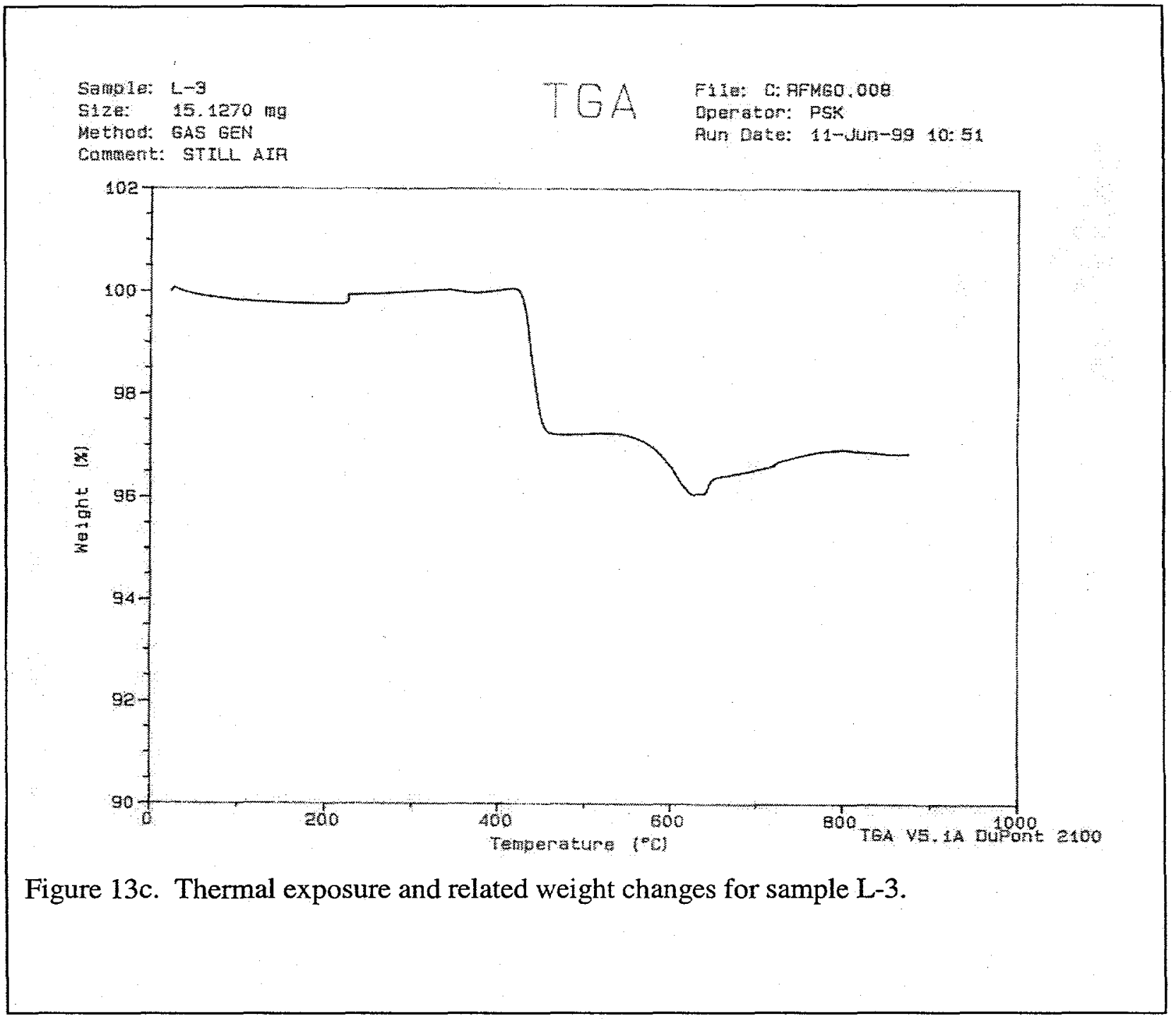


WSRC-TR-99-00275

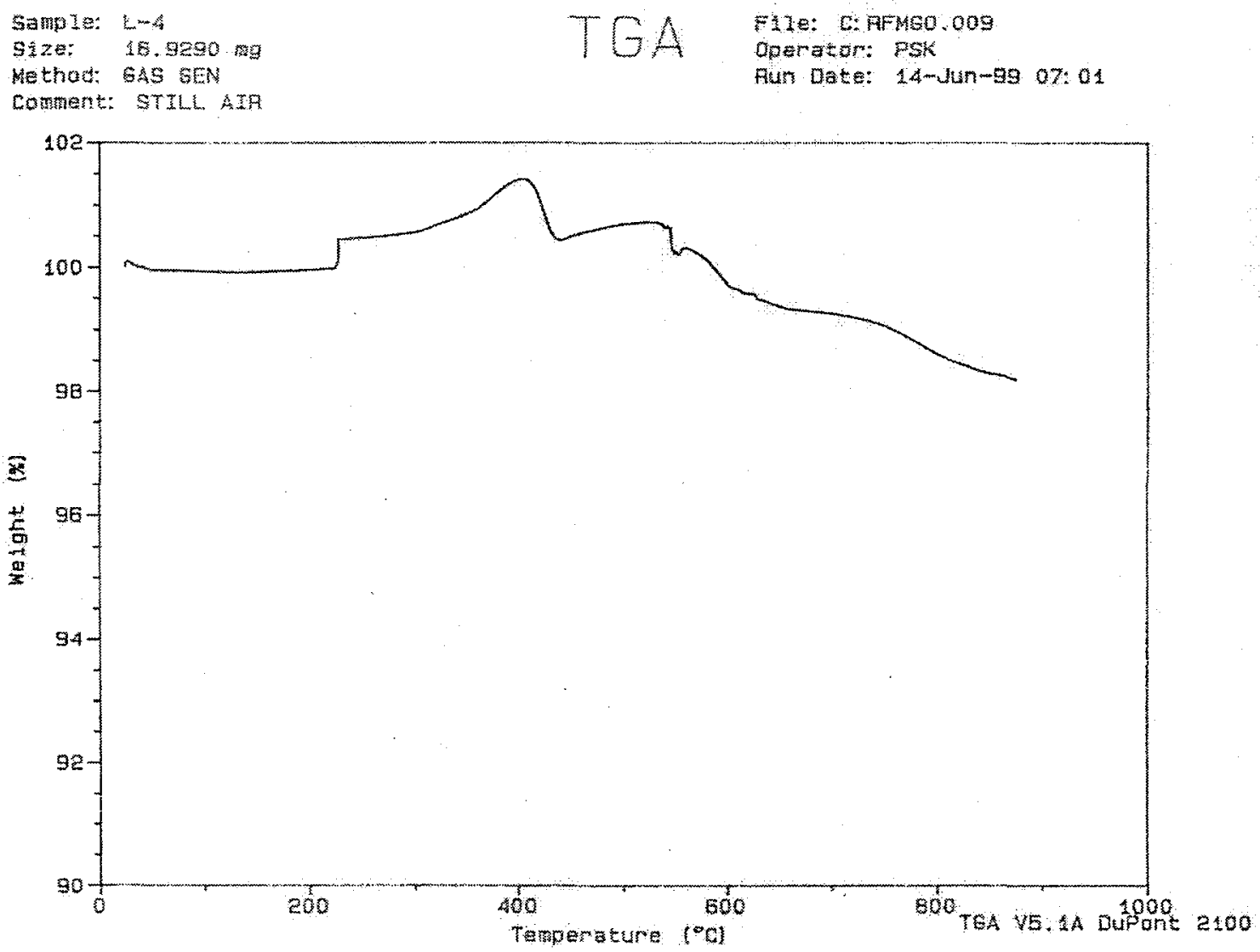

Figure 13d. Thermal exposure and related weight changes for sample L-4. 
WSRC-TR-99-00275

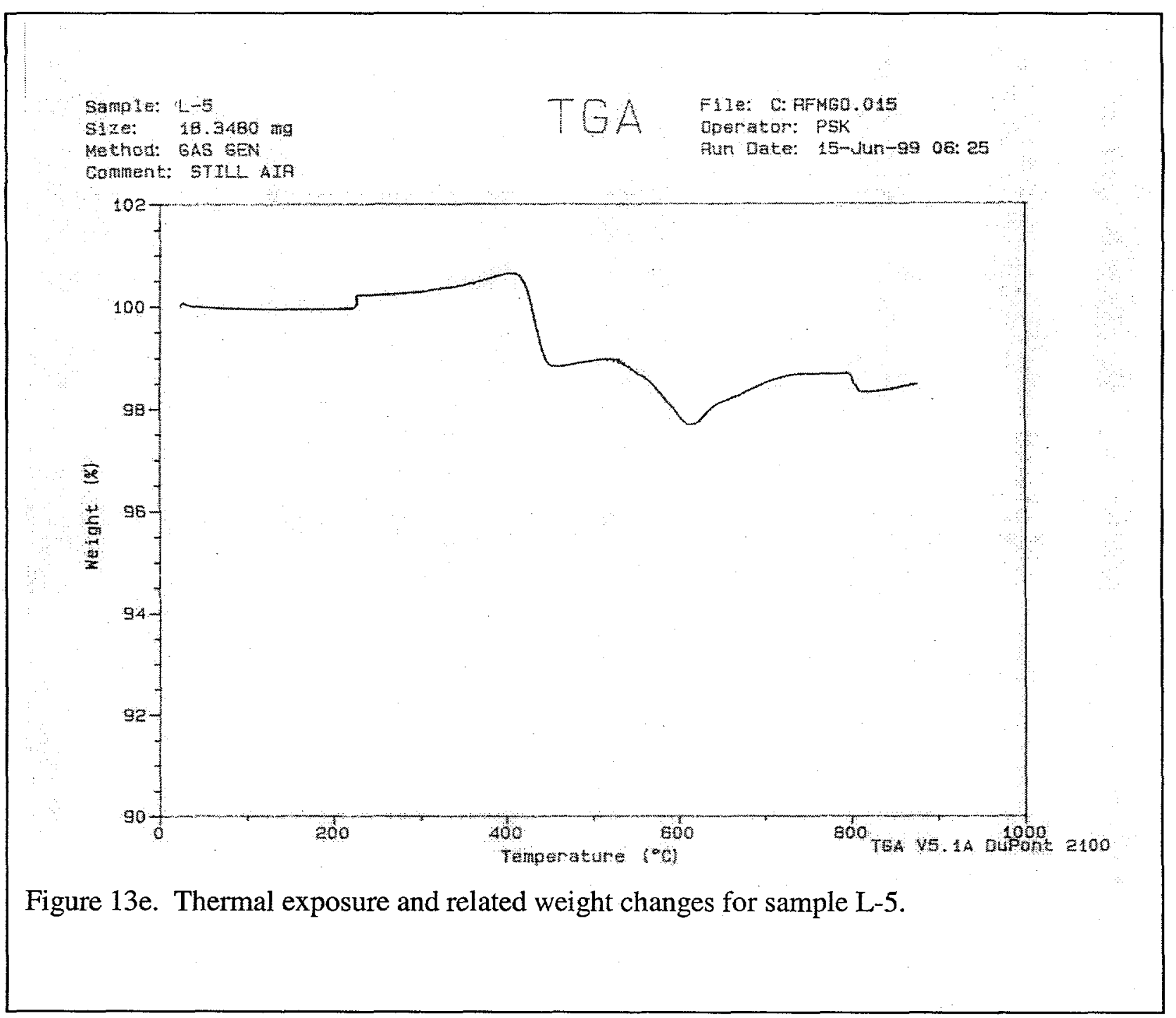




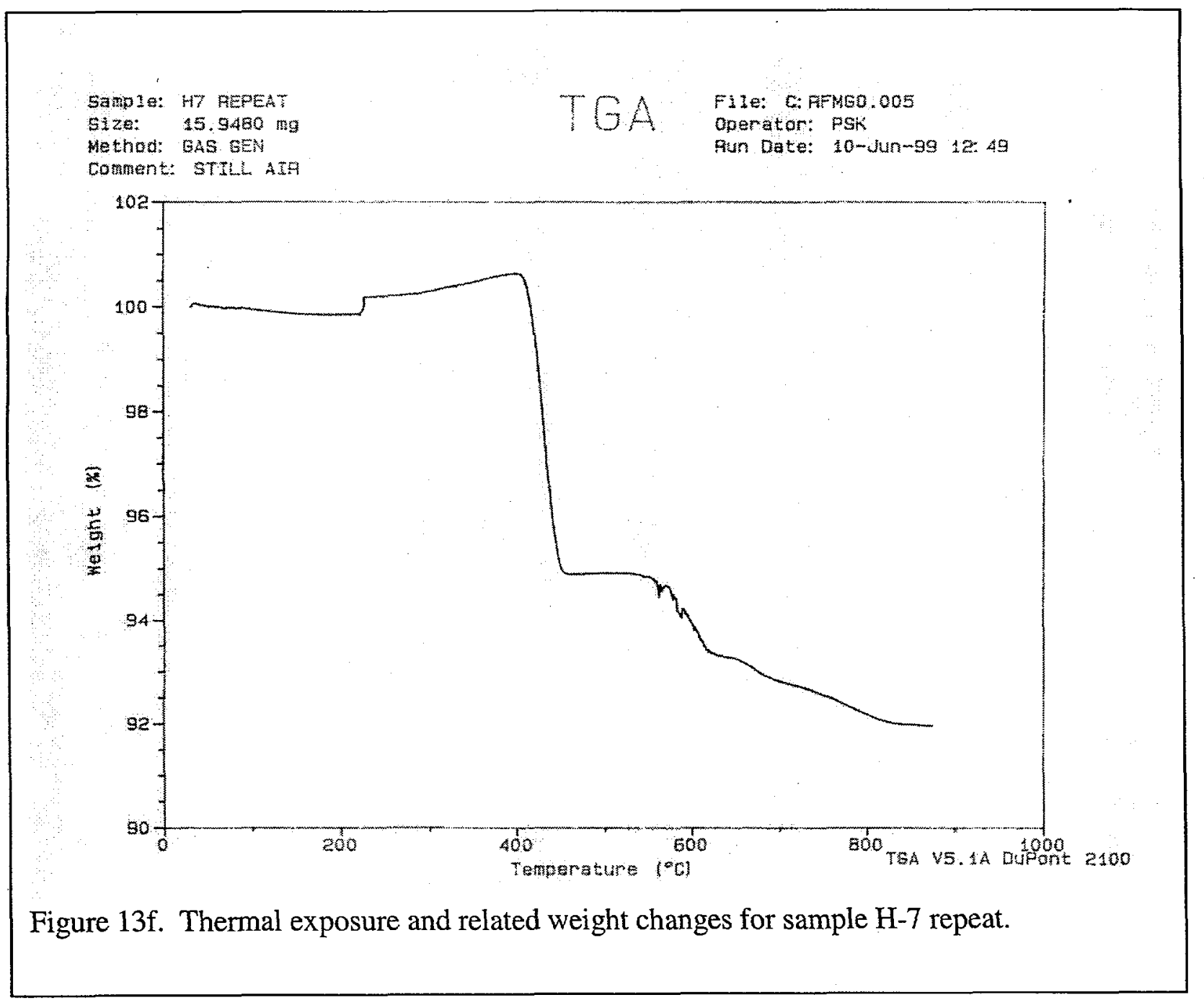


WSRC-TR-99-00275

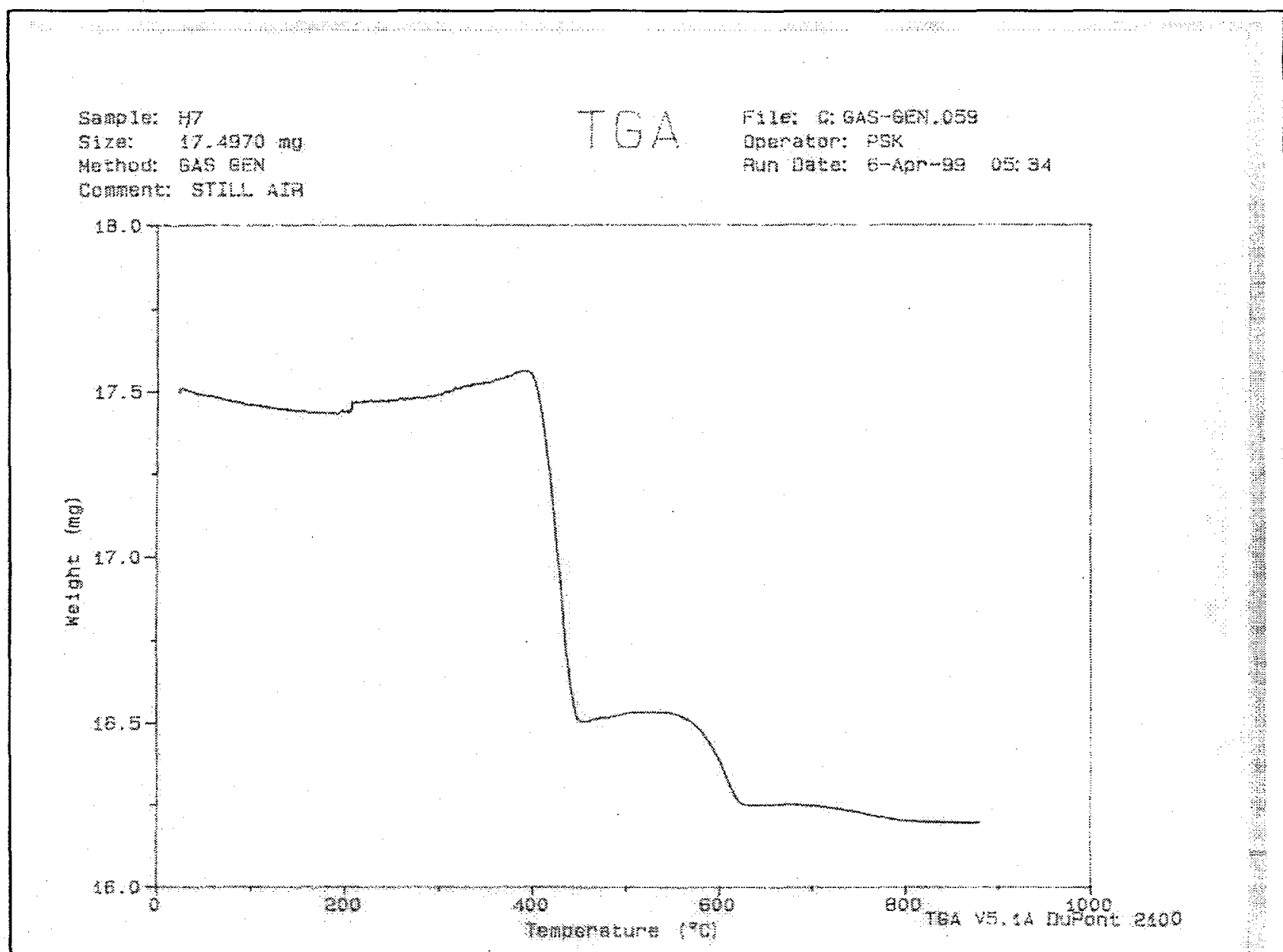

Figure 13g. Thermal exposure and related weight change for the first run of $\mathrm{H}-7$ for comparison to the repeat sample. Note the weight gain that occurred during the isothermal hold at $\sim 210^{\circ} \mathrm{C}$. 
WSRC-TR-99-00275




WSRC-TR-99-00275

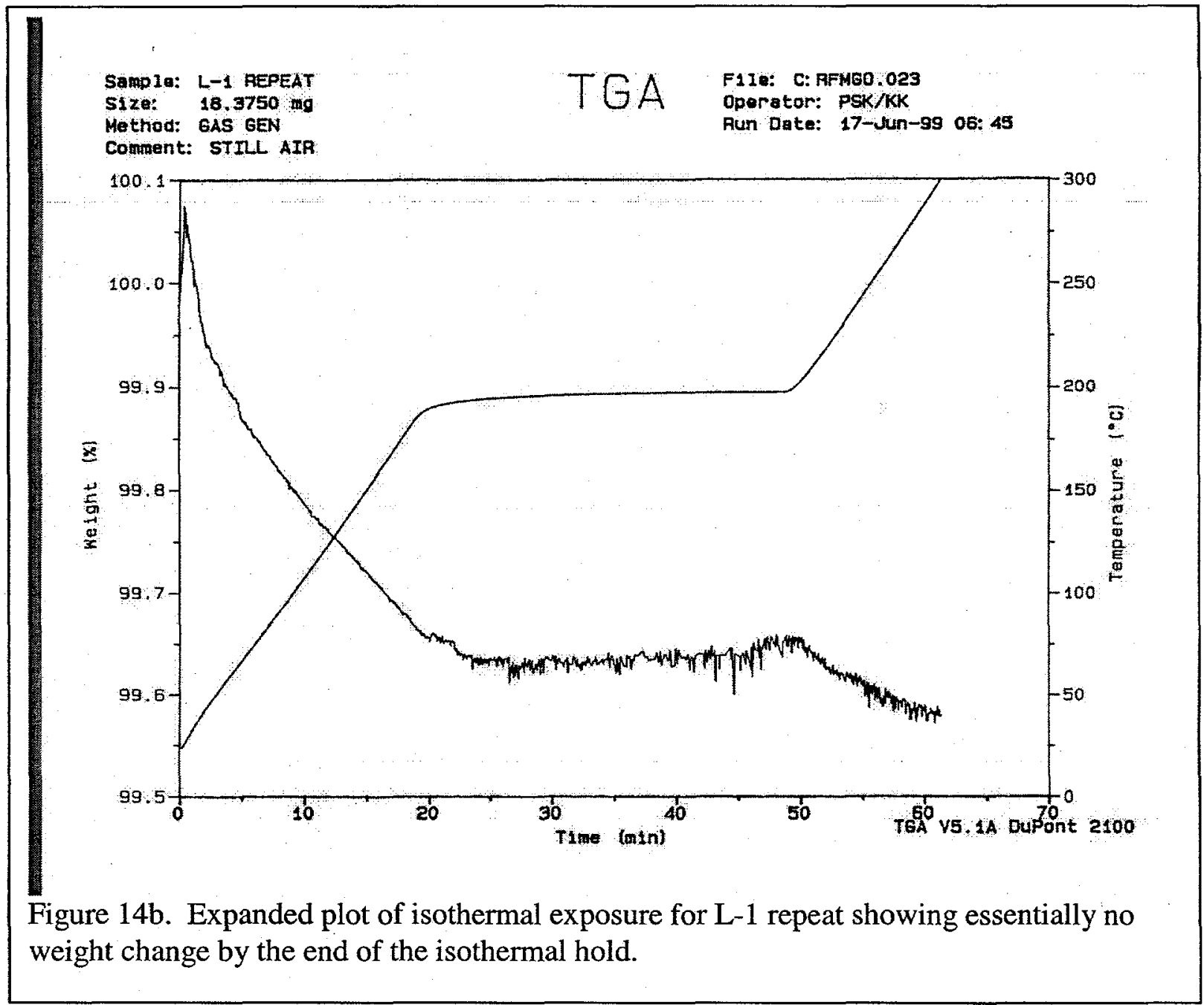




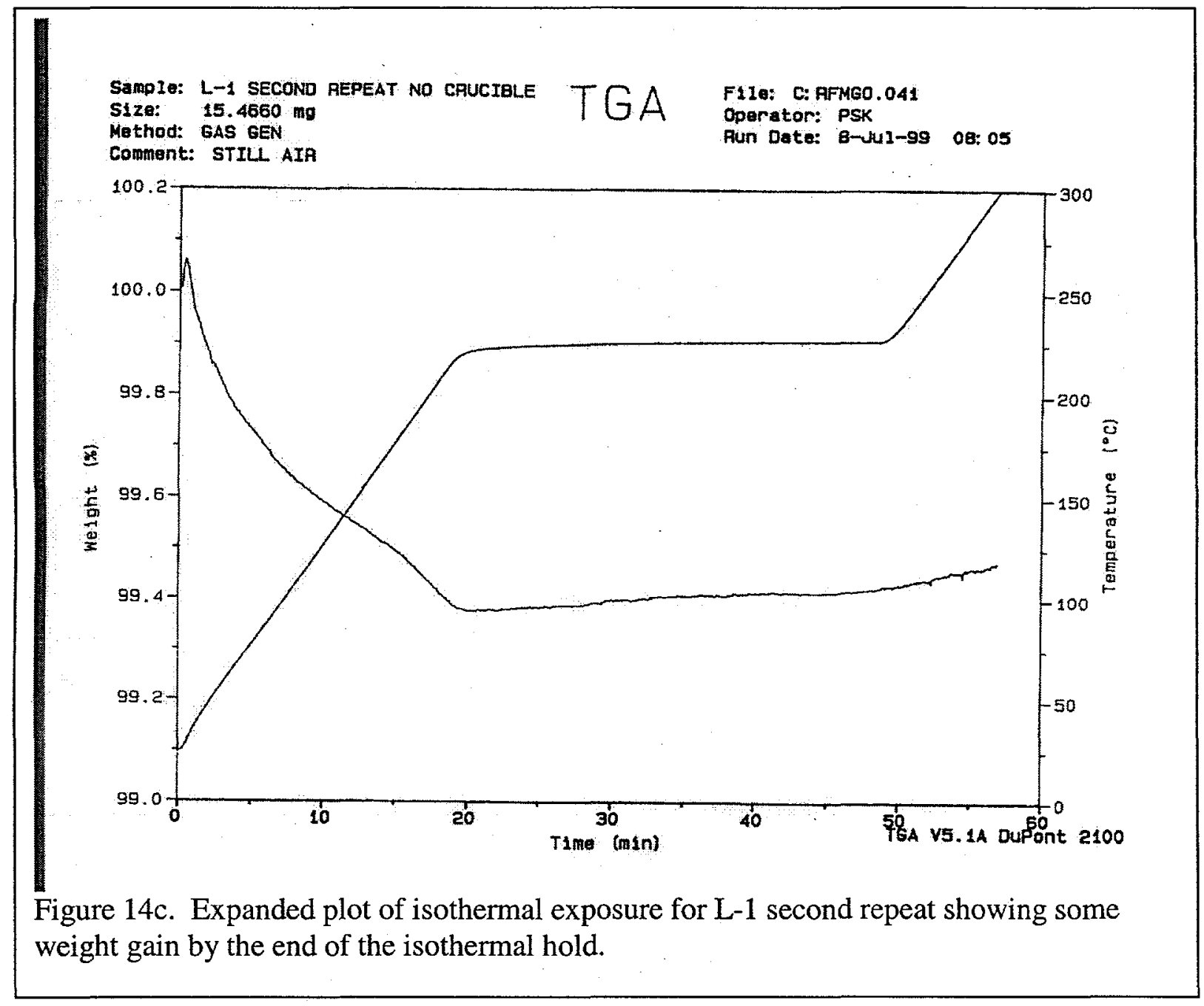




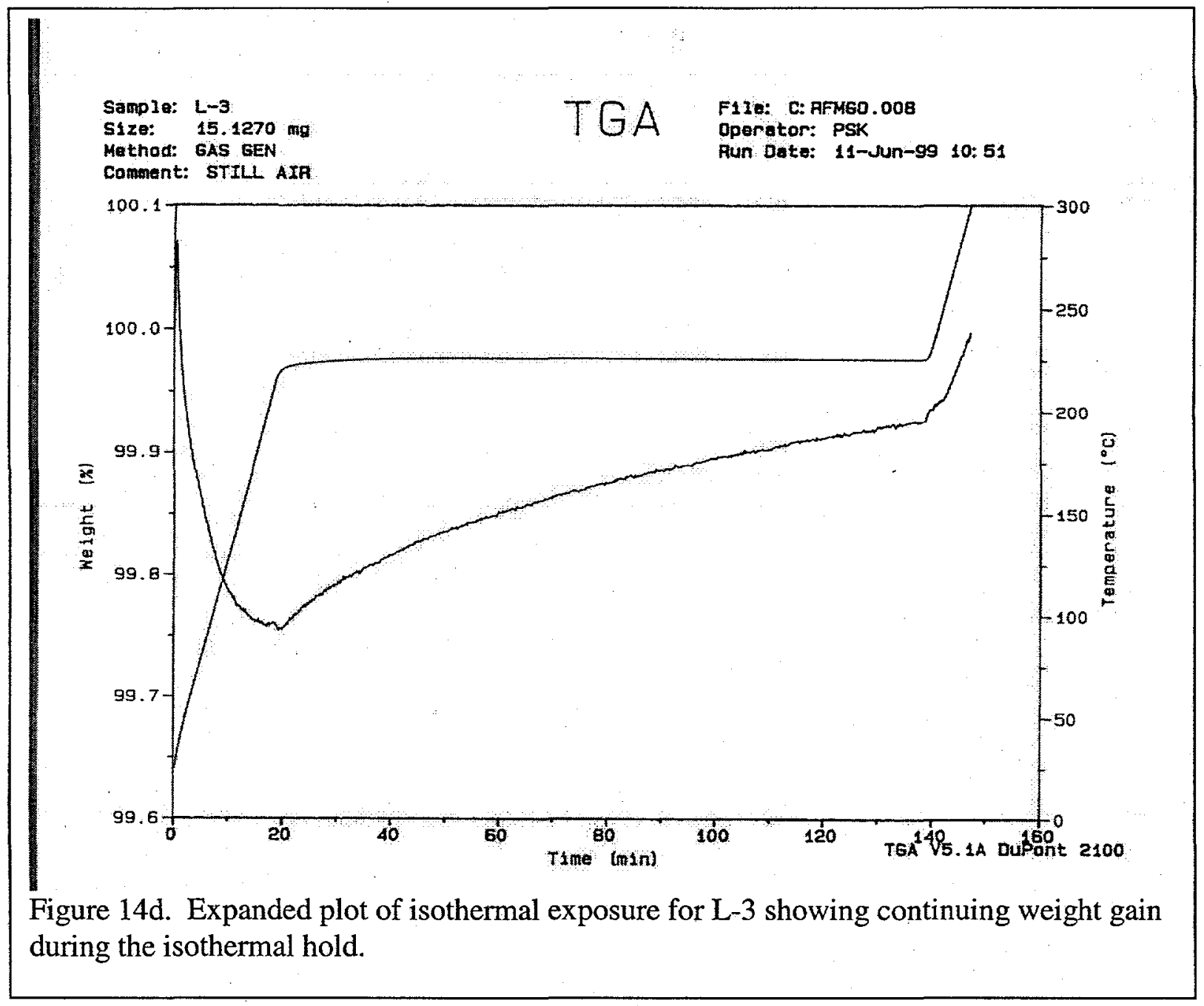







WSRC-TR-99-00275

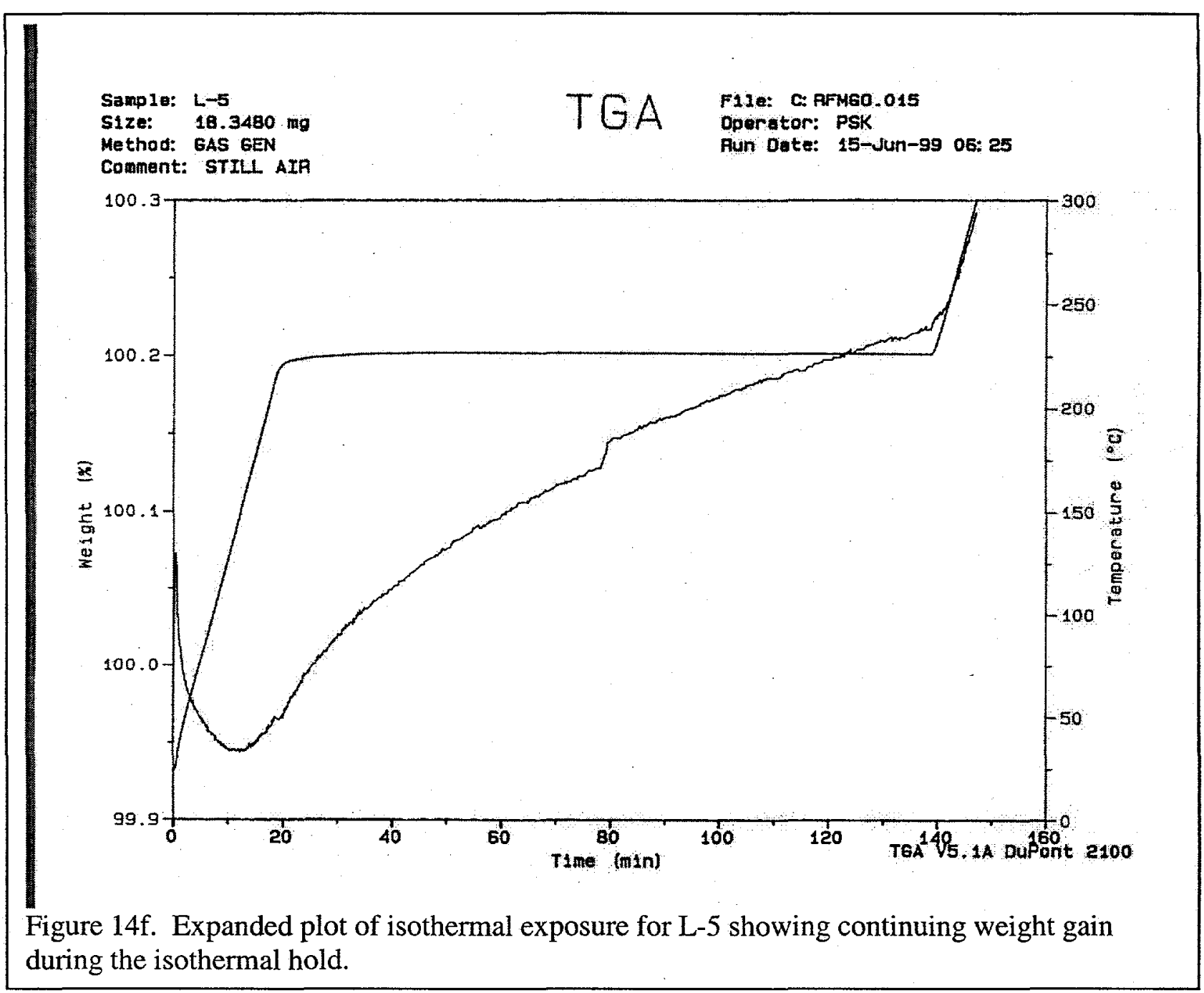


WSRC-TR-99-00275

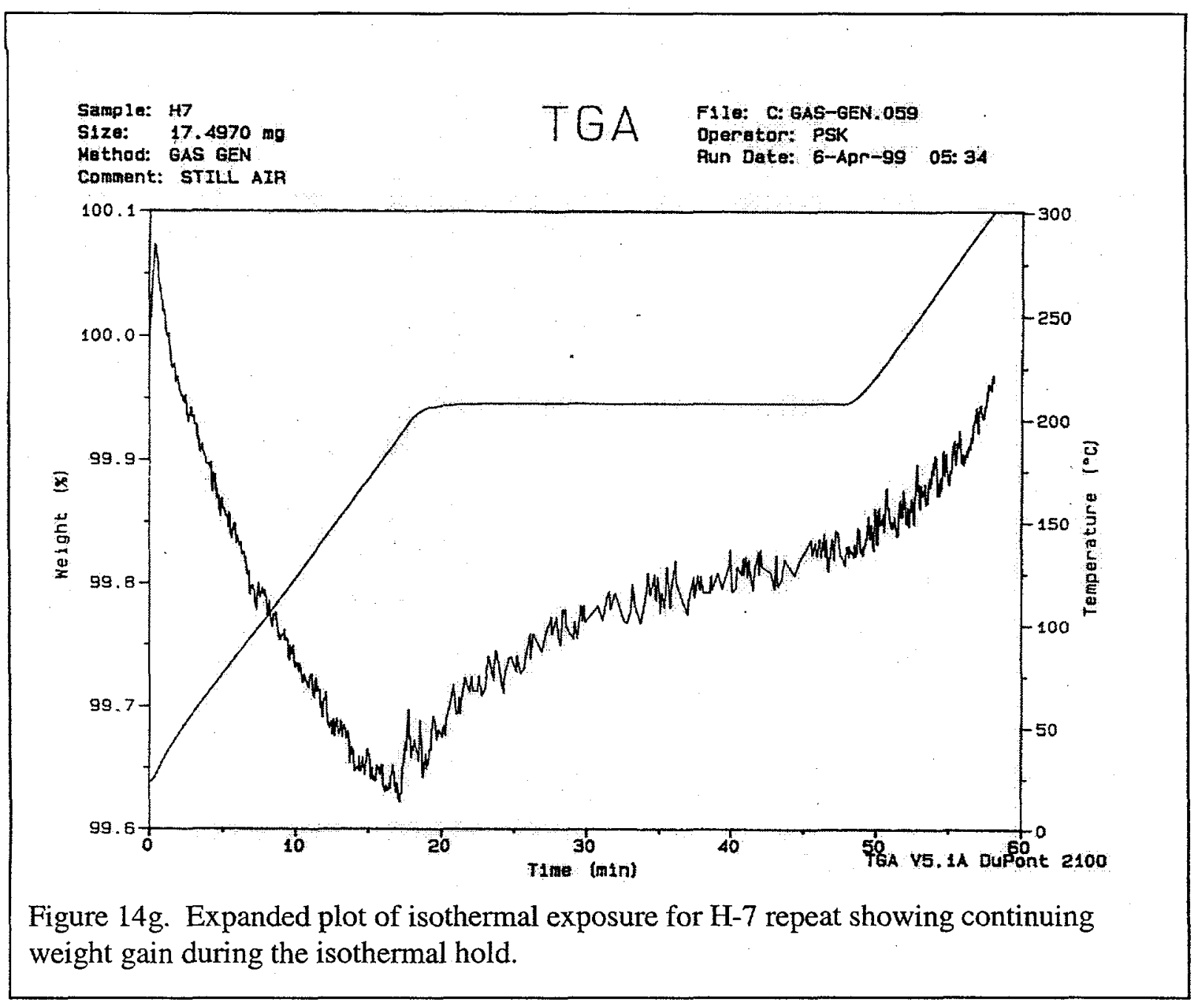


WSRC-TR-99-00275

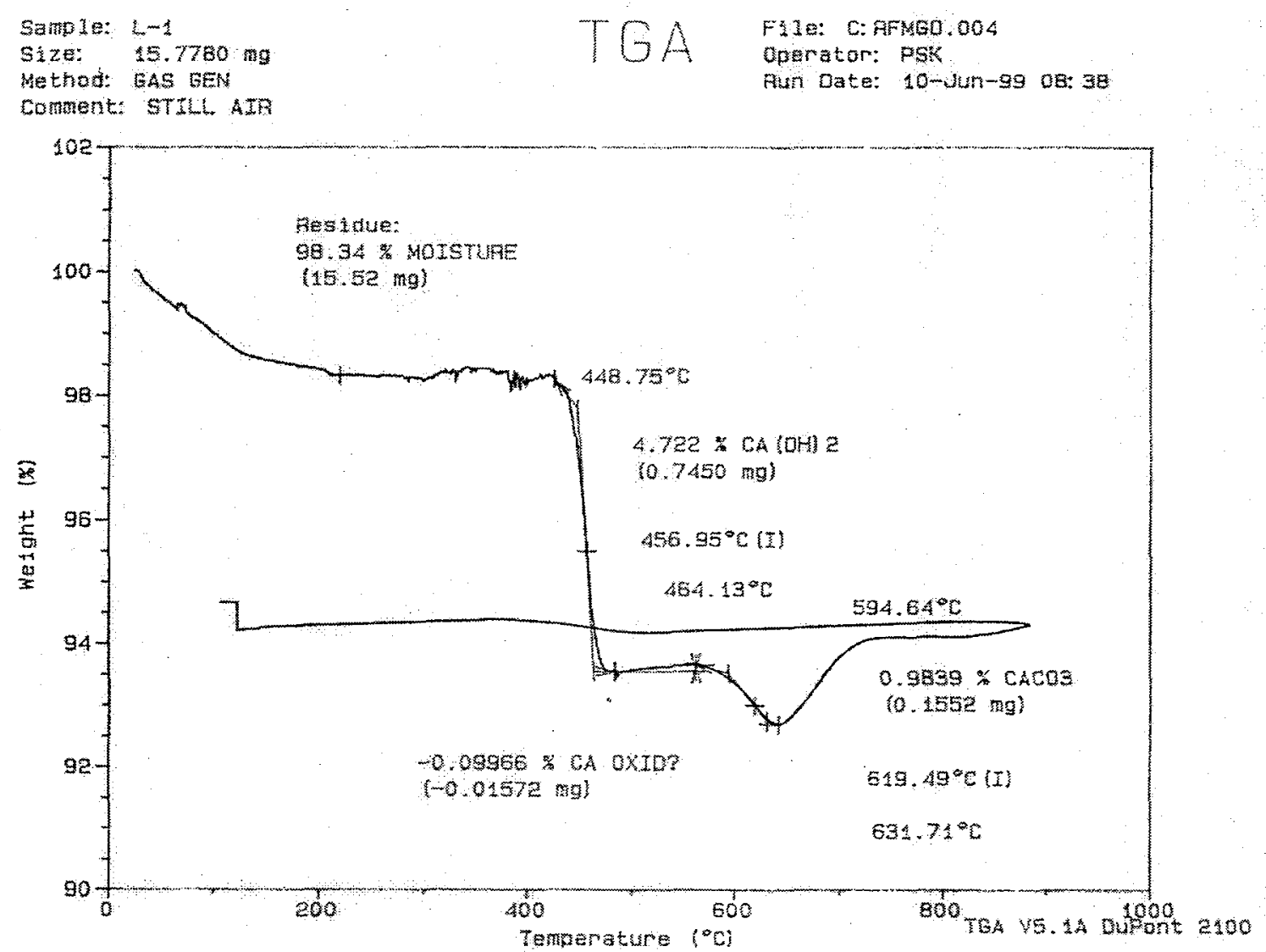

Figure 15a. Annotated plot for sample L-1 showing how the different weight changes were determined. 


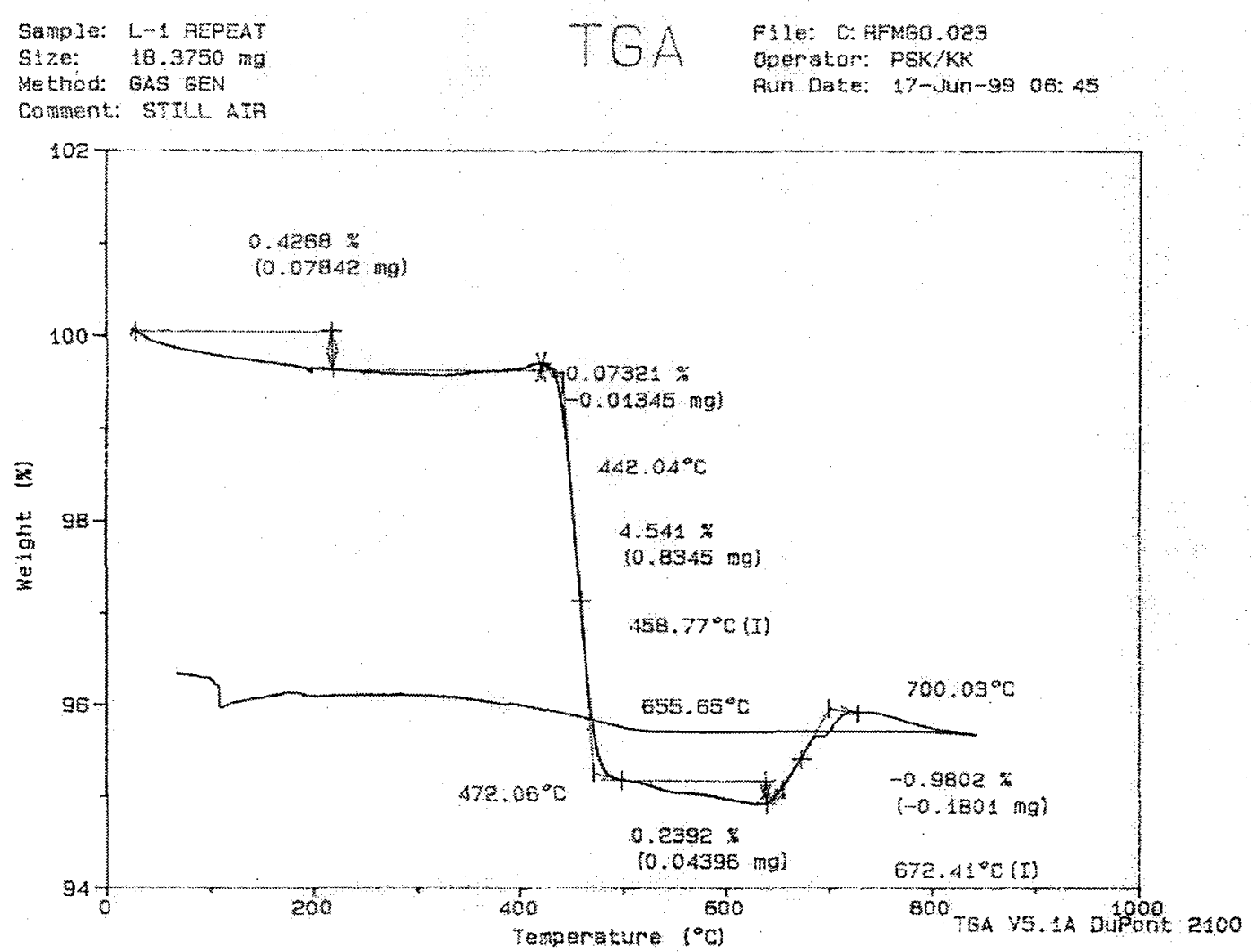

Figure 15b. Annotated plot for the repeat of sample L-1. 



Figure 16. Expanded plot of sample L-3 showing the presence of $\mathrm{Mg}(\mathrm{OH})_{2}$ by the weight change at $360^{\circ} \mathrm{C}$.

Figure A1. A scan from an empty pan exhibits the thermal buoyancy and electronics heating, although there is some lag initially. 
WSRC-TR-99-00275

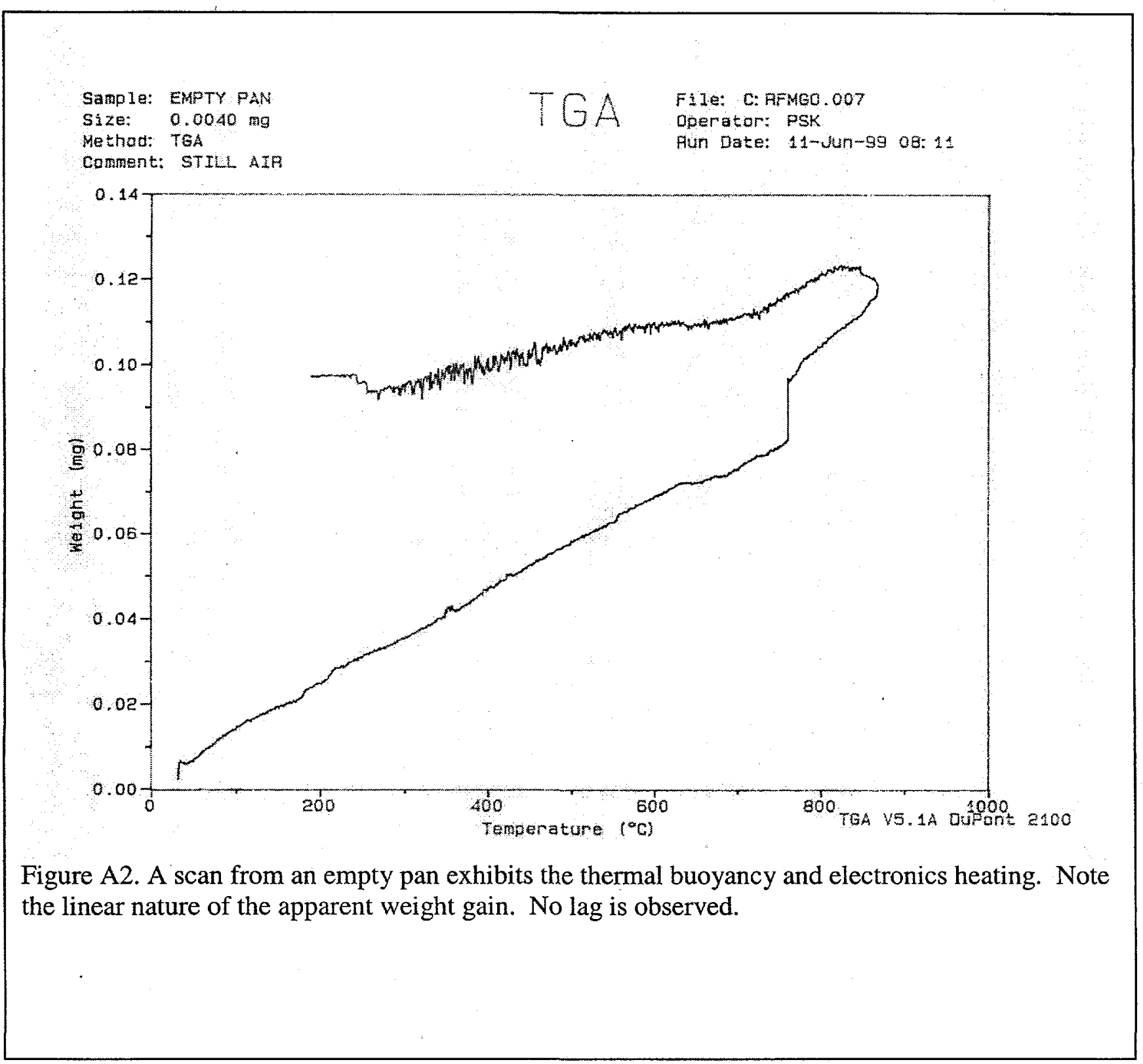


N. M. Askew, 773-A

A. L. Blancett, 773-A

R. E. Claxton, 704-F

M. A. Ebra, 773-42A

F. R. Graham, 773-A

D. J. Green, 773-A

T. C. Hasty, 235-F

S. J. Hensel, 773-42A

S. M. King, 773-54A

P. S. Korinko, 773-A

J. W. McClard, 703-F

A. M. Murray, 773-A

J. B. Schaade, 703-F

J. R. Schornhorst, 992-3W

W. S. Shingler, 703-F

D. Stimac, 703-F

J. C. Williams, 707-F

C. R. Wolfe, 773-A

D. C. Wood, 704-F

ATS File 